\title{
Initial Results in the Use of Prony Methods to Determine the Damping and Modal Composition of Power System Dynamic Response Signals
}


Initial Results in the Use of Prony Methods to Determine the Damping and Modal Composition of Power System Dynamic Response Signals

October 1988

U. S. Department of Energy

Bonneville Power Administration

Portland, Oregon 
INITIAL RESULTS IN THE USE OF PRONY METHODS TO DETERMINE THE DAMPING AND MODAL COMPOSITION OF POWER SYSTEM DYNAMIC RESPONSE SIGNALS

\author{
J. F. HAUER \\ THE BONNEVILLE POWER ADMINISTRATION \\ PORTLAND, OREGON \\ $10 / 05 / 88$
}

\title{
I. INTRODUCTION
}

Prony analysis [1-11] is an emerging method that extends Fourier analysis by directly estimating the frequency, damping, strength, and relative phase of modal components present in a given signal. This is precisely the kind of information that power system engineers would like to extract from transient stability program (TSP) simulations and from large-scale system tests or disturbances.

A tool of this sort would be particularly valuable for TSP output analysis, where it promises to provide

- parametric summaries for damping studies (data compression)

o quantified information for adjusting remedial controls (sensitivity analysis and performance evaluation)

o insight into modal interaction mechanisms (modal analysis)

o reduced simulation times for damping evaluation (prediction)

These considerations lead BPA to contract with Dr. Louis Scharf (head of Parametrics, Inc. and a professor at The University of Colorado) for the writing of a FORTRAN program based upon his research into Prony methods. The effort was lead by $\mathrm{Dr}$. Cedric DeMeure, who has just completed his doctoral research under the direction of $\mathrm{Dr}$. Scharf. Dr. DeMeure produced the interactive FORTRAN programs TRANSCIENT and DTRANSCIENT. The major difference between them is that the latter uses double precision arithmetic throughout.

BPA has since made substantial changes to DTRANSCIENT. The objectives are to evaluate the method, to revise the code for utility applications, and to fortify both for use with larger models. Polynomial rooting, a critical and numerically demanding task, is now accomplished by a routine (QPOLY) that was extracted from the NASA program SAMSAN [12] and converted to quadruple precision. The revised DTRANSCIENT is now accessed as a subroutine, PRSPAK. For interactive use the driving program is PRONY. For batch use, however, PRSPAK has been absorbed into much more comprehensive driving logic which closely parallels that of the BPA Fourier analysis program SIGPAK [13] and its reduced derivative SIGPAKR [14]. The data structures and the protocols for use of this new program, SIGPAKZ, are very similar to those for the two Fourier analysis programs. All three readily accept signal data 
from the BPA TSP, from BPA's Power System Disturbance Monitor (PSDM), and from a variety of special sources. The SIGPAKZ driver is generic enough that it can readily host other signal analysis algorithms which are more general than the prony method and its present extensions [15-17].

This report presents early results in the application of Prony analysis to power system problems. Key objectives are to

- provide a brief mathematical description of Prony analysis.

o report on progress in applying and evaluating SIGPAKZ.

o outline the development status of the Prony code itself and needed enhancements to it.

Some of this material was presented orally to the WSCC $0.7 \mathrm{~Hz}$ Oscillation Ad Hoc Work Group on August 31 and on November 29, 1988.

\section{A BRIEF DESCRIPTION OF PRONY'S METHOD}

Iike Fourier analysis, what might be called Prony analysis originated in an earlier century [1]. Its practical use has awaited the digital computer, and means for dealing with some inherently ill-conditioned mathematics.

Suppose that a linear, time-invariant dynamic system is brought to an "initial" state $x\left(t_{0}\right)=x_{0}$ at time $t_{0}$, by means of some test input or disturbance. Then, if the input is removed and there are no subsequent inputs or disturbances to the system, it will "ring down" according to a differential equation of form

$$
\dot{\mathrm{x}}=\mathrm{A} \mathrm{x}
$$

where $x$ is the state of the system and $n$ is the number of components in $x$ (i.e., the order of the system). Let $\lambda_{i}, p_{i}, q_{I}^{T}$ be respectively the eigenvalues, right eigenvectors, and left eigenvectors of ( $n \times n)$ matrix A. (See Appendix A or [18] for details.) Then the solution to (1) can be expressed as

$$
\begin{aligned}
x(t) & =\sum_{i=1}^{n}\left(q_{1}^{T} x_{0}\right) p_{i} \exp \left(\lambda_{i} t\right) \\
& =\sum_{i=1}^{n} R_{i} x_{0} \exp \left(\lambda_{i} t\right)
\end{aligned}
$$

where $R_{i}=p_{i} q_{1}^{T}$ is an $(n \times n)$ residue matrix. Note that $q_{1}^{T} x_{0}$ in (2A) is scalar (that is, a simple constant). This implies that, though $x_{0}$ (with $q_{1}^{T}$ ) determines the stimulus to the mode associated with eigenvalue $\lambda_{i}$, the distribution of modal response among the components of $x$ is entirely determined by the corresponding right eigenvector $\mathrm{Pi}_{i}$. Consequently information about $\mathrm{P}_{i}$ can be extracted by an appropriate modal decomposition of $x(t)$. 
For simplicity, suppose that there is just one output fiom the system

and that it is of form

$$
y(t)=C x(t) \text {. }
$$

Prony methods and their recent extensions are designed to directly estimate the parameters for the exponential terms in (2A) and/or ( 3 ), by fitting a function

$$
\hat{y}(t)=\sum_{i=1}^{Q} A_{i} \exp \left(\sigma_{i} t\right) \cos \left(2 \pi f_{i} t+\phi_{i}\right)
$$

to an observed record for $y(t)$. In doing this it may also be necessary to model offsets, trends, noise, and other extraneous effects in the signal.

Let the record for $y(t)$ consist of $N$ samples $y\left(t_{k}\right)=y(k), k=0,1, \ldots, N-1$, that are evenly spaced by an amount $\Delta t$. The strategy for obtaining a Prony solution (PRS) can be summarized as follows:

STEP 1: construct a discrete linear prediction model (IPM) that fits the record.

STEP 2: find the roots of the characteristic polyniomial associated with the LPM of step 1.

STEP 3: using the roots of step 2 as the complex modal frequencies for the signal, determine the amplitude and initial phase for each mode.

These steps are performed in z-domain. For power system applications the eigenvalues would usually be translated to s-domain, consistent with equations ( 1$)-(5)$.

Prony's main contribution is at step 1. Its development here parallels that of [2], pp. 378 and 379. For initial purposes, assume $N=2 n$ and that the signal record is noise-free.

The notation is simplified if $(4)$ is recast in the exponential form

$$
\hat{y}(t)=\sum_{i=i}^{n} B_{i} \exp \left(\lambda_{i} t\right)
$$

paralleling (2). At the sample times $t_{k}$ this can be contracted to

$$
\begin{aligned}
\hat{y}(k) & =\sum_{i=1}^{p} B_{i} z_{i}^{k}, \\
z_{i} & =\exp \left(\lambda_{i} \Delta t\right) .
\end{aligned}
$$

The immediate objective is to find the $B_{i}$ and $z_{i}$ that produces $\hat{y}(k)=y(k)$ for all k. For insight as to how this can be done, apply (6A) at each $t_{k}$ and form the following equation 


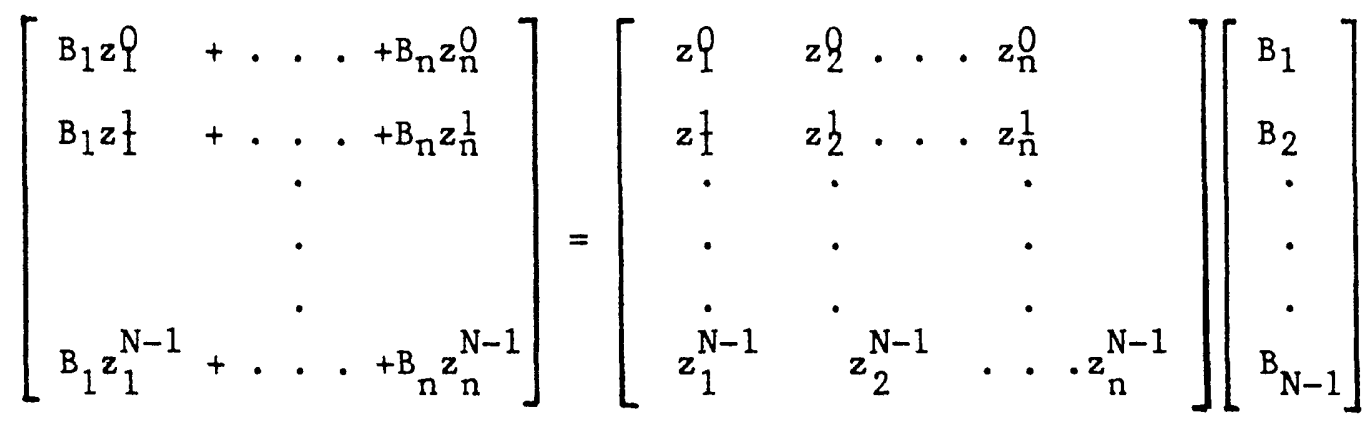

$$
\begin{aligned}
& =\left[\begin{array}{c}
y(0) \\
y(1) \\
\dot{\cdot} \\
y(N-1)
\end{array}\right] \text {. }
\end{aligned}
$$

This can be expressed more compactly as

$$
\mathrm{ZB}=\mathrm{Y} \text {. }
$$

If the $z_{i}$ are found then the eigenvalues $\lambda_{i}$ can be calculated from them via (6B). The $z_{i}$ are necessarily the roots of some nth-order polynomial with (unknown) coefficients $a_{i}$, and thus satisfy

$$
z^{n}-\left(a_{1} z^{n-1}+a_{2} z^{n-2}+\cdots+a_{n} z^{0}\right)=0
$$

Next construct the $(1 \times N)$ matrix

$$
A=\left[\begin{array}{llllllll}
-a_{n} & -a_{n-1} & \ldots & -a_{1} & 1 & 0 & \ldots & 0
\end{array}\right] \triangleq\left[\begin{array}{lll}
-a & 1 & 0
\end{array}\right]
$$

and apply it to (7): after some minor re-ordering,

$$
\begin{aligned}
A Y & =y(n)-\left[a_{1} y(n-1)+\ldots+a_{n} y(0)\right] \\
& =A Z C \\
& =B_{1}\left[z_{n}-\left(a_{1} z+\ldots+a_{n} z_{1}\right)\right]+\ldots \\
& =0
\end{aligned}
$$

where the last step follows from the fact that each $\mathbf{z}_{\mathbf{i}}$ satisfies (8). Since the intial time has been selected arbitrarily, (10) can be applied repeatedly to form

$$
\left[\begin{array}{cccc}
y(n-1) & y(n-2) & \cdots & y(0) \\
y(n-0) & y(n-1) & \cdots & y(1) \\
y(n+1) & y(n-0) & \cdots & y(2) \\
\cdot & \cdot & \cdot & \cdot \\
y(N-2) & y(N-3) & \cdots & y(N-n-1)
\end{array}\right]\left[\begin{array}{c}
a_{1} \\
a_{2} \\
\dot{\cdot} \\
\cdot \\
a_{n}
\end{array}\right]=\left[\begin{array}{c}
y(n+0) \\
y(n+1) \\
y(n+2) \\
\cdot \\
\dot{\cdot} \\
y(N-1)
\end{array}\right]
$$


Solution of this equation provides the $z$-domain poiynomial in ( 8 ), which is then rooted for the $z_{i}$ and, through $(6 \mathrm{~B})$, the eigenvalues $\lambda_{i}$. This completes steps 1 and 2 of the basic Prony method. Step 3 is the solution of (7) for the complex amplitudes $B_{i}$.

Practical use of this approach requires some extensions and refinements. A major problem is that the true system dimension, $n$, may be unknown or may be so large that any fitted model must be a reduced-order approximation. Additional modes may be needed to fit signal offsets or noise. The array dimensions in (11) will usually differ from those shown, and tend to "overfit" the signal by using a generous number of samples and fitted modes. Singular-value analysis and other mechanisms are then used to adjust model features at each solution step. By design, the reconstructed signal $\ddot{y}(t)$ will usually $f i t y(t)$ inexactly. An appropriate measure for the quality of this fit, used here, is the "signal-to-noise" ratio

$$
\operatorname{SNR}=-20 \log || \hat{y}(k)-y(k)|| /\|y(k)\|
$$

where ||$.||$ denotes the usual root-mean-square norm and the SNR is in decibels $(\mathrm{db})$.

\section{I. SOME STRATEGIC ISSUES}

Prony analysis has the potential of becoming a highly valuable tool for power system analysis, and for the design of remedial action schemes or stability controls. The present BPA effort is intended to assess its present capabilities, and to conduct or promote further development as needed.

There are many aspects to this. Those which are intrinsic to the method itself include

o criteria for the model fit

o software for achieving the model fit

o software for rooting the predictor polynomial

For a given record, there are questions as to

o preprocessing, to mitigate the effects of noise or hidden inputs

o how much of the record to use in the model fit

o order of the fitted model

o pruning and/or adjustment of the fitted model

The power system models ordinarily used in stability studies pose severe difficulties for Prony analysis (and for other methods that rely upon linearization). They are strongly nonlinear, and of dimensions that seem infinitely beyond those of models that any fitting procedure would 
reliably construct. Linear characterizations can be developed for power system transient behavior but, if they are taken with respect to the actual operating point, they should be expected to vary with time. It appears that Prony analys is performs such a characterization implicitly.

The evaluation of Prony analysis in this context requires special attention to the factors below:

- The Prony model will normally be of far lower order than the dynamic process underlying the signal record.

- For large-signal cases, PRS results will change with the magnitude of the system disturbance or input.

- For large-signal cases, PRS results will change with record length and position.

- For large-signal cases, there is probably a maximum record length beyond which information is lost in the PRS.

- For small-signal cases, substantial changes in record length should not produce material changes in PRS results.

These are being examined through a series of test cases, which range from very simple to rather difficult. Salient results are presented in the sections that follow. The map shown as Figure 0 indicates some of the place names associated with those cases taken from BPA system studies.

\section{PRS CHECK SERIES 非0}

This series of checks is based upon two elementary models. The first of these, shown in Figure 1, has two complex modes. Both have zero damping. Model 1 非 has the same structure and parameters, except that the $0.67 \mathrm{~Hz}$ mode has a damping of 0.02 and the $0.71 \mathrm{~Hz}$ mode has a damping of -0.005 . The unit for damping here is inverse seconds, divided by $2 \mathrm{n}$ to be dimensionally consistent with frequency in $\mathrm{Hz}$. (Later versions of SIGPAKZ may express damping as a percentage of the natural frequency $\left|f_{i}\right|$, to avoid possible ambiguities.)

Model 非1 was introduced in [19], as a proposed benchmark for damping estimators. The modal frequencies are realistic for the western power system, and there is a ris'. that the modal damping may be so as well. Figure 1.0 illustrates that the direct examination of such damping can require very long simulations for correct results. A hoped-for benefit of Prony analysis is the minimization of simulation length.

Figures 1.1 through 1.4 show PRS results for successively longer values of the record length, TBAR. In all cases the sample spacing was $\Delta t=0.10$ seconds. The solution logic, though permitted to develop a model of order 90 , in ea:h case recognized that just two significant (complex) modes were present and pruned the initial step 1 model to reflect this. Each figure actually shows two curves: the signal record, $y(t)$, and the response $\hat{y}(t)$ of the fitted Prony model (tagged by triangles). Excellent 
results are obtained with a record just 2 seconds long, and they improve with record length. Figures 2.0 through 2.4 show like results for Model 2 .

\section{PRS CHECK SERIES 非}

The basic model for PRS check series 1 保 has the frequency response shown in Figure 3. It represents a linear characterization of bus frequency response to small-signal control action during a major disturbance (see [20], Section V). It has 14 complex modes, and hence is of order 28. Some modes are closely spaced, as may be deduced from the beating effects in the impulse response of Figure 3.0 .

Figures 3.1 through 3.3 show typical SIGPAKZ outputs. In the first of these, the plot header data indicates that the signal name is POUT $1 / 1$, that the signal extends from 0.6 to 20.5 seconds, and that the SNR for the model fit is $120.87 \mathrm{db}$. This indicates an excellent $\mathrm{fit}$, as may also be seen from the superposed curves. The "PRS table" shown in Figure 3.2 exactly reproduces the frequency and damping of the model poles. A corresponding "PRS 1ocus" is shown in Figure 3.3. The header indicates that the locus represents a single solution, and that any mode with a relative amlitude of less that 0.01 has been trimmed from the locus.

It should be recognized that this is a fairly demanding model. Some of the modes are close together, and the model order (28) is high enough to present nontrivial dimension problems. This model, and variations of it, are of continuing value in the development of guidelines for the best use of SIGPAKZ.

\section{ANALYSIS OF KEMANO GENERATOR RESPONSE}

The Kemano generator, in northwestern British Columbia, attaches to the main power system through a long radial connection (see Figure 0). Kemano has a frequency-domain "signature" that is conspicuous throughout the western power system.

Figure 4 shows the frequency response of Kemano generator power to the modulation of reactive load at the Malin $500 \mathrm{kv}$ bus. This data was produced by Fourier analyzing the ringdown signal of Figure 4.0, and dividing the results by the Fourier transform of the applied pulse. The single dominant peak makes Kemano a good initial case for testing SIGPAKZ against transient stability output data.

Figure 4.1 shows the quality of the Prony fit for the first 15 seconds of Kemano ringdown. The full solution is indicated in Figure 4.2. A11 but one of the modes are complex, and a great many of them are very weak modes accessory to the fit: ing process. It is not unusual for signal offsets to produce modes near $0 \mathrm{~Hz}$, or very near to the Nyquist frequency $1 /(2 \Delta t)$. Modes 1 and 56 appear to be $n f$ this type. For summary purposes it is usually more convenient to work with "trimmed" PRS tables, from which all modes that are very weak or that lie at uninteresting frequencies have been removed. Figure 4.3 shows a sequence of such tables, labeled as $s$-tables since they are expressed in $s$-domain rather than $z-$ domain. Line 7 of the header indicates that all modes with a relative 
weight below (TRIMTAB $\Rightarrow$ ) 0.20 have been trimmed from the display. (This normalization is performed with respect to the strongest mode within a designated frequency range FTRIML to FTRIMH.)

Linearized characteristics of stability output signals should be expected to vary with time (e.g., according to system stress). It is useful to examine such a signal by sliding a data window along it and processing the window contents (a sub-record) at preset positions. This provides an indication of dynamic variability, assists the identification of dominant modes, and checks the solution process for consistency. Figures 4.3 and 4.4 show results for a sliding-window analysis in which the window was advanced 10 samples ( 0.667 seconds) between successive solutions. The figures indicate that, consistent with the peak in Figure 4, Kemano is strongly involved in a mode that is essentially fixed near 0.628-0.629 $\mathrm{Hz}$, with a damping near 0.0231-0215 (also scaled in "Hz"). Kemano is also involved in a strong mode near $0.77 \mathrm{~Hz}$, which seems to be either more variable or less accurately estimated.

VII. MODE SHAPE VIA PRONY ANALYSIS

Figures 5 through 9.2 show other responses and PRS results corresponding to the Kemano ringdown discussed in the previous section. The $0.628 \mathrm{Bz}$ "Kemano mode" is conspicuous throughout, in the PRS 1oci, and it is represented by sharp peaks in the frequency response at Grand Coulee, Shasta, and Palo Verde. The PRS tables show Grand Coulee and Shasta about 180 degrees behind Kemano for this mode, and Palo Verde about 370 degrees behind. Intermountain phasing is intermediate, at 250 degrees.

Except for Kemano, all signals show a significant mode near $0.76 \mathrm{~Hz}$. The indicated damping for this mode is about $0.012-0.018$-- except at Grand Coulee, for which the damping is ten times higher. This result is persistent enough to raise the possibility of 2 modes at essentially the same natural frequency. The PRS tables indicate that Shasta is swinging against both $\mathrm{Palo}$ Verde, and that the phasing of Intermountain swings is once again intermediate.

Toward the end of the system ringdown, all signals other than Kemano show a mode near $0.868 \mathrm{~Hz}$ for which the damping is essentially zero. Phase data suggests that this may be Intermountain swinging against Palo Verde and Shasta, and those machines in turn swinging Coulee.

Continuation of this analysis would provide a progressively better view of the phase distribution for the eigenvectors associated with key modes (for which machine electrical power is implicitly being taken as a state variable). Insight into the interaction mechanisms for each mode can be considerably improved by examining the mode strengths at each machine, and by performing Prony analysis on major lines. In doing this, however, it is necessary to compensate for situations where the TSP output represents just one machine or circuit among several that are connected in parallel. Manual insertion of the necessary scale factors is laborious, and prone to error. The problem is a generic one in output analysis. Consideration ought be given to automatically inserting the needed scale factors in the TSP output itself. 


\section{EVALUATION OF REMEDIAL ACTION SCHEMES VIA PRONY ANALYSIS}

This section treats two separate large-signal stability cases involving loss of the 3100 MW Celilo-Sylmar HVDC Intertie. In the reference case (93JTAS434) only standard remedial actions are taken, and growing oscillations are observed at the Malin $500 \mathrm{kv}$ bus. These same actions are taken in the experimental case (93JTAS438). In addition, a $1000 \mathrm{MW}$ discharge is taken from a (fictional) superconducting magnetic energy storage (SMES) unit at Sylmar. These cases are part of an initial determination of stability control benefits that a 20 MWH SMES unit might bring to the western system. In the present scenario such a device can serve as a spinning reserve equivalent for roughly two minutes.

Comparison of Figures 10 and 11 shows that the SMES power injection into the grid has reduced the level of the oscillations, and that it may have improved their damping. A rough indication of their modal content is provided by the autospectra of Figures 10.0 and 11.0 . It is evident that the injection has also affected the natural frequency of the critical modes near $0.27 \mathrm{~Hz}$ and $0.70 \mathrm{~Hz}$. The associated PRS tables and loci display these effects more clearly, in a quantitative format that is well suited to refinement of pulse level and timing.

\section{CONCLUSIONS}

The BPA evaluation of Prony analysis has been very encouraging. It should be noted, though, that the work to this point has concentrated upon the effectiveness of the method rather than its efficiency. At present a large-scale case $(n=120)$ may require up to 5 minutes on BPA's VAX $11 / 780$. The bulk of this is probably due to the blanket use of quad precision in the polynomial rooter QPOLY. Future work will reduce this to the necessary minimum, and establish tighter bounds for the required model order.

Overall, though it is definitely slanted toward the expert user, SIGPAKZ is clearly ready to perform useful work. (Chuck Frank at EPRI aptly describes such programs as of "engineering grade".) Portability of the code developed under contract is limited somewhat by extensive use of features special to VAX computers, but these are gradually being removed.

Prony analysis promises to become a very useful tool for power system analysis. While it may well assume a place alongside eigenanalysis and Fourier analysis, it will not replace them. Each such tool has its own merits and applications. and provides a different view into power system (or model) behavior.

There are other emerging methods that may well improve upon Prony analysis, or be more generally applicable. Among these lattice filters [1517] seem to be the most promising. BPA is presently reviewing this possibility with Dr. Scharf. 


\section{REFERENCES}

[1] G.R.B. Prony,"Essai experimental et analytique ...," J. 1'Ecole Polytech. (Paris), vol. 1, pp. 24-76, 1795.

[2] F.B. Hildebrand, Introduction to Numerical Analysis. New York: McGraw-Hil1, 1956. (See esp. Chapter 9.)

[3] S.M. Kay and S.L. Marple,"Spectrum analysis--a modern perspective," Proc. IEEE, Pp. 1380-1419, Nov. 1981.

[4] A.J. Poggio,M.L. Van Blaricum,E.K. Miller, and R. Mittra,"Evaluation of a processing technique for transient data," IEEE Trans. Antennas and Propagation, pp. 165-173, January 1987.

[5] M.L. Van Blaricum and R. Mittra,"Problems and solutions associated with Prony's method for processing transient data," IEEE Trans. Antennas and Propagation, pp. 174-182, January 1978.

[6] D.W. Tufts and R. Kumaresan,"Singular value decomposition and improved frequency estimation using linear prediction," IEEE Trans. Acoustics, Speech, and Signal Processing, pp. i71-675, Aug. 1982.

[7] D.W. Tufts and R. Kumaresan,"Frequency estimation of multiple sinusoids: making linear prediction perform like maximum likelihood," Proc. IEEE, pp. 975-989, Sept. 1982.

[8] R. Kumaresan and D.W. Tufts, "Estimating the parameters of exponentially damped sinusoids and pole-zero modeling in noise," IEEE Trans. Acoustics, Speech, and Signal Processing, pp. 833-840, Dec. 1982.

[9] R. Kumaresan,"On the zeros of the linear prediction-error filter for deterministic signals," IEEE Trans. Acoustics, Speech, and Signal Processing, pp. 217-220, Feb. 1983.

[10] R. Kumaresan,D.W. Tufts, and L.L. Scharf,"A Prony method for noisy data: choosing the signal components and selecting the order in exponential signal models," Proc. IEEE, pp. 230-233, February 1984.

[11] R. Kumaresan. L.L. Scharf, and A.K. Shaw, "An algorithm for polezero modeling and spectral analysis," IEEE Trans. Acoustics, Speech, and Signal Processing, pp. 637-640, June 1986.

[12] H.P. Frisch and F.H. Bauer,"Modern Numerical Methods for Classical Sampled Systems Analysis - SAMSAN II User's Guide." NASA/Goddard Space Flight Center, Greenbelt, Maryland, 1984. [COSMIC Program 非GSC-12827]

[13] J.F. Hauer, "An Overview of BPA Software for Signal Processing and Other Systems Analysis Tasks Involved in Identification and Control of Power System Dynamics," letter to the WSiC $0.7 \mathrm{~Hz}$ Oscillation Ad Hoc Work Group, Nov. 16, 1987. 
[14] J.F. Hauer,"Description of Reduced-Scale FFT Sof tware Package SIGPAKR," BPA working notes, May 23, 1988. Distributed to the WSCC $0.7 \mathrm{~Hz}$ Ad Hoc Work Group, June 6, 1988.

[15] B. Friedlander, "Lattice methods for spectral estimation," Proc. IEEE, pp. 990-1017, Sept. 1982.

[16] S. Li and B.W. Dickinson, "Application of the lattice filter to robust estimation of AR and ARMA models," IEEE Trans. Acoustics, Speech, and Signal Processing, pp. 502-512, April 1988.

[17] P. Strobach,"Recursive covariance ladder algorithms for ARMA system identification," IEEE Trans. Acoustics, Speech, and Signal Processing, pp. 560-580, April 1988.

[18] T. Kailath,"Linear Systems. Prentice-Ha11: Englewood Cliffs, 1980.

[19] J.F. Hauer, "Fast Damping Estimators for Use with the Transient Stability Program," BPA Memorandum, Feb. 20, 1987. Cormunicated to the WSCC $0.7 \mathrm{~Hz}$ Ad Hoc Work Group on October 22, 1.987.

[20] J.F. Hauer, "Reactive Power Control as a Mears for Enhanced Interarea Damping in the Western U.S. Power System--A Frequency-Domain Perspective Considering Robustness Needs," invited paper in Application of Static Var Systems for System Dynamic Performance, IEEE Pub1ication 87TH0187-5-PWR, pp. 79-92. Proceedings of a symposium presented at the IEEE PES 1987 Winter Meeting, New Orleans, LA, and at the IEEE PES 1987 Summer Meeting, San Francisco, CA.

[21] J.F. Hauer and S.W. Taylor,"Feedback Control and Frequency Domain Analysis of Large Electric Power Systems," notes provided with a course presented at Portland, Oregon on April 13-14, 1988, and at Burbank, California on May 11-12, 1988. 
APPENDIX A. EIGENVALUES AND RELATED TOPICS

\section{A1. THE EIGENVALUE PROBLEM}

Given the system equation

$$
\dot{x}=A x+B u,
$$

find a transformation $x=T x_{m}$ so that

$$
\dot{x}_{m}=\Lambda x_{m}+B_{m} u,
$$

$$
\Lambda=\operatorname{diag}\left(\lambda_{1}\right)=\left[\begin{array}{lll}
\lambda_{1} & & 0 \\
\lambda_{2} & \\
& \cdot & \\
& & \lambda_{n}
\end{array}\right] \text {. }
$$

If this is successful, then the $\lambda_{i}$ are the eigenvalues of $A$ and they are all distinct (otherwise a Jordan form must be used). Note that

$$
\begin{aligned}
& \dot{x}=T \dot{x}_{m}=A T x_{m}+B u, \\
& \dot{x}_{m}=\left(T^{-1} A T\right) x_{m}+\left(T^{-1} B\right) u=\Lambda x_{m}+B_{m} u .
\end{aligned}
$$

Let $T_{j}$ be column $j$ of $T$; then

$$
A T=T \Lambda \rightarrow A T_{j}=\lambda_{j} T_{j} \rightarrow\left(A-\lambda_{j} I\right) T_{j}=0 \text {. }
$$

Since $T_{j}$ is not the zero vector, this requires

$$
\operatorname{det}\left(A-\lambda_{j} I\right)=\left|A-\lambda_{j} I\right|=a\left(\lambda_{j}\right)=0 \text {. }
$$

Let $T=\left[\begin{array}{lll}P_{1} & \cdot & \cdot p_{n}\end{array}\right]=P, T^{-1}=\left[\begin{array}{c}q I \\ \cdot \\ \cdot \\ q_{n}\end{array}\right]=Q^{T}$.

Then $A P_{i}=\lambda_{i} P_{i}, q \frac{T}{I} A=\lambda_{i} q \frac{T}{I}$

where $p_{i}, q_{I}^{T}$ are respectively right and left eigenvectors of $A$. 
System "ringdown" from an initial state $x\left(t_{0}\right)=x_{0}$ can be found as follows:

$$
\begin{aligned}
x(s) & =[s I-A]^{-1} x_{0}=P^{-1}[s I-A]^{-1} P^{-1} x_{0} \\
& =P[s I-\Lambda]^{-1} P^{-1} x_{0} \\
& =\sum_{i=1}^{n} \frac{p_{i}\left(q_{1}^{T} x_{0}\right)}{s-\lambda_{i}}=\sum_{i=1}^{n} \frac{\left(q_{1}^{T} x_{0}\right) p_{i}}{s-\lambda_{i}}, \\
x(t) & =\sum_{i=1}^{n}\left|\left(q_{1}^{T} x_{0}\right) \exp \left(\lambda_{i} t\right)\right| p_{i} \\
& =\sum_{i=1}^{n} R_{i} x_{0} \exp \left(\lambda_{i} t\right)
\end{aligned}
$$

(note that $\mathrm{q}_{1}^{\mathrm{T}} \mathrm{x} 0$ is a scalar quantity. Kailath [17] terms $\mathrm{R}_{i}=\mathrm{p}_{i} \mathrm{q}_{1}^{\mathrm{T}}$ a residue matrix. One should note, however, that the "signal residues" for a particular $x_{0}$ are given by $R_{i} x_{0}$.)

\section{Observations:}

a) Vector $q_{1}^{T}$ determines the influence of $x_{0}$ upon mode $i$.

b) Vector $p_{i}$ determines the distribution of mode $i$ among the components of $x(t)$.

\section{A2. EIGENVECTORS AND PARTICIPATION FACTORS}

Scaling uncertainties greatly reduce the direct usefulness of eigenvectors in determining system mode shape. The underlying transformation between $x$ and $\mathrm{x}_{\mathrm{m}}$ requires $\mathrm{Q}^{\mathrm{T}}=\mathrm{P}^{-1}$, by which

$$
\begin{aligned}
\mathrm{q} \mathrm{j}_{\mathrm{j}} & =1 & & \text { if } i=j, \\
& =0 & & \text { otherwise. }
\end{aligned}
$$

This still leaves $p_{i}$ indeterminant with regard to length and directional sense. Arbitrary scaling rules can resolve this, but leave a more important problem: effects due to relative scaling of the state variables themselves. An alternative is to inspect

$$
P_{k i}=p_{k i} q_{k i}
$$

where $p_{k i}$ and $q_{k i}$ are the $k$ th elements of $p_{i}$ and $q_{i}$. These "participation factors" are dimensionless measures of state $x_{k}$ in mode $i$. From (AIOB), $P_{k i}$ is also element $k k$ of $R_{i}$, and thus represents the residue that is produced for mode $i$ by a unit impulse in element $i$ of $x_{0}$. 


\section{A3. SINGULAR VALUES}

Control theory, especially that for MIMO systems and robustness, makes heavy use of the singular-value decomposition

$$
F=U \Sigma V \text {. }
$$

This decomposition includes the following features:

a) Matrix $E$ need not be square.

b) Matrices U, $V$ are orthogonal, and are constructed from the eigenvectors of $\mathrm{AA} \mathrm{T}, \mathrm{A}^{\mathrm{T}} \mathrm{A}$ respectively.

c) $\Sigma$ is a diagonal matrix whose entries are the singular values $\sigma_{i}$ of $F$, usually ordered by descending magnitude.

Singular value $\sigma_{i}$ for a matrix $F$ is the non-negative square root of the eigenvalue $\lambda_{i}\left[F^{T} F\right]$ for $F^{T}$. For a square matrix $A$ we have a special interest in the particular singular values

$$
\begin{aligned}
& \bar{\sigma}[A]=\lambda_{\max }\left[A^{T_{A}}\right] \\
& \underline{\sigma}[A]=\lambda_{\min }\left[A^{T_{A}}\right]
\end{aligned}
$$

\section{Properties:}

$$
\begin{aligned}
& \underline{\sigma}[A] \leqslant\left|\lambda_{i}[A]\right| \leqslant \bar{\sigma}[A] \\
& \max _{\|x\|=1}\|A x\|=\bar{\sigma}[A] \\
& \min _{\|x\|=1}\|A x\|=\underline{\sigma}[A]
\end{aligned}
$$

where $\|x\|$ is the Euclidian norm $\left(x_{1}^{2}+\ldots+x_{n}^{2}\right)^{1 / 2}$ of $x$. 


\section{APPENDIX B. KEY NAMES AND TERMINOLOGY}

Discussion will be made easier by the introduction of some key terms associated with the Prony codes. To this end the more important program names and control parameters are introduced below.

DTRANSCIENT

PRONY

SIGPAKZ

PRSPAK

PRS

NN

NNHAT

T (or TSTEP)

TSTART

TBAR

LAPSTP

LPOCON

LPMCON

FBCON

PIRCON
The original Prony analysis program received from Drs. Louis Scharf and Cedric DeMeure, in the doubleprecision version.

The direct $\mathrm{BPA}$ revision of DTRANSCIENT (for interactive use).

The BPA extension of DTRANSCIENT, for batch use. Very similar to Fourier analysis program SIGPAKR.

The primary subroutine for accessing the logic of DTRANSCIENT. Common to PRONY and SIGPAKZ.

Acronym for "Prony Solution". Analogous to use of "FFT" in the fast-Fourier transform logic of SIGPAK and SIGPAKR.

Number of signal samples $y(k)$ provided to PRSPAK for fitting.

Number of signal samples $y(k)$ provided to PRSPAK for display of the constructed signal. Usually not less than NN.

Spacing of the samples $y(k)$, usually in seconds.

Time of the first sample, $y(0)$.

Nominal length of the record. Actually calculated as NN*TSTEP, for consistency with FFT conventions.

For "sliding-window" cases, this is the number of samples by which the window will be advanced for each record. The overlap for successive records is then NN-LAPSTP points, or (NN-LAPSTP)/NN percent.

Control for linear prediction order (in construction of the Prony model).

Control for 1 inear prediction method.

Control for direction of 1 inear prediction (forward or backward).

Control on rank of the pseudo-inverse to the data matrix constructed from the signal record. 
QCON

SNR

FTR IML,

FTR IMH .

TR IMLPM

TR IMTAB

TR IMLOC [to be amended, along with code in PRSPAK]

A measure of model fitting accuracy, expressed as a signal-to-noise ratio (in $\mathrm{db}$ ). The calculation is

$\mathrm{SNR}=20 \log || \hat{y}(k)-y(k)|| /|| y(k) \|$

where $y(k)$ is Prony model response at time tk. SNR values of $20 \mathrm{db}$ and $40 \mathrm{db}$ would indicate accumulated fitting errors of $10 \%$ and $1 \%$, respectively.

Modes at frequencies outside the range FTRIML to FTRIMH are regarded as potentially uninteresting. The relative weight of each mode is calculated with respect to the strongest mode within this range.

Any mode with a relative weight less than TRIMLPM will be deleted from the linear prediction model (within PRSPAK).

Any mode with a relative weight less than TRIMTAB will be deleted from the PRS table display.

Any mode with a relative weight less than TRIMLOC will be deleted from the PRS locus display. 


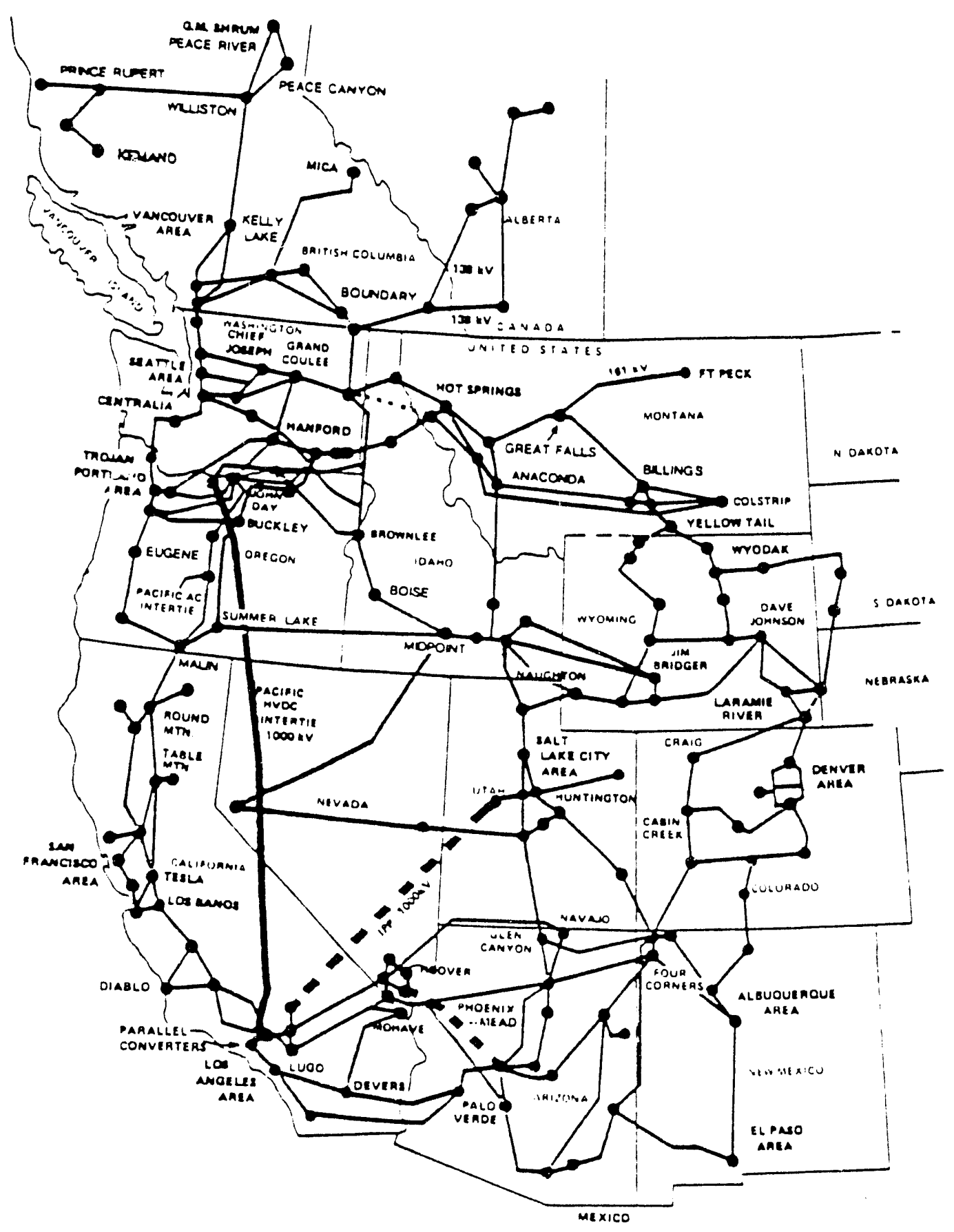

FIOURE O. GENERAL STRUCTURE OF THE WESTERN U.S. POWER SYSTEM 


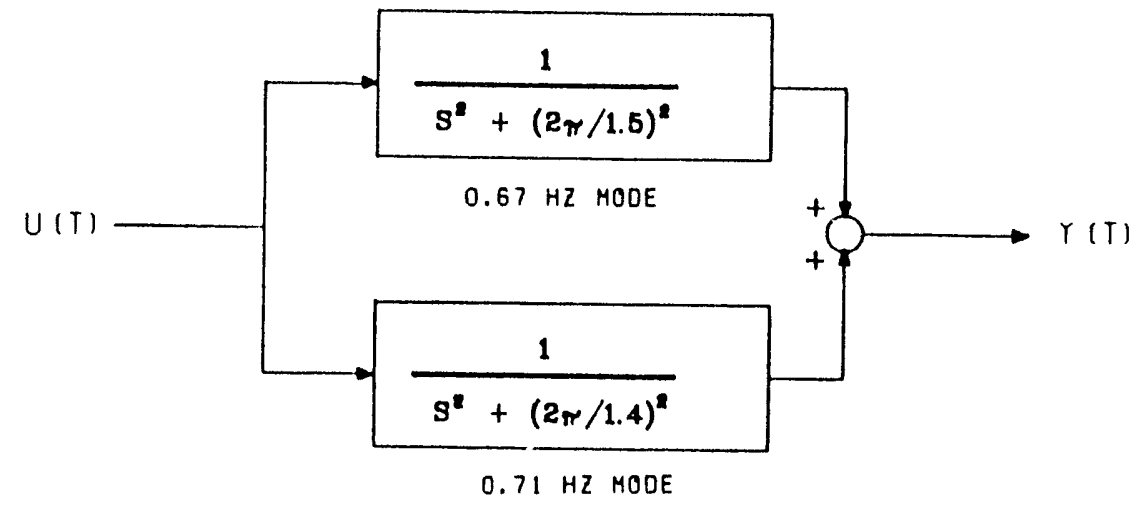

PRSCKSO MODEL "1

POLES: $0.0000+J \times 0.66666667 \mathrm{HZ}$

$0.0000+J \times 0.71428571 \mathrm{~Hz}$

FICURE 1. MONEL "I FOR PRONY SOLUTION CHECK SERIES "O

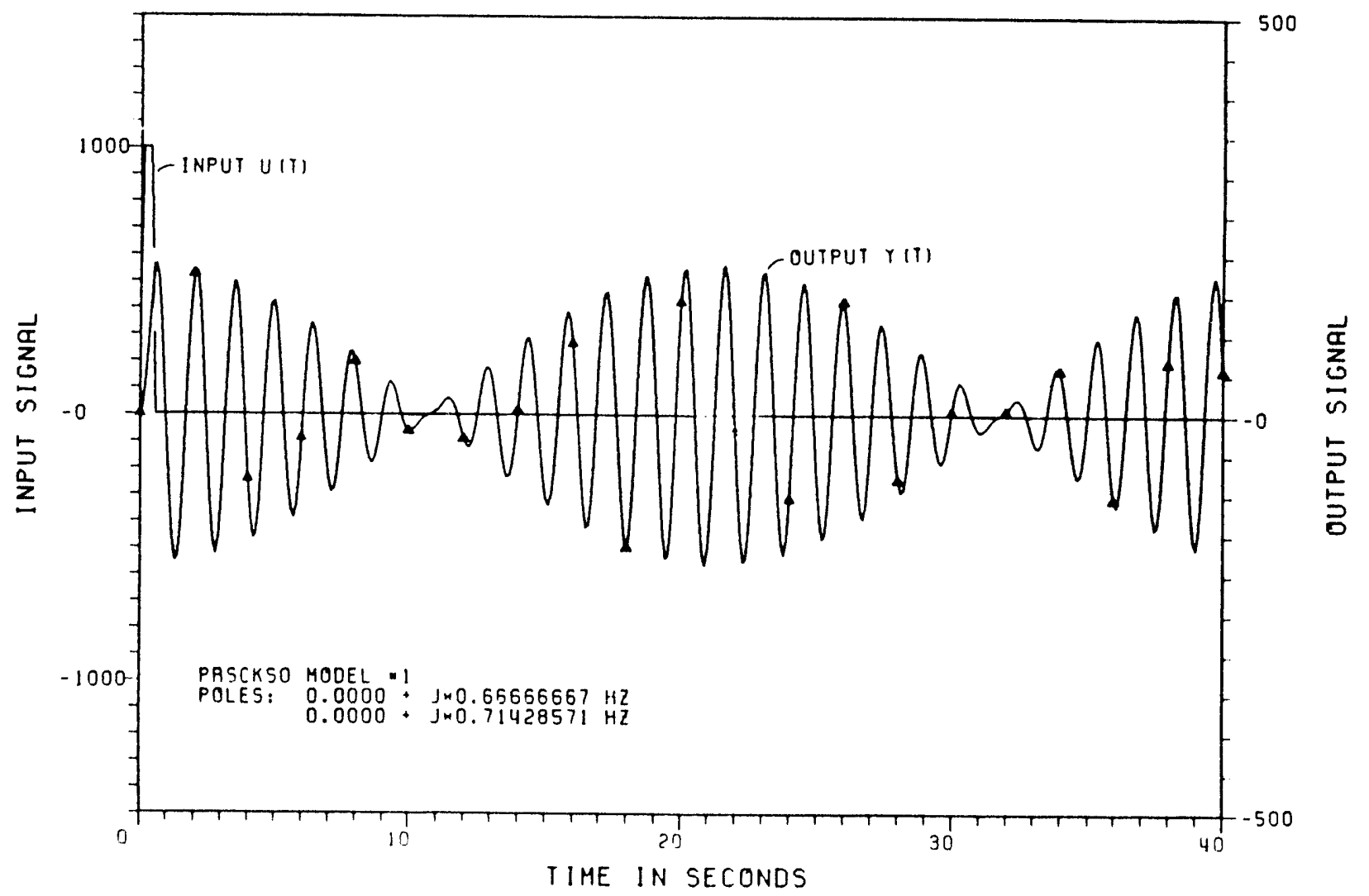

FIGURE 1.0 RESFOHSE OF PRSCKSO MOOEL 1 TO BRIEF PULSE INPUT 

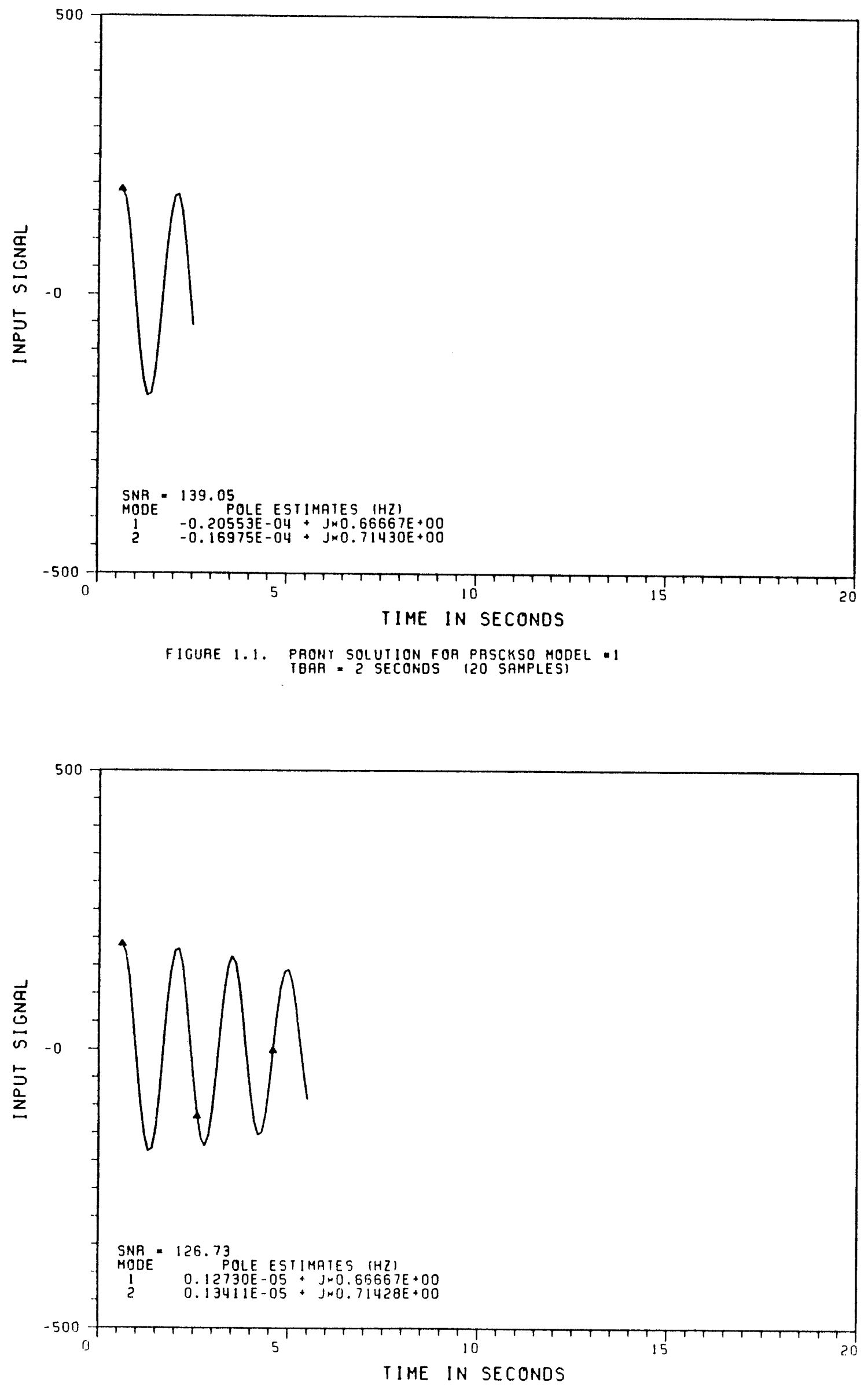

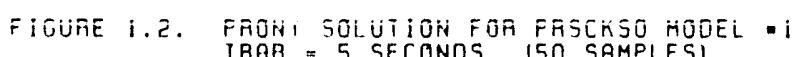




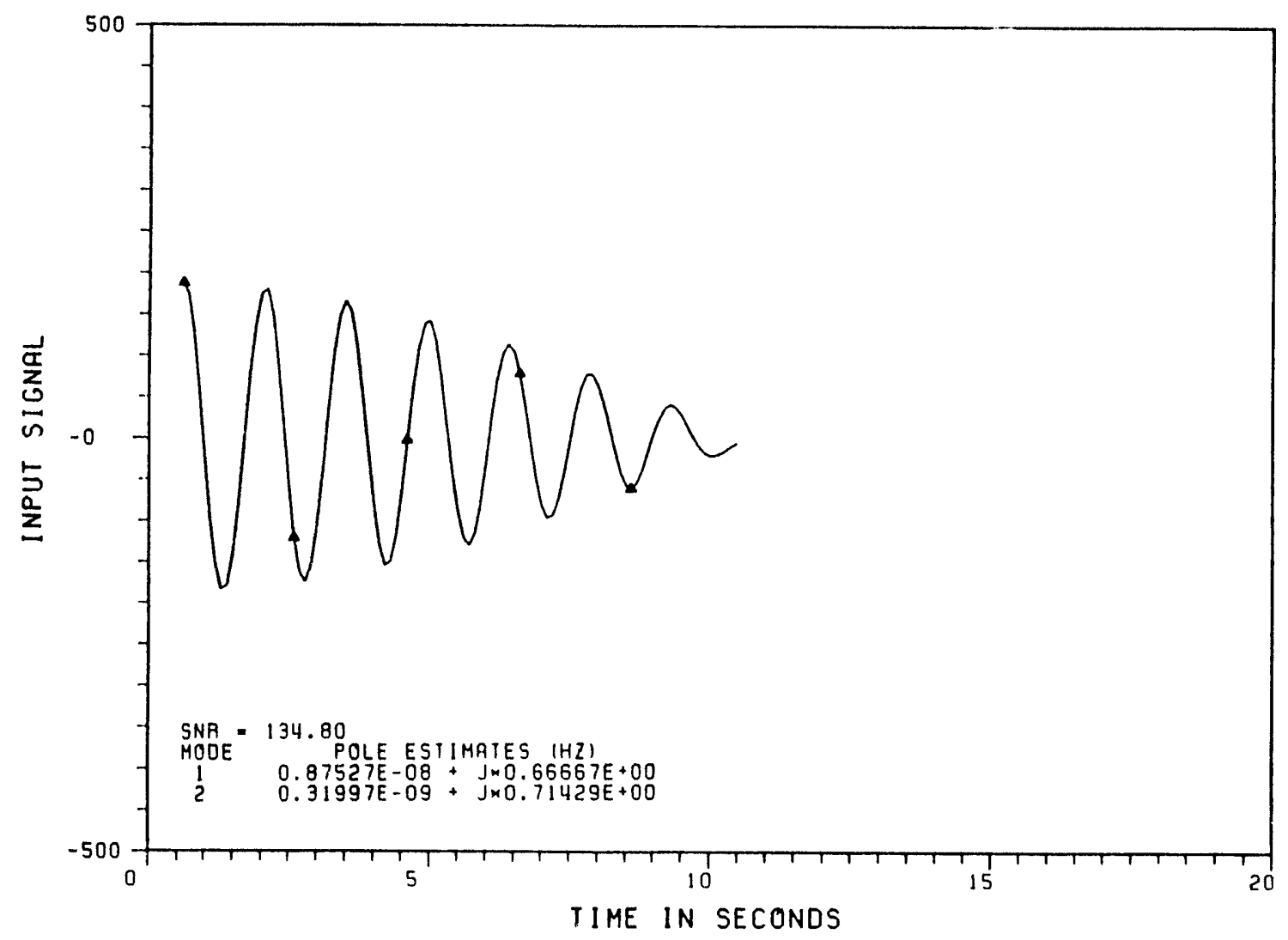

FIGURE 1.3. PRONY SOLUTION FOR PASCKSO MODEL "I TBAA = 10 SECONDS 1100 SAMPLESI

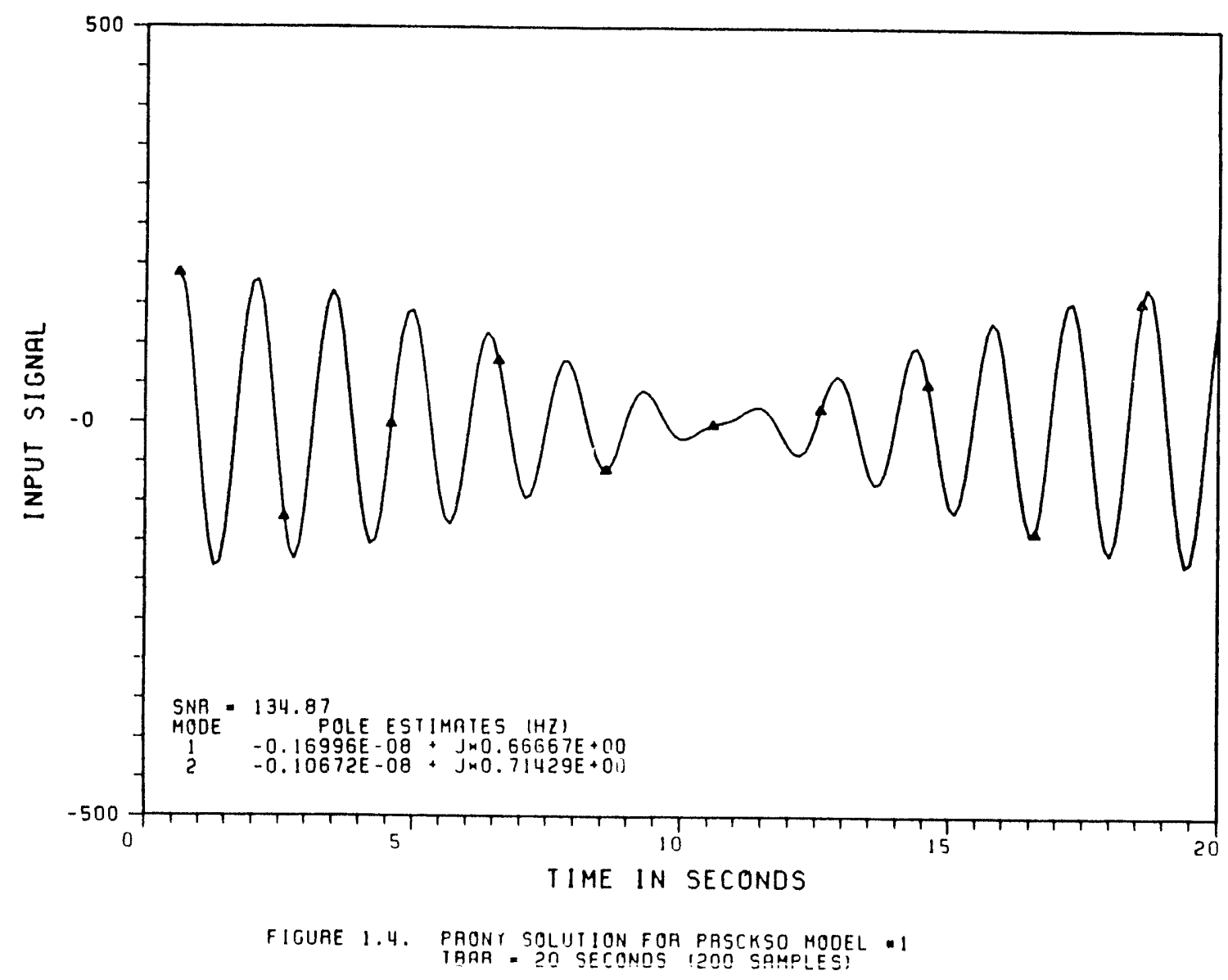




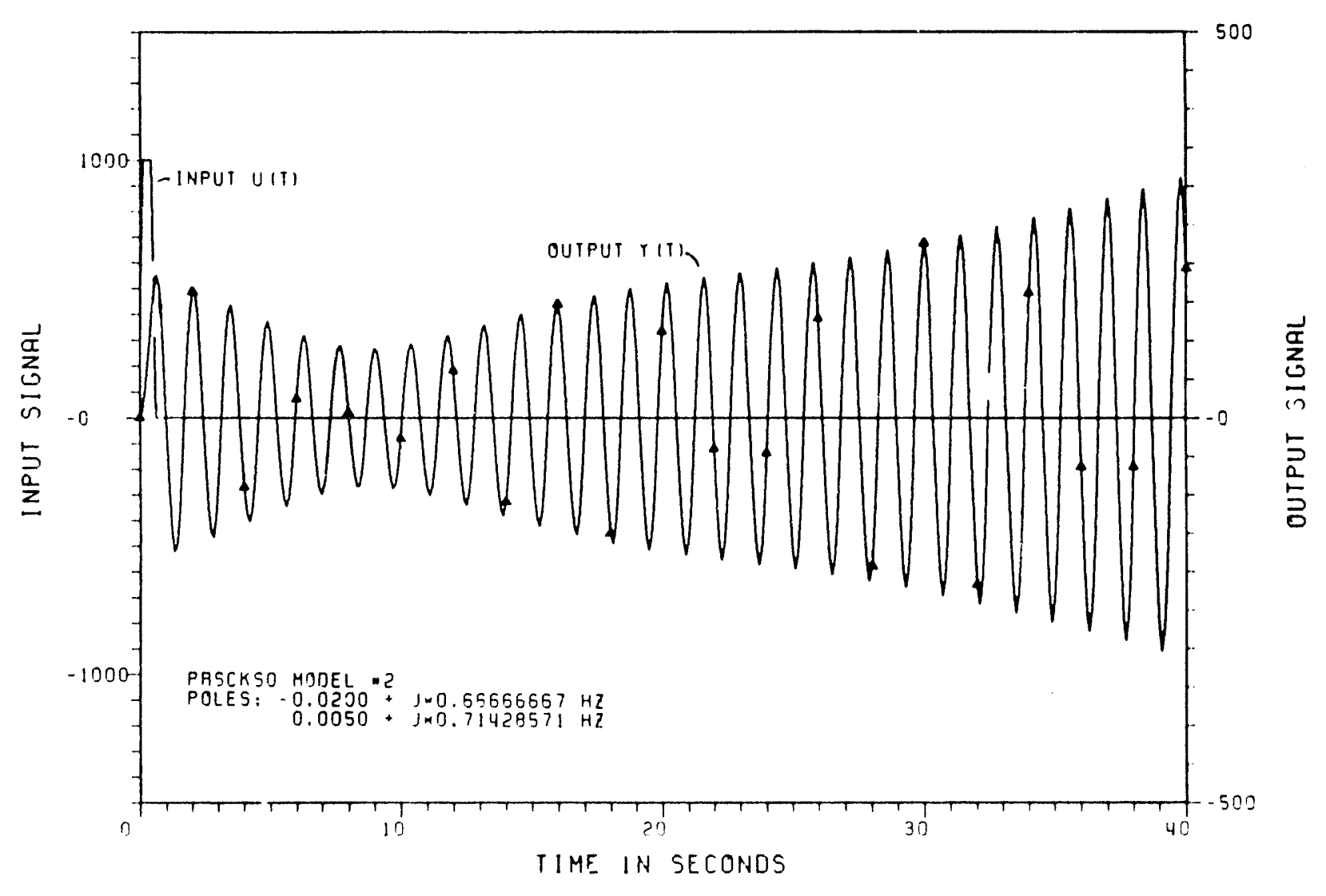

FIGUAE 2.0 MESPONSE OF FRSCKSO MODEL 210 BRIEF PULSE INPUT 

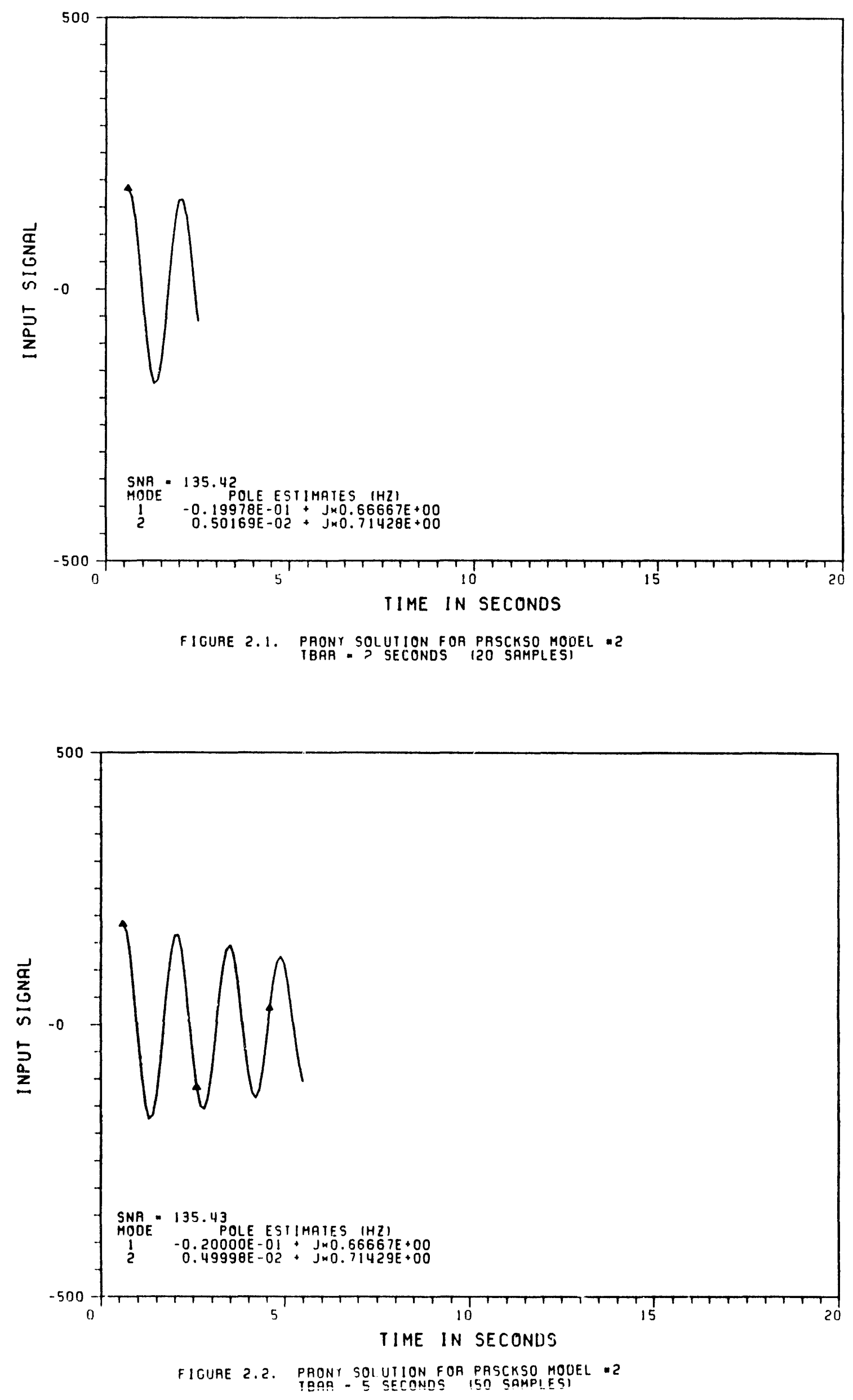

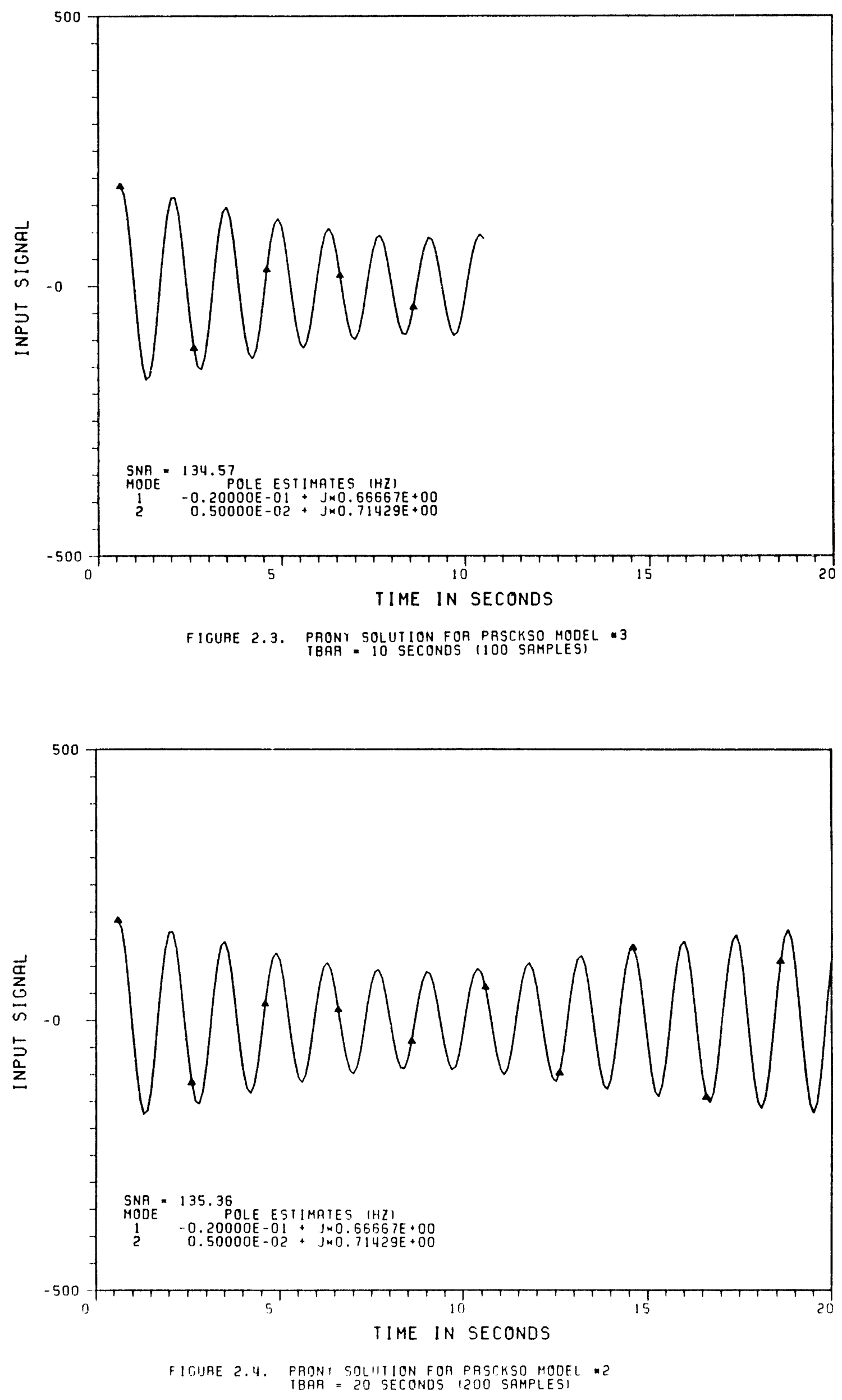


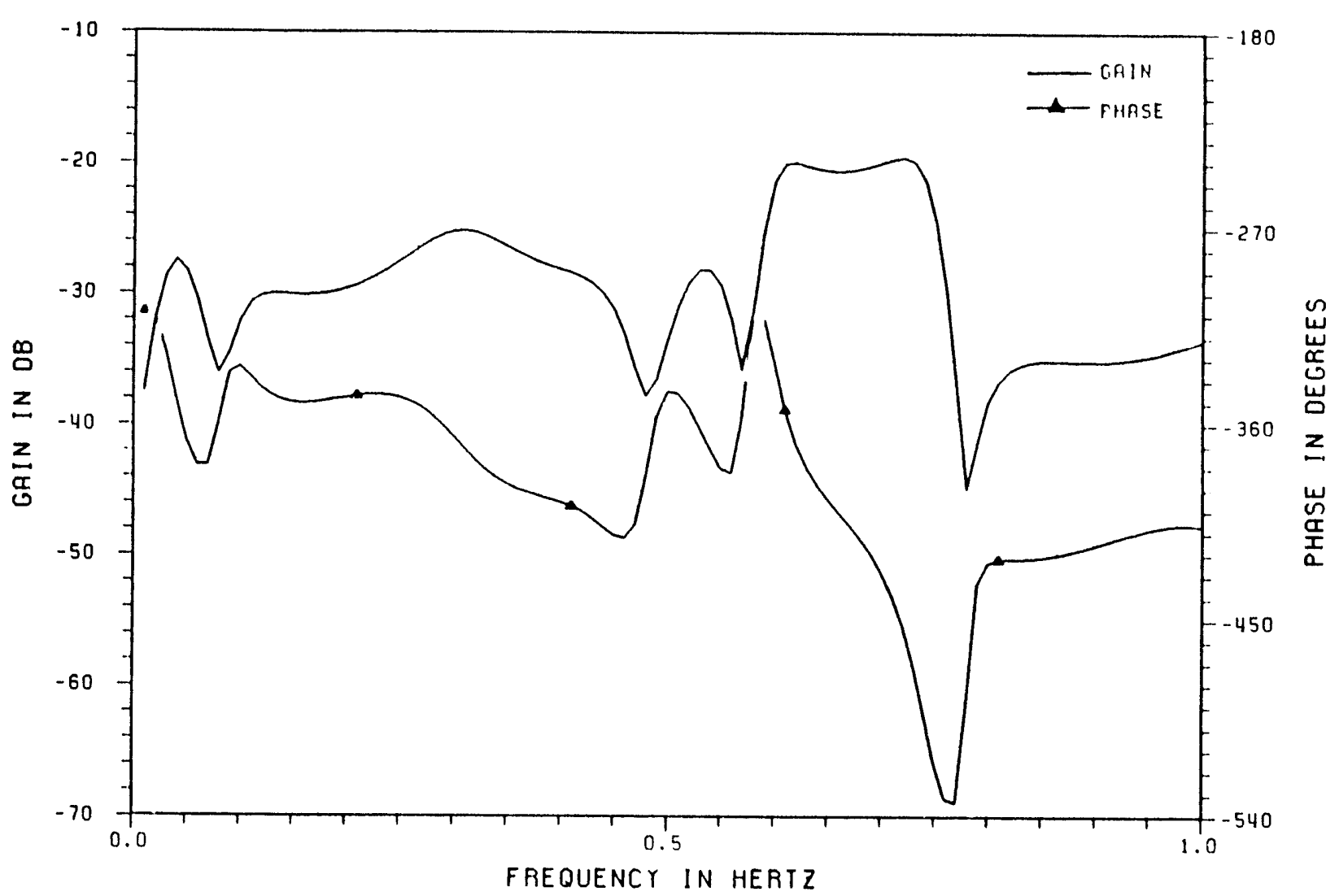

26

FIGURE 3. FREOUENCY RESPONSE FOR PRSCKSY MOOEL - 1

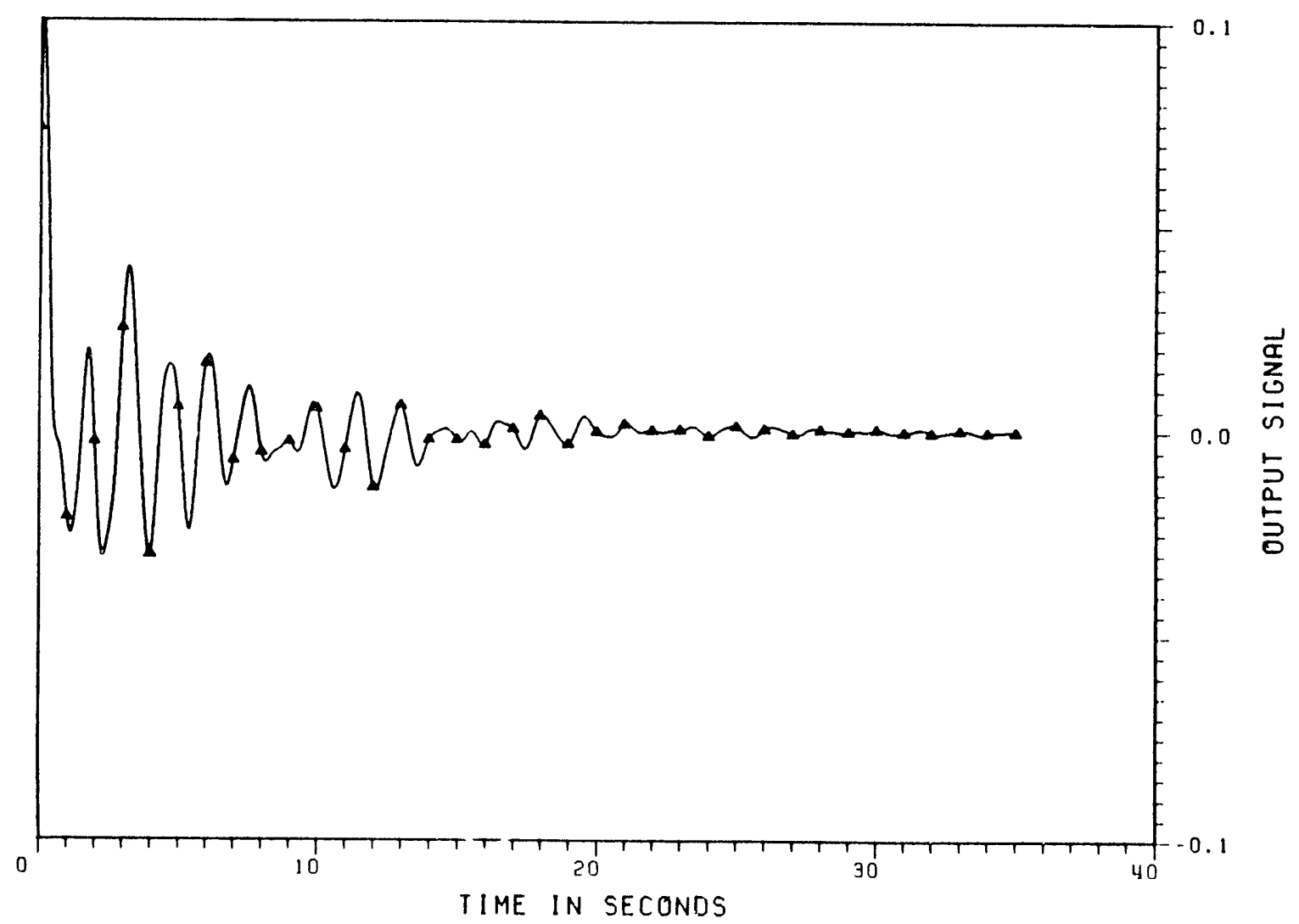

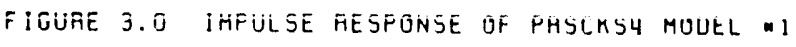


SIGPAKZ ANALYSIS RESULTS:

C $K$ SIOPAKZ FLOTTING FOR PRS SIGNAL DATA ION, FO8 FILE)

PLOT * 1

POUT $1 / 1$

ISPAN $=[0000.0,0019.9]$

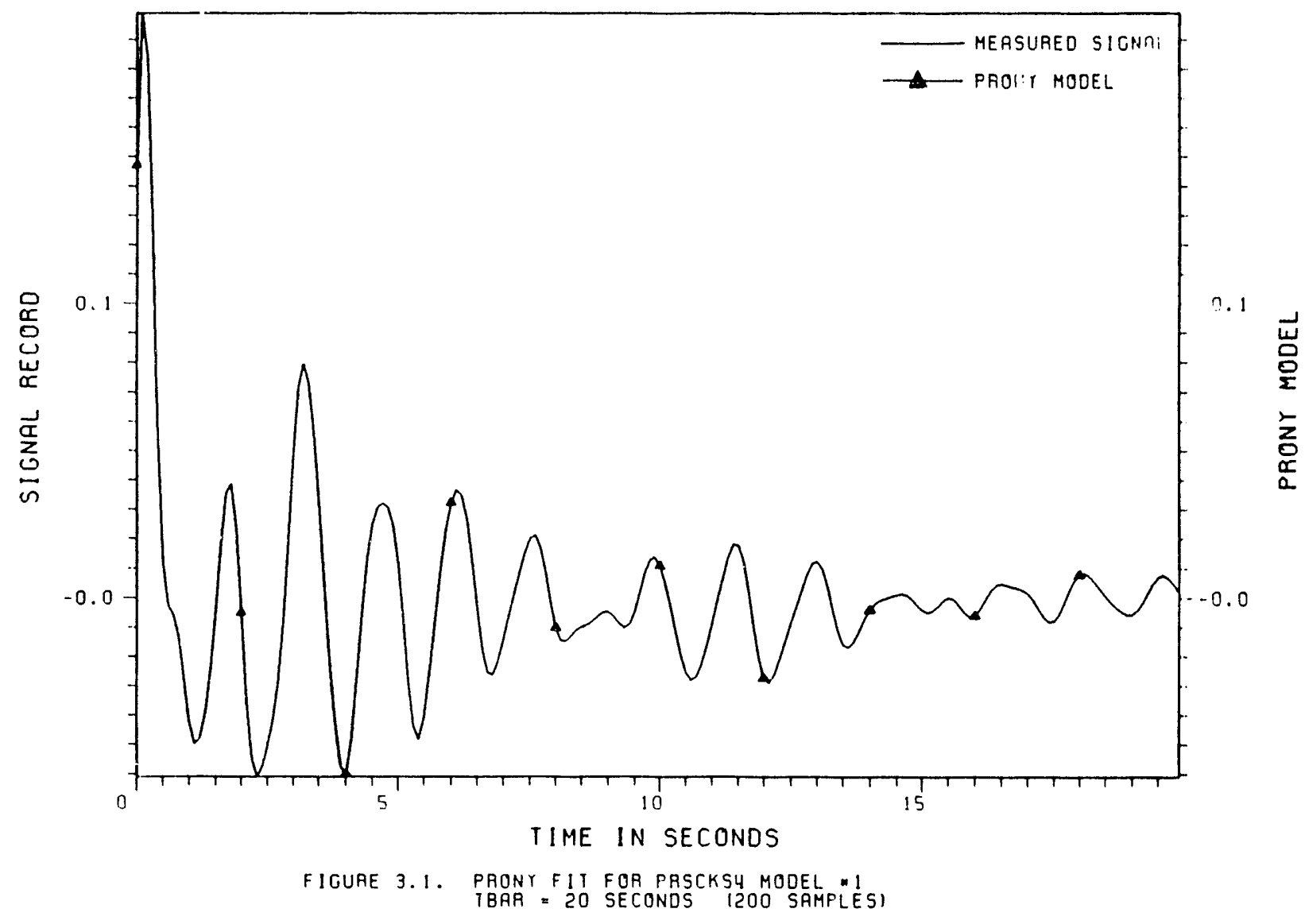

岁
0
0
2
$z$
0
0
0
0 


$\begin{array}{cc}\text { HOUE } & \text { DAHPING } \\ 1 & 0.0239805 \\ 2 & 0.0318409 \\ 3 & 0.0596168 \\ 4 & 0.0508920 \\ 5 & 0.0438688 \\ 6 & 0.0227360 \\ 7 & 0.0857313 \\ 8 & 0.0257093 \\ 9 & 0.0633062 \\ 10 & 0.0560974 \\ 11 & 0.0176936 \\ 12 & 0.0265640 \\ 13 & 0.0394194 \\ 14 & 0.1446441\end{array}$

FHO $\quad(1+2)$
0.0367401
0.0912621
0.3045262
0.4608535
0.5357940
0.5975186
0.7275286
0.7126974
1.0428168
1.1506412
1.2396401
1.2919787
1.5015666
1.6059325

REL HT

0.2690819

0.1865634

0.4499747

0.3286152

0.5348253

0.5201265

1.0000000

0.6577225

0.1417231

0.1704997

0.0785724

0.0757616

0.1254782

0.4546648
PHASE

30.119507

116.554008

$-4.998126$

$-119.239242$

0.052731

76.963143

$-53.600270$

174.971951

$-84.687450$

$-21.813123$

$-86.217684$

$-28.926462$

167.056914
AMPL I TUDE

0.0144529

0.0100207

0.0241690

0.0176505

0.0287265

0.0279370

0.0537119

0.0353275

0.0076122

0.0091579

0.0042203

0.0040693

0.0067397

0.0244209

FIGURE 3.2. PRONY SOLUTION TABLE FOR PRSCKSY MODEL 1 $1 B \cap A=20$ SECONOS 1200 SAMPLESI

SI GPAKE ANALYSIS RESULTS: PLOT
FIO FILES) NO. SOLUTIONS $=1$ TRIMLOC $=0.10 E-01$

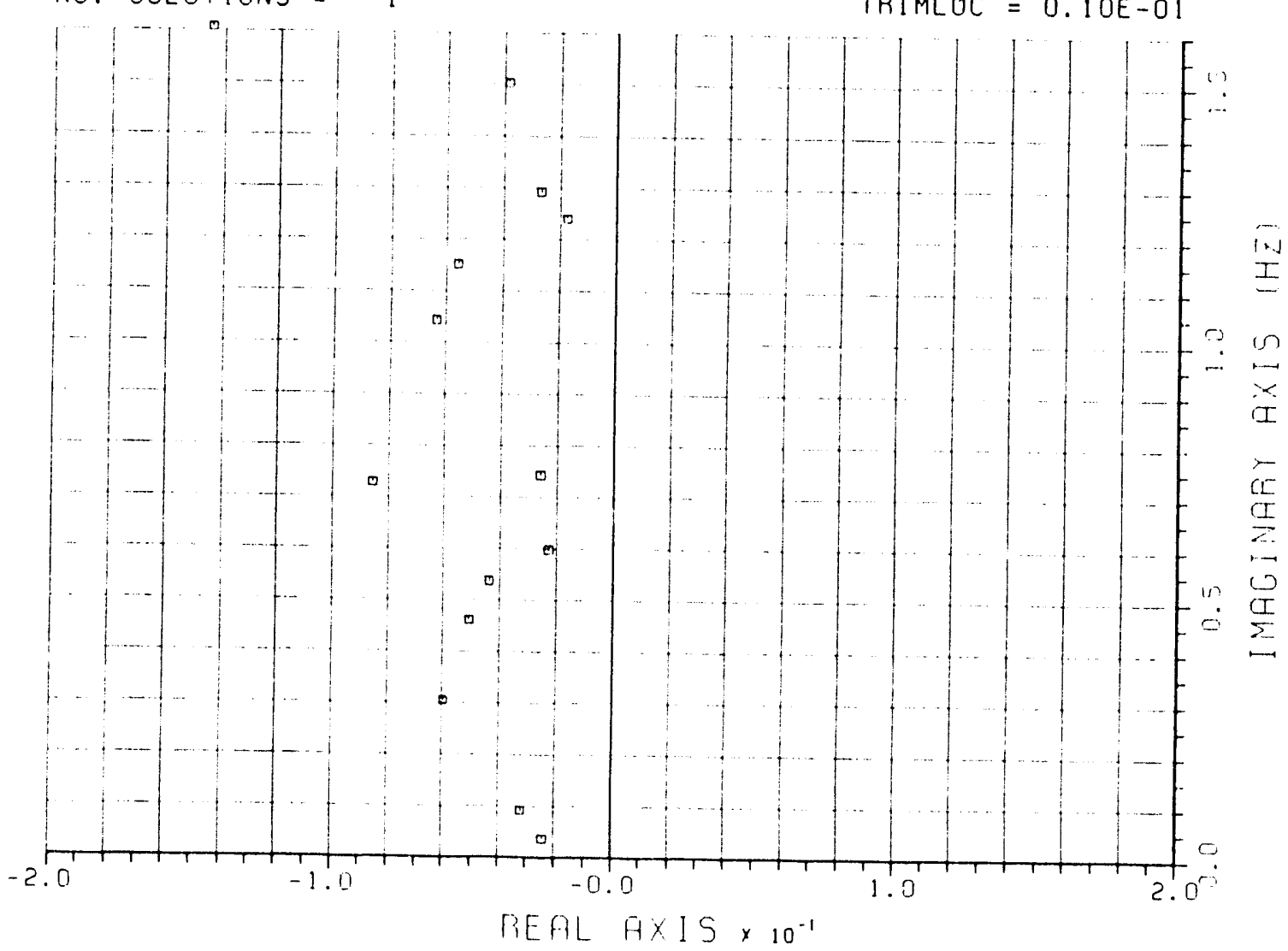

FIGURE 3.3. PROHY SO: UTION LOCUS FOR PASCKSY MOOEL "I TORA $=20$ SECOHOS 1200 SAMFLESI 


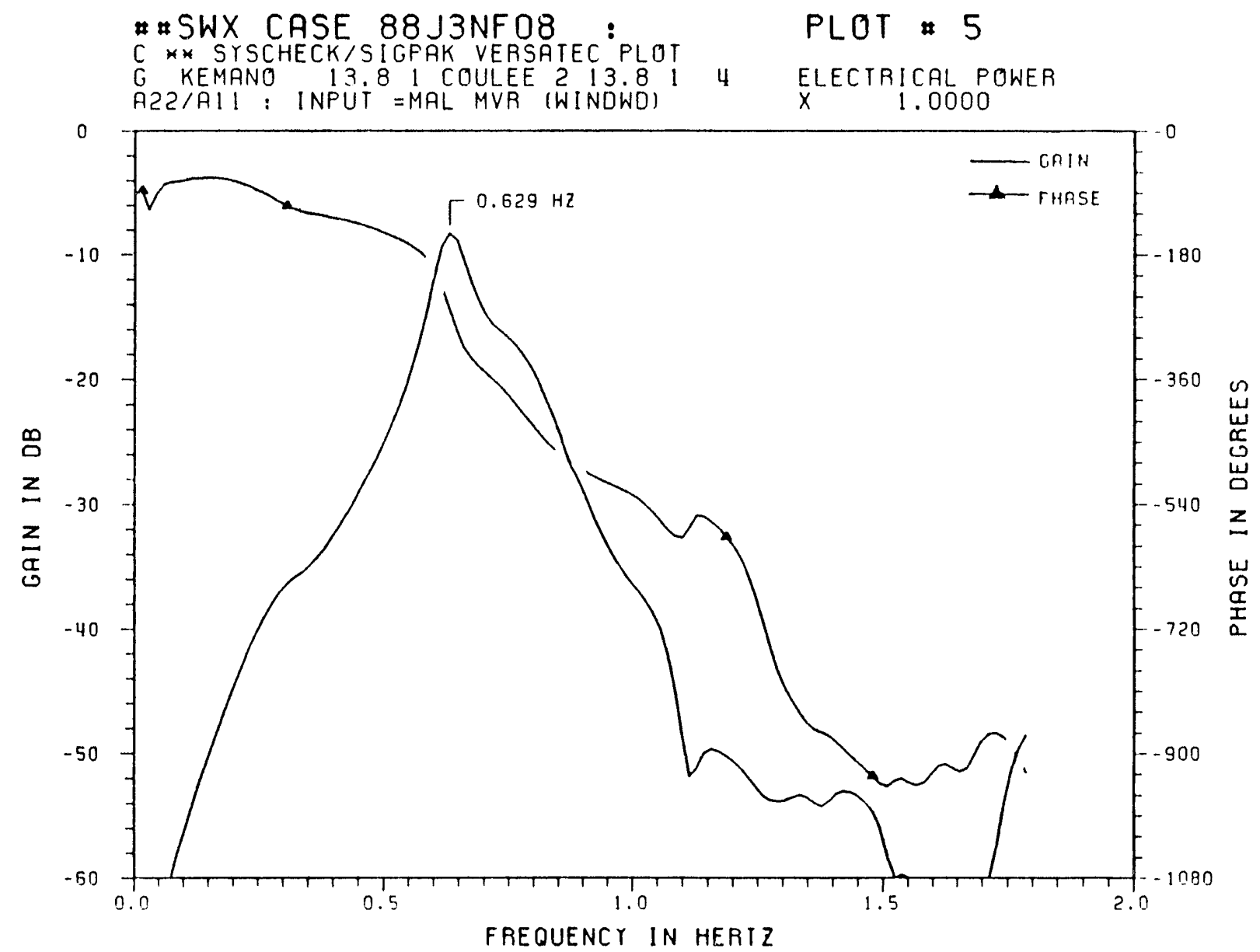

FIGURE 4. FREOUENCY AESPONSE OF KEMANO ELECTRICAL POWER TO SHUNT AEACTIVE CONTROL AT MALIN, CASE BO J JNFOB

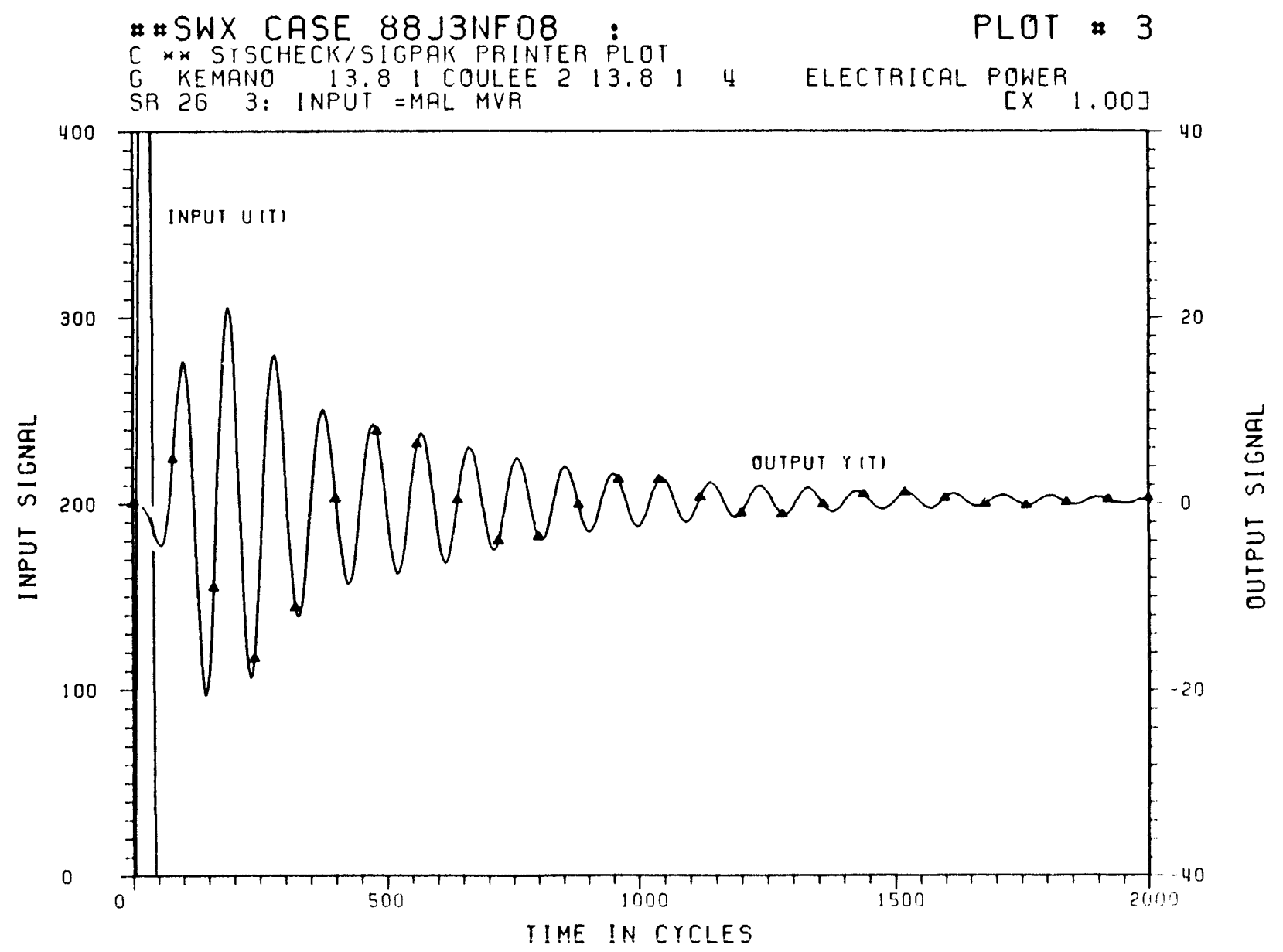

FICURE 4.0 KEHANO RINGDOWN FOR BRIEF MVAR LORD PULSE AT MALIN 


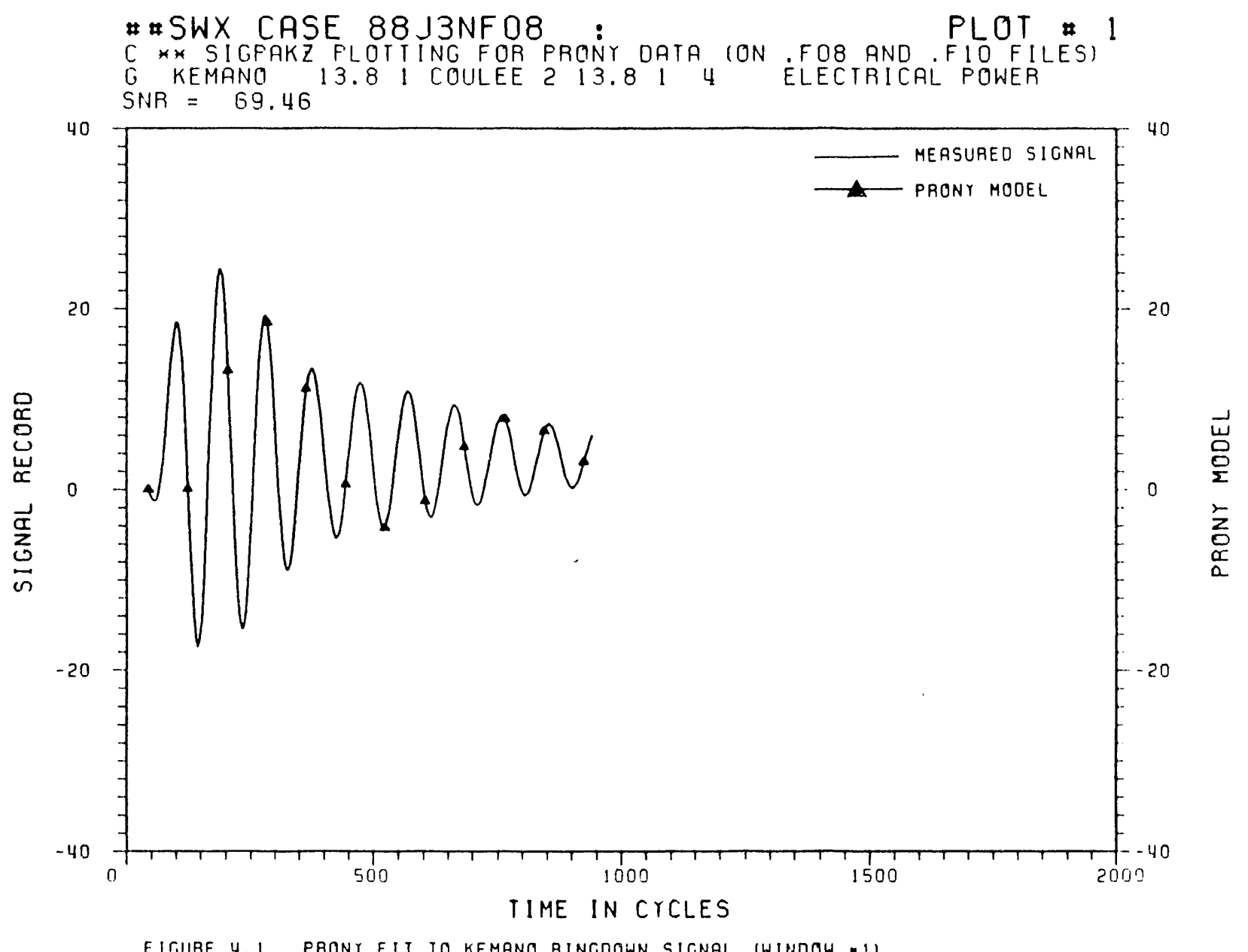

FIGURE 4.1. PRONY FIT TO KEMANO RINGDOWN SICNAL IWINDOW *1)

TBAR $=15$ SECONOS 1225 SAMPLESI 


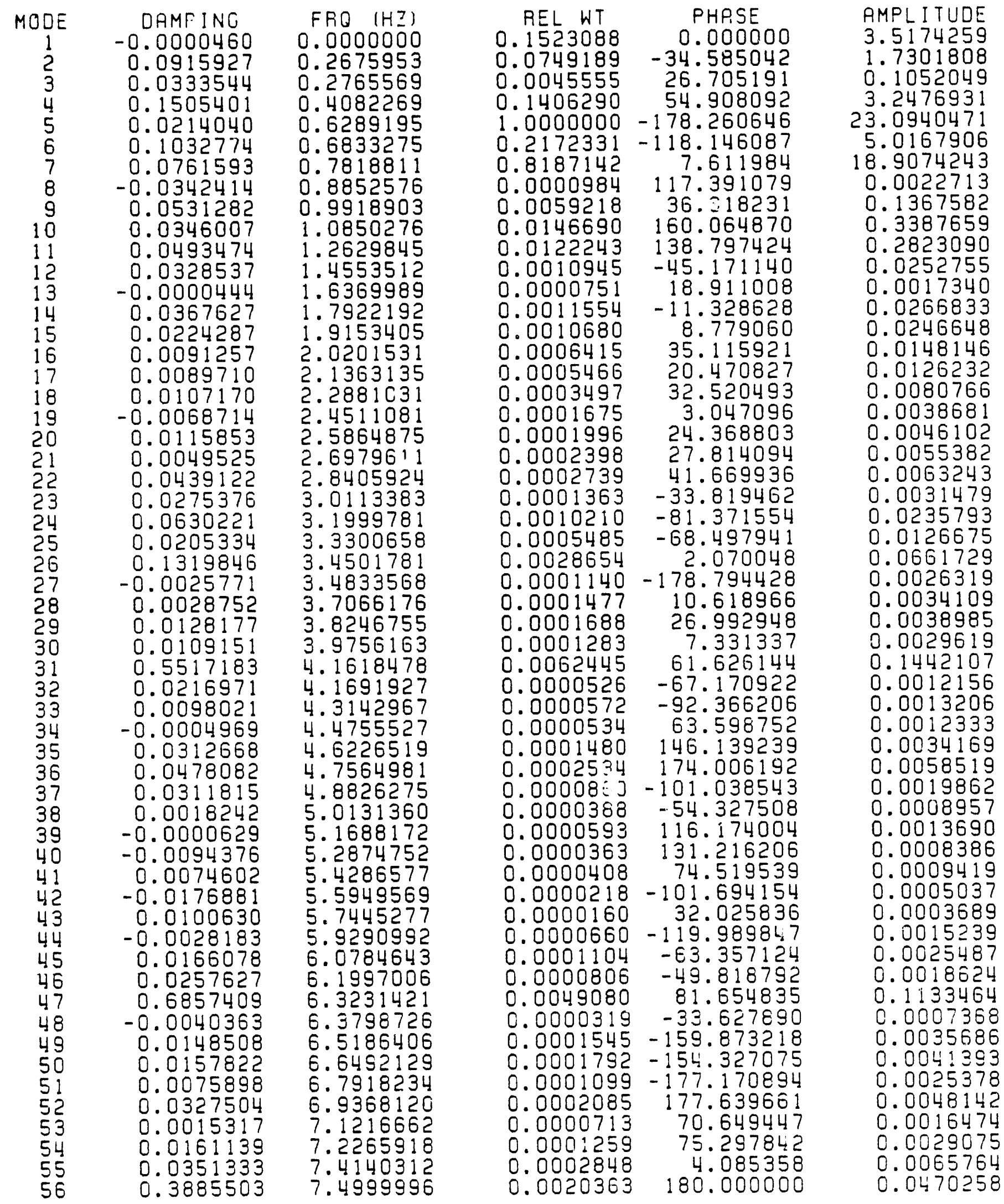

FICURE 4.2. PRONY SOLUTION TABLE FOR FIT TO KEMANO RINGDOWN (WINDOW 1 ) TBAR $=15$ SECONOS (225 SAMPLES) 
SIGPAKZ PROCESSING FOR 88J3NF08. SWX

(INPUT SIGNAL $=400$ MVAR PULSE AT MALIN)

(CASE 20: KEMANO GENERATION) [SLIDING WINDOW, TBAR $=15$ SEC]

" PRONY S-TABLE FOR PRS NUMBER 1

*SICNAL-TO-NOISE RATIO= 69.4550 FOR NMODES $=56$

DISPLAY TRIM LEVEL $=0.20000 E+00$

$\begin{array}{cccccr}\text { MODE } & \text { DAMPING } & \text { FRO (HZ) } & \text { REL WT } & \text { PHASE } & \text { AMPLITUDE } \\ 5 & 0.0214040 & 0.6289195 & 1.0000000 & -178.260646 & 23.0940471 \\ 6 & 0.1032774 & 0.6833275 & 0.2172331 & -118.146087 & 5.0167906 \\ 7 & 0.0761593 & 0.7818811 & 0.8187142 & 7.611984 & 18.9074243\end{array}$

*PRONY S-TABLE FOR PRS NUMBER?

* SIONAL -TO-NOISE RATIO = 75.6260 FOR NMODES $=56$ DISPLAY TRIM LEVEL $=0.20000 E+00$
$M O D E$
$\frac{6}{7}$
DAMPING
0.0212416
FRO $(\mathrm{HZ})$
0.6286833
0.7819447
REL WT
PHASE
0.0711585
1.0000000
$-26.579108$
AMPL I TUDE
20.8513308
12.0813190

*PRONY S-TRBLE FOR PRS NUMBER 3

* SIONAL-TO-NOISE RATIO = 67.9670 FOR NMODES $=57$ DISPLAY TRIM LEVEL $=0.20000 E+00$
$M O D E$
6
7
DAMPING
0.0213526
FRO [HZ]
0.6287557
REL WT
1.0000000
PHASE
0.7764332
0.4830101
124.125559
AMPLITUDE
19.2038697
9.2756624

* PRONY S-TABLE FOR PRS NUMBER 4

* SISNAL - TO-NOISE RATIO = 65.2870 FOR NMODES $=56$ DISPLAY TRIM LEVEL $=0.20000 E+00$

$\begin{array}{ccc}\text { MODE } & \text { DAMPING } & \text { FRO (HZ) } \\ 5 & 0.0212042 & 0.6280298 \\ 7 & 0.0877736 & 0.7698994\end{array}$

REL WT PHASE

$1.0000000-82.598303$

AMPL I TUDE

17.3684915

$0.5908038-143.795953$

10.2613704

*PRONY S-TABLE FOR PRS NUMBER 5

$\because$ SICNRL-TC-NOISE RATIO = 72.8740 FOR NMODES $=56$ DISPLAY TRIM LEVEL $=0.20000 E+00$
$M O D E$
6
7
DAMPING
0.0215034
FRO $(\mathrm{HZ})$
0.0644864
0.6284879
0.7700647
REL WT
1.0000000
PHASE
0.2488102
66.594427
AMPL ITUDE
16.1728315
4.0239653

FIOURE H.. PRONY SOLUTION TABLE FOR SLIDINO-WINOOW FITS TO KEMANO RINCDOWN TBAR $=15$ SECONCS (225 SAMPLESI 


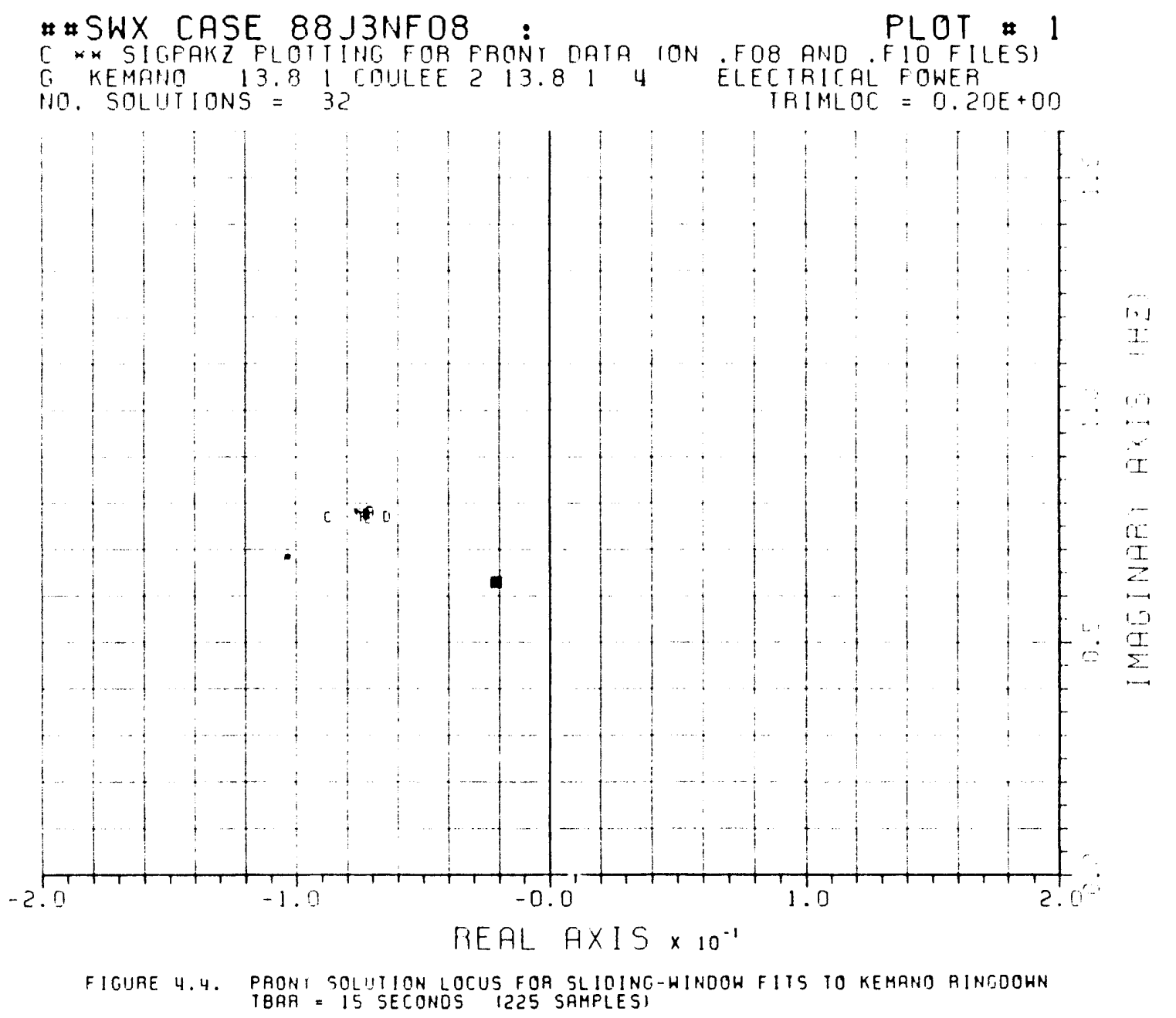




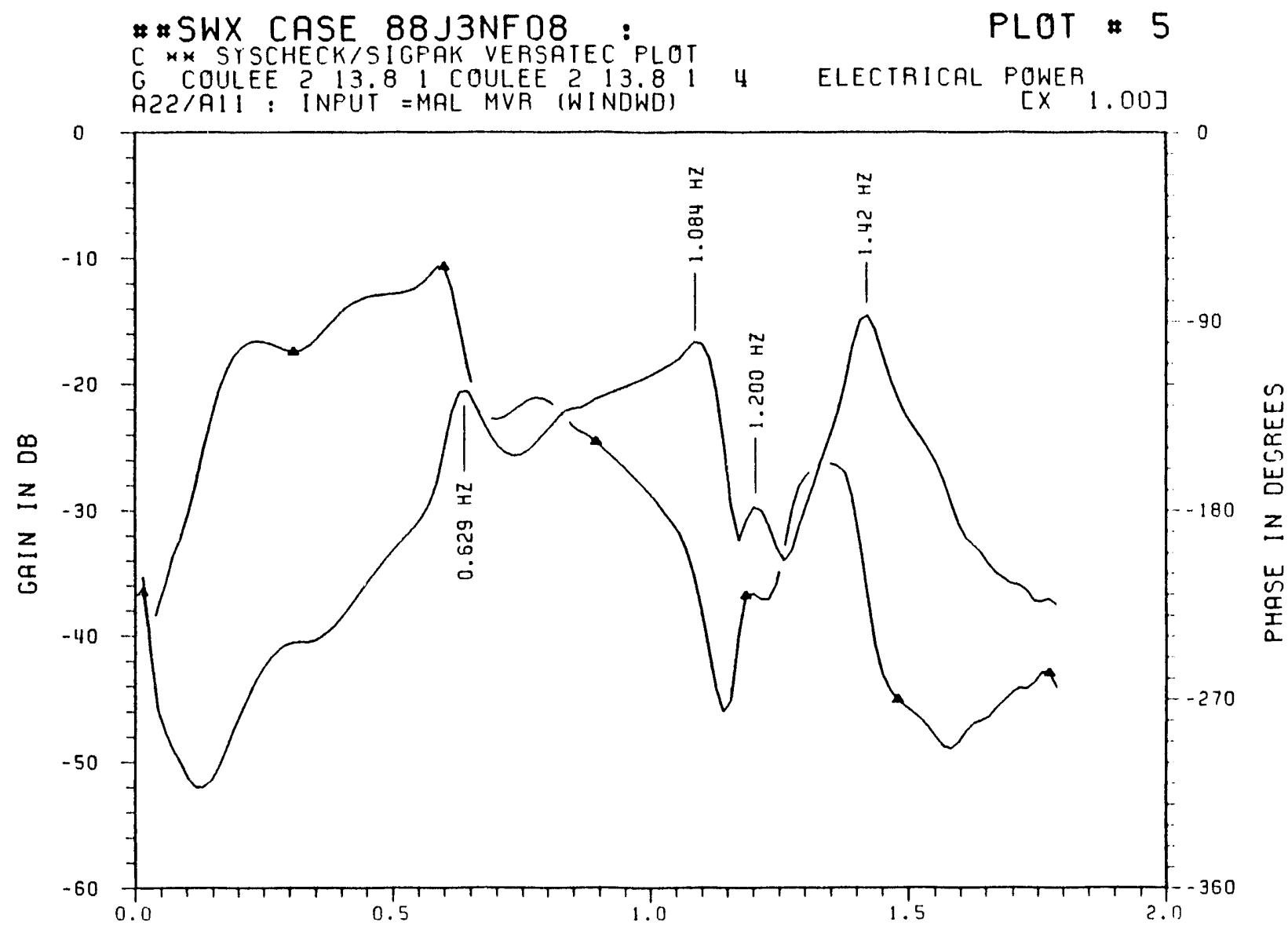

FREQUENCY IN HERTZ

Figure 5. FREOUENCY RESPONSE OF CRANO COULEE ELECIRICAL POHER 10 SHUN REACTIVE CONIROL AT MALIN. CASE BBJJNFOO

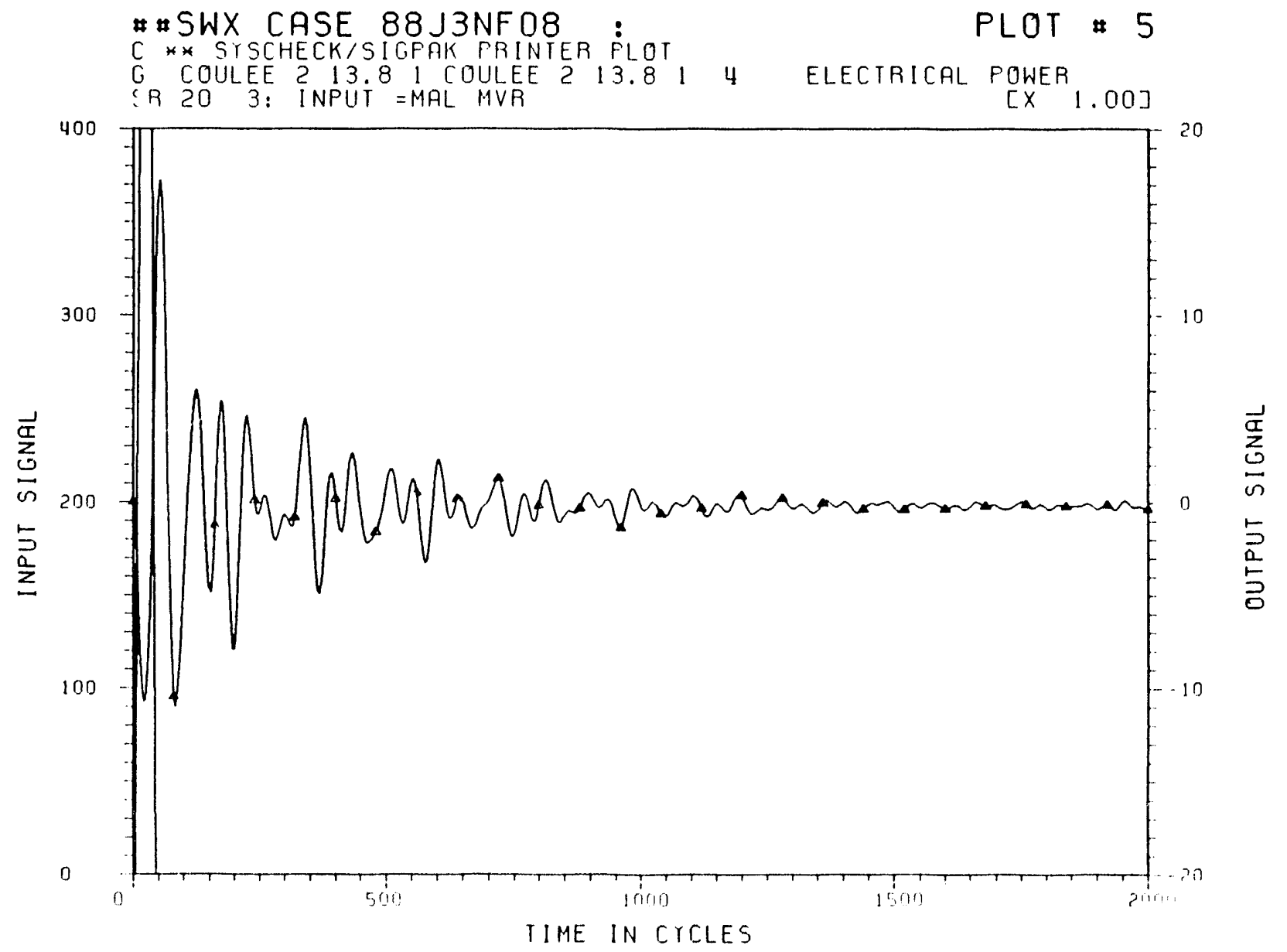

FICURE 5.0. CRANO COULEE RIMIIIIHH FOR BRIEF MVAR LOAD PIJLSE AI MALIH 
\#PRONY S-TABLE FOR PRS NUMBJER

-SIGNAL-TO-NOISE RATIO = 76.9200 FOR NMOOES = 5?

DISPLOY TPIIM LEVEL $=0.20000 \equiv+00$

$\begin{array}{ccccc}\text { MODE } & \text { DAMPING } & \text { FRO (HZ) } & \text { REL WT } & \text { PHASE } \\ 2 & 0.0000121 & 0.0000000 & 1.0000000 & 180.000000 \\ 5 & 0.1714490 & 0.5849845 & 0.6643203 & -24.840629 \\ 6 & 0.0213050 & 0.6285543 & 0.2825898 & 2.211894 \\ 7 & 0.0935907 & 0.7885799 & 0.4576850 & 55.072924 \\ 9 & 0.1081152 & 1.0315457 & 0.3415994 & -87.653386 \\ 10 & 0.0271046 & 1.1117995 & 0.3803402 & -143.306714 \\ 12 & 0.0191384 & 1.4166899 & 0.2276238 & -46.593526\end{array}$

" $P R O N Y$ S-TABLE FOR PRS NUMBER 2

* SIGNAL-TO-NOISE RATIO = 62.2740 FOR NMODES $=57$ DISPLAY TRIM LEVEL $=0.20000 E+00$

$\begin{array}{ccc}\text { MODE } & \text { DAMPINC } & \text { FRO }(\mathrm{HZ}) \\ 2 & 0.2762722 & 0.0000000 \\ 5 & 0.2252735 & 0.5064690 \\ 6 & 0.0208683 & 0.6284520 \\ 7 & 0.1039441 & 0.7586371 \\ 10 & 0.0340882 & 1.1175964 \\ 11 & 0.0570722 & 1.2150878 \\ 12 & 0.0203240 & 1.4150188\end{array}$

REL WT
0.2583904
0.8847686
0.5496024
0.8187653
1.0000000
0.3604350
0.4797156

PHASE

180.000000

$-169.312284$

153.154691

$-72.668157$

106.202465

163.975121

$-60.146025$
AMPL I TUDE

12.7991281

8.5027202

3.6169033

5.8579688

4.3721745

4.8680235

2. 9133867

* PRONY S-TABLE FOR PRS NUMBER 3

* SIINAL-TO-NOISE RRTIO = 65.0990 FOR NMODES = 58 DISPLAY TPIM LEVEL $=0.20000 E+00$

$\begin{array}{ccc}\text { MODE } & \text { DAMPINC } & \text { FRO (HZ) } \\ 7 & 0.5653865 & 0.7645359 \\ 8 & 0.1225762 & 0.7654033 \\ 10 & 0.0293104 & 1.0952112 \\ 11 & 0.0609731 & 1.1020010\end{array}$

REL WT
1.0000000
0.3308220
0.2665533
0.5932094

PHASE

$-95.086255$

103.906899

109.931609

$-7.572606$
AMPL I TUDE

1.5116550

5.1761401

3.2153256

4.7900024

5.8502755

2. 1086440

2.8064682

*PRONY S-TABLE FOR PRS NUMBER 4

* SIGNAL-TO-NOISE RATIO = 65.9490 FOR NMODES $=56$ DISPLAY TRIM LEVEL $=0.20000 E+00$

$\begin{array}{ccc}\text { MODE } & \text { DAMPING } & \text { FRO (HZ) } \\ 1 & 0.8260150 & 0.0000000 \\ 6 & 0.0208481 & 0.6282780 \\ 7 & 0.1263652 & 0.7557108 \\ 9 & 0.0641013 & 1.0629498 \\ 10 & 0.0319567 & 1.1047070 \\ 11 & 0.0507833 & 1.1960494 \\ 12 & 0.0201382 & 1.4145743\end{array}$

REL $W T$

0.3252024

0.5863109

0.6649297

0.4536526

1.0000000

0.3625417

0.5100473
PHASE

180.000000

95.389133

$-61.299435$

$-112.340079$

$-40.197141$

73.557191

$-99.708609$

AMPL I TUDE

15.0051530

4.9640347

3. 9996729

8.9011980

* PRONY S-TABLE FOR PRS NUMBER 5

*SIINAL - TO-NOISE RATIO= 58.1000 FOR NMODES = 56 DISPLAY TRIM LEVEL $=0.200005+00$

$\begin{array}{ccc}\text { MODE } & \text { DAMPING } & \text { FRQ (HZ) } \\ 5 & 0.0209409 & 0.6282848 \\ 6 & 0.1283117 & 0.7736774 \\ 8 & 0.3238557 & 0.9472265 \\ 10 & 0.0288555 & 1.1158272 \\ 12 & 0.0195285 & 1.4144407 \\ 13 & 0.3696908 & 1.4763510\end{array}$

$\begin{array}{lr}\text { REL HT } & \text { PHASE } \\ 0.7889842 & -113.819176 \\ 0.6804827 & 104.520295 \\ 0.5225938 & -94.268561 \\ 1.000000 & -164.928599 \\ 0.6781224 & -119.891132 \\ 0.2945121 & 153.523109\end{array}$

AMPL I TUDE

2.4784325

2. 1375971

1.6416216

3.1412956

2.1301829

0.9251494

FIOURE 5.1. PRONY SOLUTION TABLE FOR SLIDING-WINDOW FITS TO GRAND COULEE RINGDOWN

TEAT = 15 SECONDS (Z25 SAMPLES 
* SWX CASE 88J3NF08

PLOT \# 1

C *K SIGPAKZ PLOTIING FOR PRONY DATA ION. F08 AND FIO FILESI

G COULEE 213.8 I COULEE 213.814 ELECIRICAL POWER

NO. SOLUIIONS $=32$ TRIMLOC $=0.20 E+00$

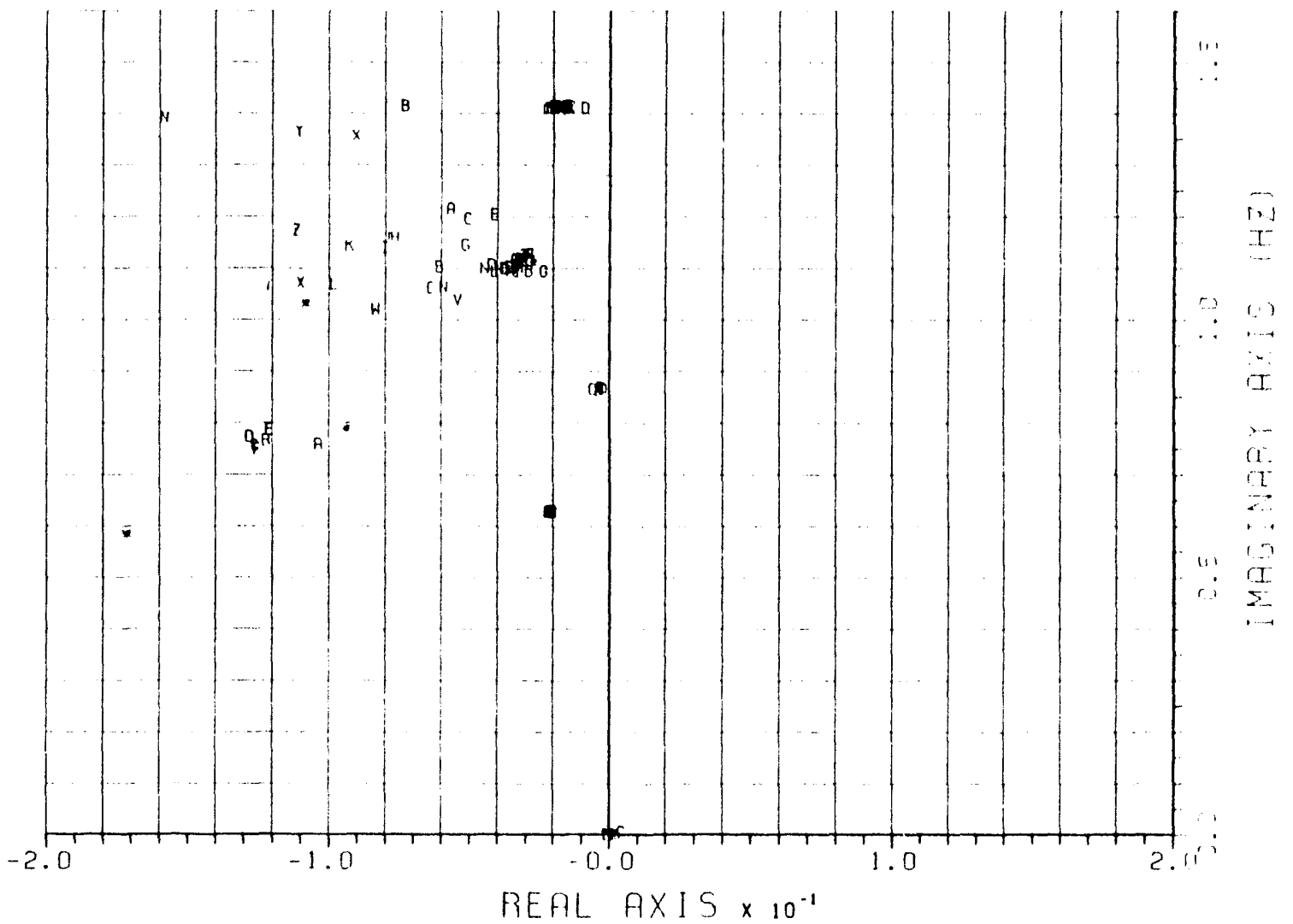
FIGUAE 5.2. PAONY SOLUIION LOCUS FOA SLIOING-WINOOW FITS TO GRANO COULEE RINGDOWN
TBAR $=15$ SECONOS I2Z5 SAMPLESI 


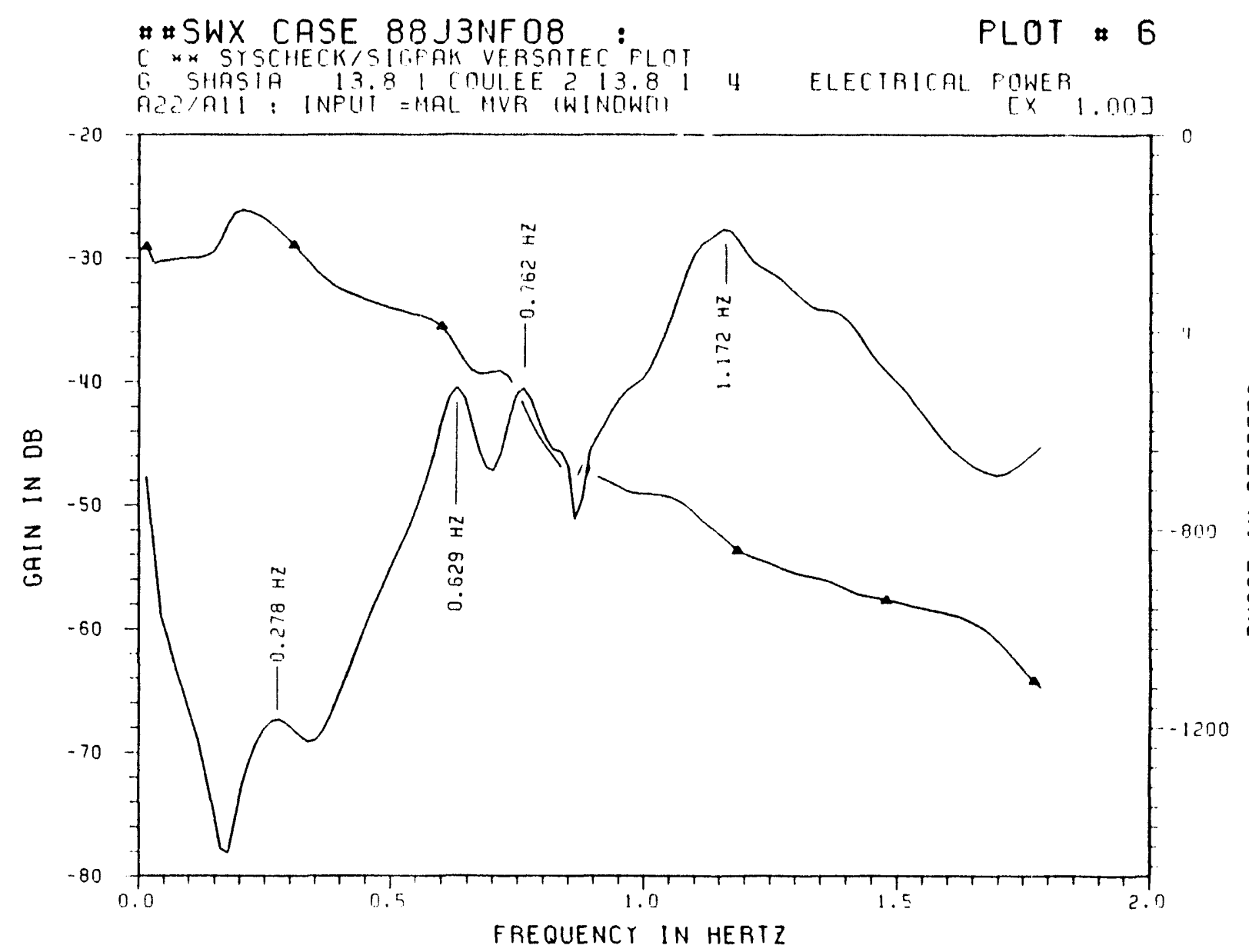

FIGUAE 6. FREOUENCY RESFOHSE OF SHASTA ELECTAICAL POHER TO SHUNT
REACTIVE COHTROL AT MALIN. CASE OBJJNFOB

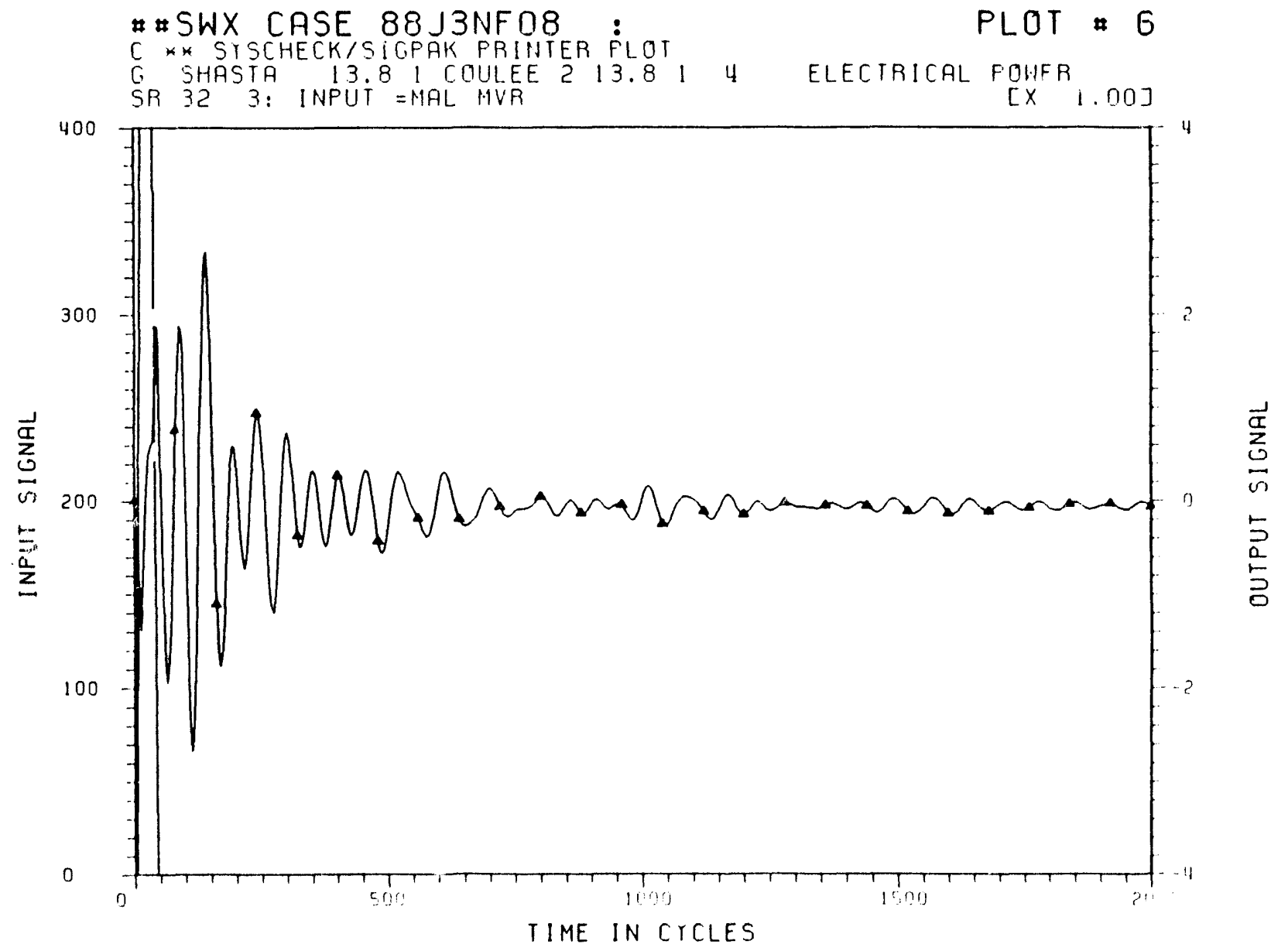

FIGUARE 6.0. SHASIR RINGDOWH FOR RAIEF MVAR LOAO FULSE AI MALIN 
*PRONY S-TABLE FOR PRS NUMBEF 1

* SIUNAL-TO-NOISE RATIC = 78.6570 FOR NMODES $=57$

DISPLAY TRIM LEVEL $=0.20000 E+00$

$\begin{array}{cccccr}\text { MODE } & \text { DAMPINC } & \text { FRO }(H Z) & \text { REL WT } & \text { PHASE } & \text { AMPLITUDE } \\ 2 & 0.0000147 & 0.0000000 & 0.6236347 & 180.000000 & 1.9351998 \\ 11 & 0.0559060 & 1.1430360 & 1.0000000 & 57.416009 & 3.1030984\end{array}$

"PRONY S-TABLE FOR PRS NUMBER 2

*SIGNAL-TO-NOISE RATIO=67.8140 FOR NMODES $=56$ DISPLAY TRIM LEVEL $=0.20000 E+00$

$\begin{array}{cccccc}\text { MODE } & \text { DAMPING } & \text { FRO (HZ) } & \text { REL WT } & \text { PHASE } & \text { AMPLITUDE } \\ 8 & 0.0873423 & 0.9806037 & 0.3249831 & -65.325787 & 0.8744046 \\ 9 & 0.0604547 & 1.1160129 & 1.0000000 & -3.692468 & 2.6906155\end{array}$

"PRONY S-TABLE FOR PRS NUMBER 3

* IIGNAL-TO-NOISE RATIO= 75.2930 FOR NMODES $=56$ DISPLAY TRIM LEVEL $=0.20000 E+00$

\begin{tabular}{|c|c|c|c|c|}
\hline $\begin{array}{c}\text { MODE } \\
8 \\
9\end{array}$ & $\begin{array}{c}\text { DAMP ING } \\
0.1005724 \\
0.0618862\end{array}$ & $\begin{array}{l}\text { FRO }(\mathrm{HZ}) \\
0.9734286 \\
1.1112630\end{array}$ & $\begin{array}{c}\text { REL WT } \\
0.3718138 \\
1.0000000\end{array}$ & $\begin{array}{c}\text { PHASE } \\
-175.282491 \\
-88.646791\end{array}$ \\
\hline
\end{tabular}

*PRONY S-TABLE FOR PRS NUMBER 4

* SIGNAL-TO-NOISE RATIO = 65.3750 FOR NMODES $=56$

DISPLAY TRIM LEVEL $=0.20000 E+00$

$\begin{array}{ccccrr}\text { MADE } & \text { DAMPINC } & \text { FRO (HZ) } & \text { REL WT } & \text { PHASE } & \text { AMPLITUDE } \\ 2 & 0.2840114 & 0.1643471 & 0.3324675 & -170.179473 & 0.3552443 \\ 5 & 0.0206658 & 0.6281218 & 0.3275875 & 96.775829 & 0.3500300 \\ 6 & 0.0175612 & 0.7547974 & 0.3268882 & 114.902072 & 0.3492823 \\ 9 & 0.0513900 & 1.0959000 & 1.000000 & -162.723370 & 1.0685083 \\ 14 & 0.1608307 & 1.7876513 & 0.2282731 & -25.494541 & 0.243917 \\ 15 & 0.4064986 & 1.8421872 & 0.4125310 & 103.467051 & 0.4407928\end{array}$

*PRONY S-TABLE FOR PRS NUMBER 5

*SICNAL-TO-NOISE RATIO = 60.1690 FOR NMODES $=56$

DISPLAY TRIM LEVEL $=0.20000 E+00$

$\begin{array}{cccccc}\text { MODE } & \text { DAMPINL } & \text { FRO (HZ) } & \text { REL WT } & \text { PHPSE } & \text { AMPLITUDE } \\ 5 & 0.0205556 & 0.6281598 & 0.3596967 & -112.657722 & 0.3192980 \\ 6 & 0.0173369 & 0.754599 & 0.3605438 & -63.373701 & 0.3200499 \\ 9 & 0.0526018 & 1.0955534 & 1.0000000 & 101.469387 & 0.8876867\end{array}$

FIGURE 6.1. PRONY SOLUTION TABLE FOR SLIOINO-WINDOW FITS TO SHASTA RINCDOWN

TEAP $=15$ SECONOS $(225$ SAMPLES $)$ 
\# SWX CASE 88 I3NFO8 : $\begin{aligned} & \text { PLOT } \\ & \text { a } 1\end{aligned}$ G. SHASTA 13.8 I COULEE 2 : 13.81 1 4 ELECIRICAL FOWER

NO. SOLUITIONS $=32$

TRIMLOC $=0.20 E+00$

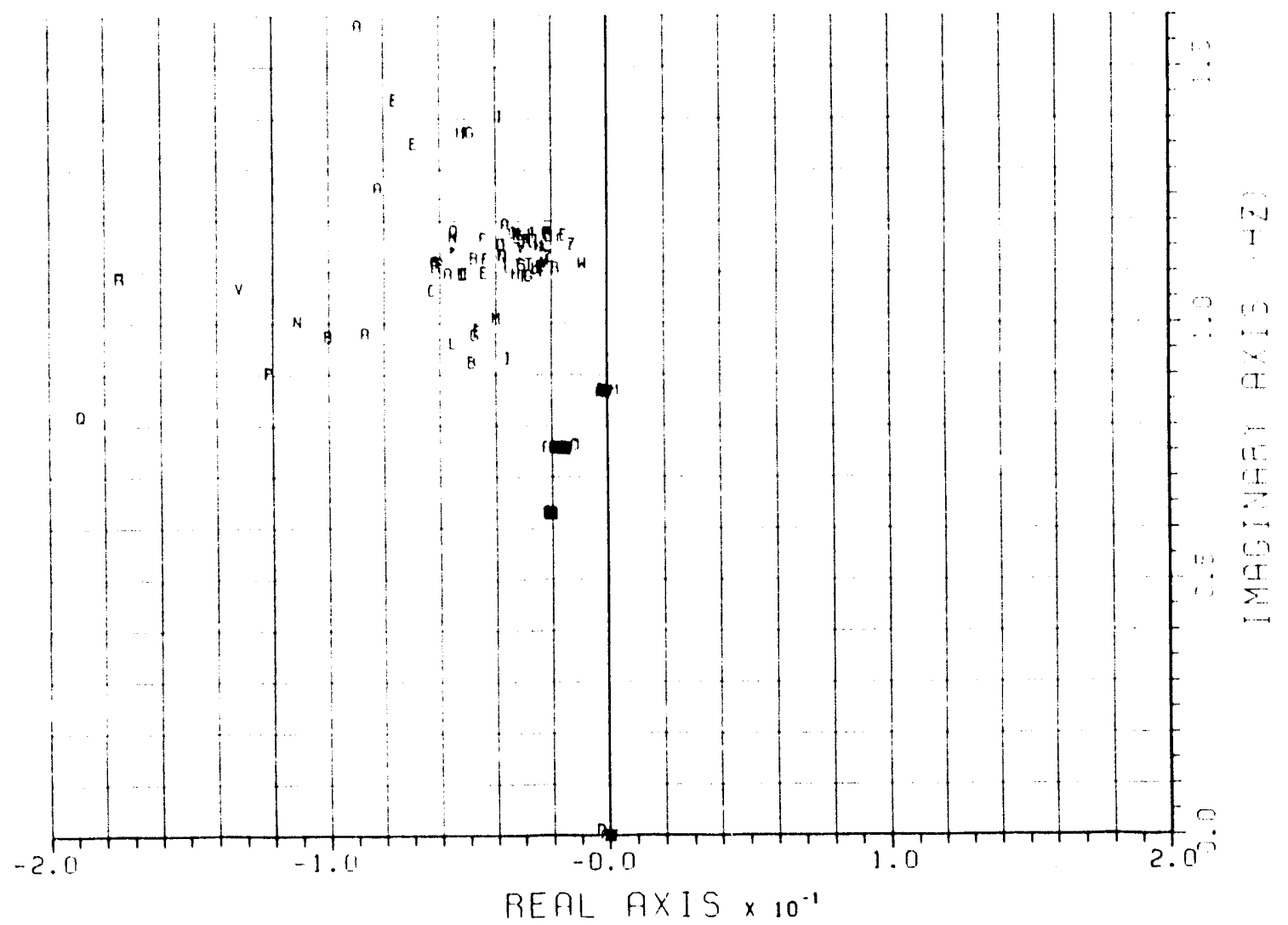

FIGUAE 6.2. PRONY SOLIIIINN LOCIJS FOR SLIDING-HIHDOW FITS TO SHASTA RINGDOWN TBAR $=15$ SECONDS 1225 SAMPLESI 


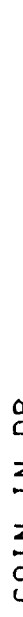

-11
-20

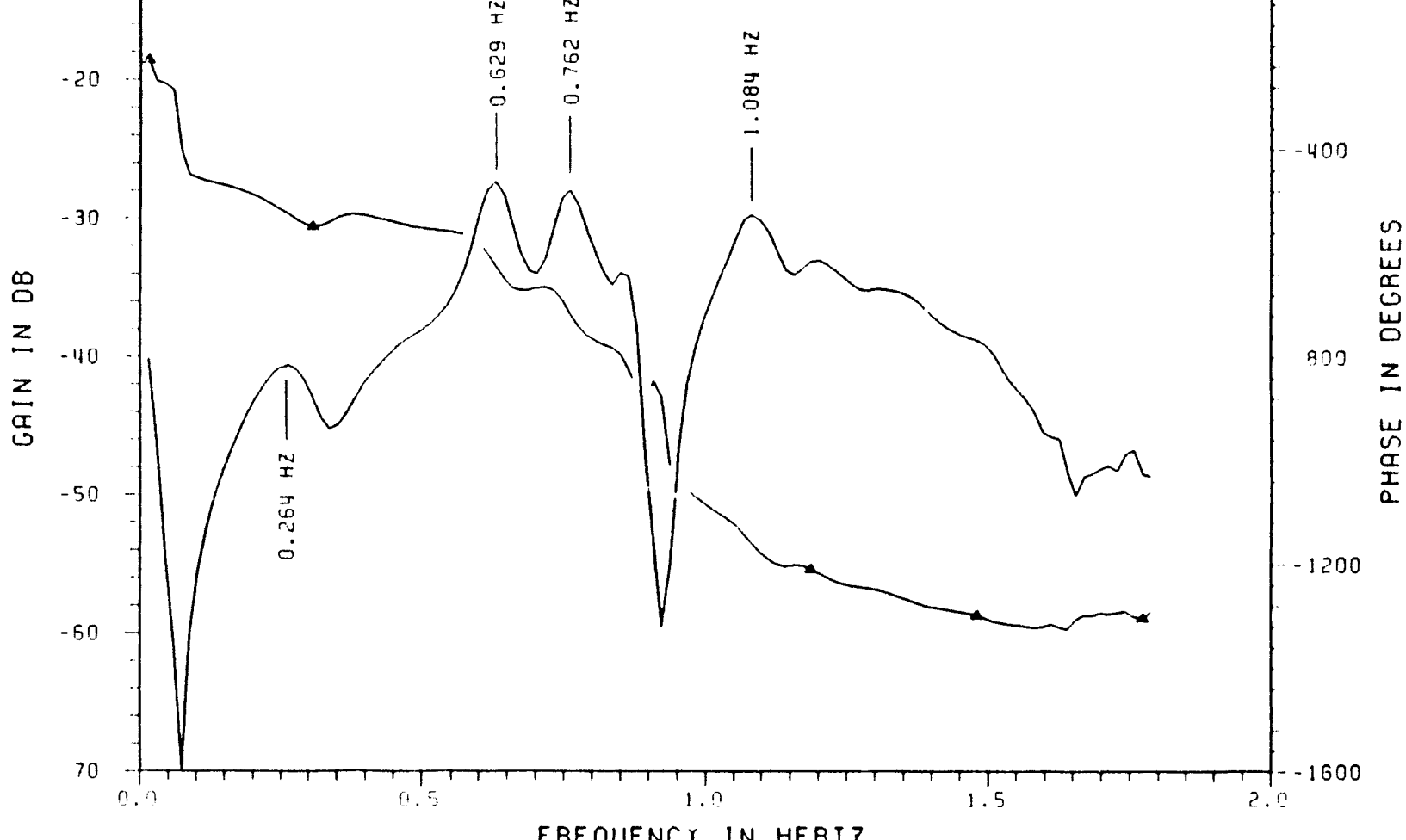

FREOUENCY IN HERTZ

FIGUAE 7. FREDUENC, RESPONHSE OF PALO VEADE ELECTAICAL POWER IO SHUNT REACIIVE CONTAOL AI MALIN. CASE $88 J 3 N F O H$
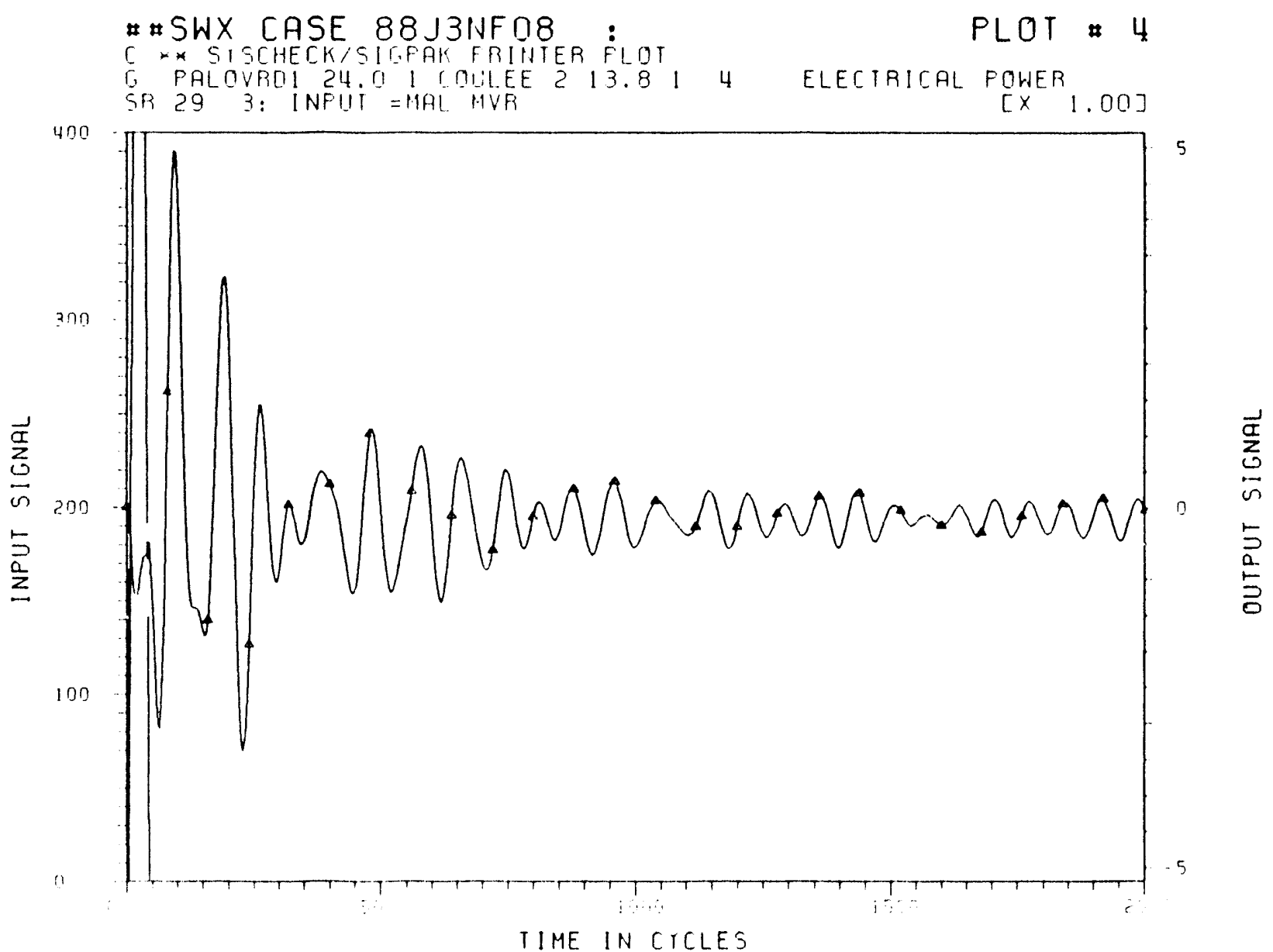

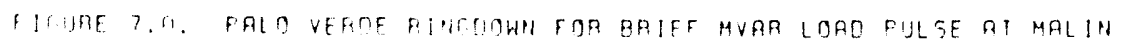


*PRONY S-TABLE FCR PRS NIJMBER 1

*SIUNA! - TO-NOISE RRTIO = 71.0880 FOR NMODES $=56$

DiSPLAY TFIM LEVEL $=0.20000 \equiv+00$

$\begin{array}{ccc}\text { MODE } & \text { DAMPINC } & \text { FRO (HZ) } \\ 2 & 0.0784432 & 0.2537408 \\ 4 & 0.1099590 & 0.4582658 \\ 5 & 0.0215942 & 0.6294444 \\ 6 & 0.0222847 & 0.7580719 \\ 8 & 0.6530660 & 0.9475308 \\ 9 & 0.0902369 & 0.9586493 \\ 10 & 0.0326451 & 1.0931824 \\ 1 ? & 0.0974320 & 1.3501417\end{array}$

REL WT PHASE

$0.3884187-125.115988$

$0.3954828-127.855330$

$0.6143338 \quad 167.280802$

0.5303981108 .103273

$1.0000000 \quad 1.590849$

$0.7930519-146.442701$

$0.3666928 \quad 16.532271$

$0.2851505-44.868328$
AMPL I TUDE

1.3452108

1. 3696758

2.1276230

1.8369283

3.4633010

2.7465775

1.2699675

0.9875622

*PRONY S-TABLE FOR PRS NUMBER 2

*SIGNAL-TO-NOISE RATIO=62.4910 FOR NMODES $=56$ DISPLAY TRIM LEVEL $=0.20000 E+00$

$\begin{array}{ccc}\text { MODE } & \text { DAMPING } & \text { FRO (HZ) } \\ 5 & 0.0187972 & 0.6302957 \\ 7 & 0.0540874 & 0.8138000 \\ 9 & 0.1960338 & 1.0045698 \\ 10 & 0.0360547 & 1.0991668\end{array}$
REL WT
PHASE
0.3667230
$-46.289754$
$0.6002149-110.655109$
1.0000000
39.799072
$0.2843185-99.646175$

10

0.1960338
0.0360547

AMPL I TUDE

1.7011466

2.7842636

4.6387779

1. 3188904

\#PRONY S-TABLE FOR PRS NUMBER 3

*SIGNAL-TO-NOISE RATIO = 53.9140 FOR NMODES $=55$ DISPLAY TRIM LEVEL $=0.20000 E+00$

$\begin{array}{ccc}\text { MODE } & \text { DAMPING } & \text { FRQ (HZ) } \\ 2 & 0.0993002 & 0.2402758 \\ 3 & 0.0608364 & 0.3106814 \\ 5 & 0.0203149 & 0.6286020 \\ 6 & 0.0164000 & 0.7563073 \\ 8 & 0.0696487 & 0.8997352 \\ 9 & 0.0377948 & 1.0942890 \\ 10 & 0.0560862 & 1.1991670 \\ 11 & 0.1062555 & 1.3394454\end{array}$
REL WT
0.4338793
0.4470482
1.0000000
0.6947976
0.9493147
0.7467464
0.4006823
$0.3559354-106.002752$
PHASE 45.386386 $-112.273107$
110.828939
113.628453
9.401998
178.167282
$-142.071052$

AMPL I TUDE 0.7174966 0.7392737 1.6536778 1.1489714 1.5698606 1. 2348779 0.6625994 0.5886024

*PRONY S-TABLE FOR PRS NUMBER 4

SIGNAL-TO-NOISE RATIO = 51.1090 FOR NMODES $=57$ DISPLAY TRIM LEVEL $=0.20000 E+00$

$\begin{array}{ccc}\text { MODE } & \text { DAMPINC } & \text { FRO (HZ) } \\ 1 & 1.3117952 & 0.0000000 \\ 4 & 0.0628569 & 0.2978800 \\ 6 & 0.0214090 & 0.6280366 \\ 7 & 0.0207875 & 0.7566131 \\ 10 & 0.0424768 & 1.0950723 \\ 11 & 0.0623607 & 1.1970763 \\ 12 & 0.1187711 & 1.3718049\end{array}$

REL WT
0.4612931
0.4423503
1.000000
0.8344029
0.8181547
0.4492991
0.3538183

PHASE

180.000000

$-6.890386$

$-96.119448$

$-63.497948$

78.654215

142.226322

0.1187711

0.3538183

172.008060

AMPL I TUDE

0.7355995

0.7053924

1. 5946467

1. 3305778

1. 3046677

0.7164733

0.5642152

* $P R O N Y$ S-TABLE FOR PRS NUMBER 5

* SIONAL-TO-NOISE RATIO = 60.2590 FOR NMODES = 50 DISPLFYY TRIM LEVEL $=0.20000 \equiv+00$

$\begin{array}{ccc}\text { MODE } & \text { DAMPINE } & \text { FRO }(H Z) \\ 3 & 0.0685207 & 0.3029037 \\ 5 & 0.0202937 & 0.6277372 \\ 6 & 0.4352444 & 0.6883008 \\ 7 & 0.0201857 & 0.7525882 \\ 10 & 0.0399053 & 1.1064367 \\ 11 & 0.0755221 & 1.2230252\end{array}$

$R E L W T$
0.2829000
0.5817735
0.0000000
0.4867526
0.4156352
0.2523528

PHPSE
53.664514
54.819843
107.880798
128.663093
-45.820015
8.181061

RMPL I TUDE

0.6073105

1. 3723120

2. 3588422

1. 1481725

0.9804178

0.5052605

FICURE 7.1. PRONY SOLUTION TABLE FOR SLIDINO-WINDOW FITS TO PALO VERDE RINOOOWN

TBAR $=15$ SECONDS (225 SAMP:ES) 


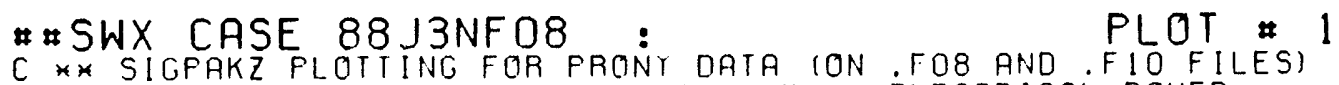

G PAIOVROI 24.0 LOULEE 213.814 ELECTRICAL POWER

NO. SOLUTIONS = 32 TRIMLOC $=0.20 E+O C$

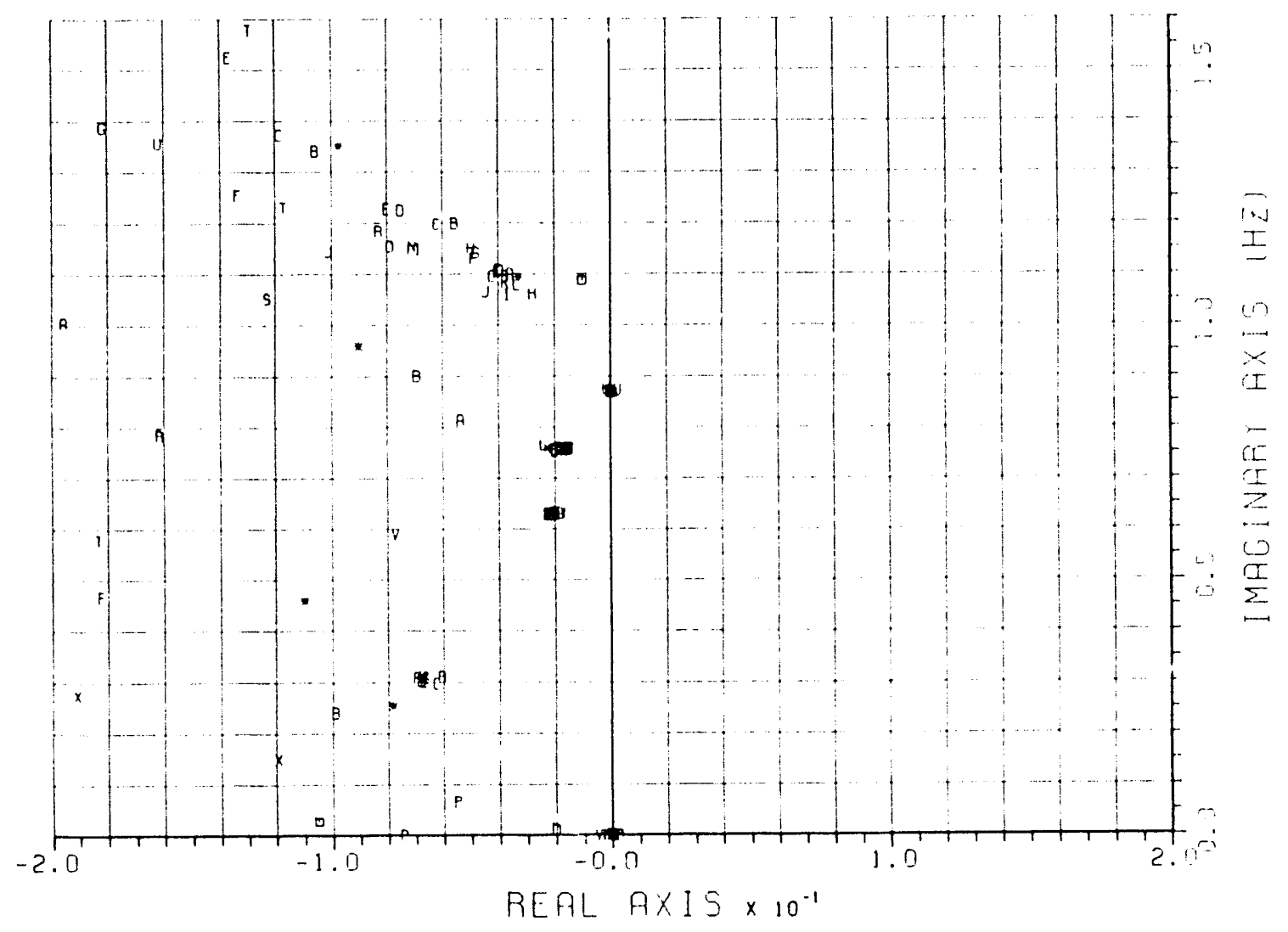

FIGURE 7.2. PRONY GRLIITION LOCIIS FOR SLIDING-HINDOH FITS TO PALO VERDE RINGDOHN TBAA = IS SECONOS 1225 SAMPLESI 


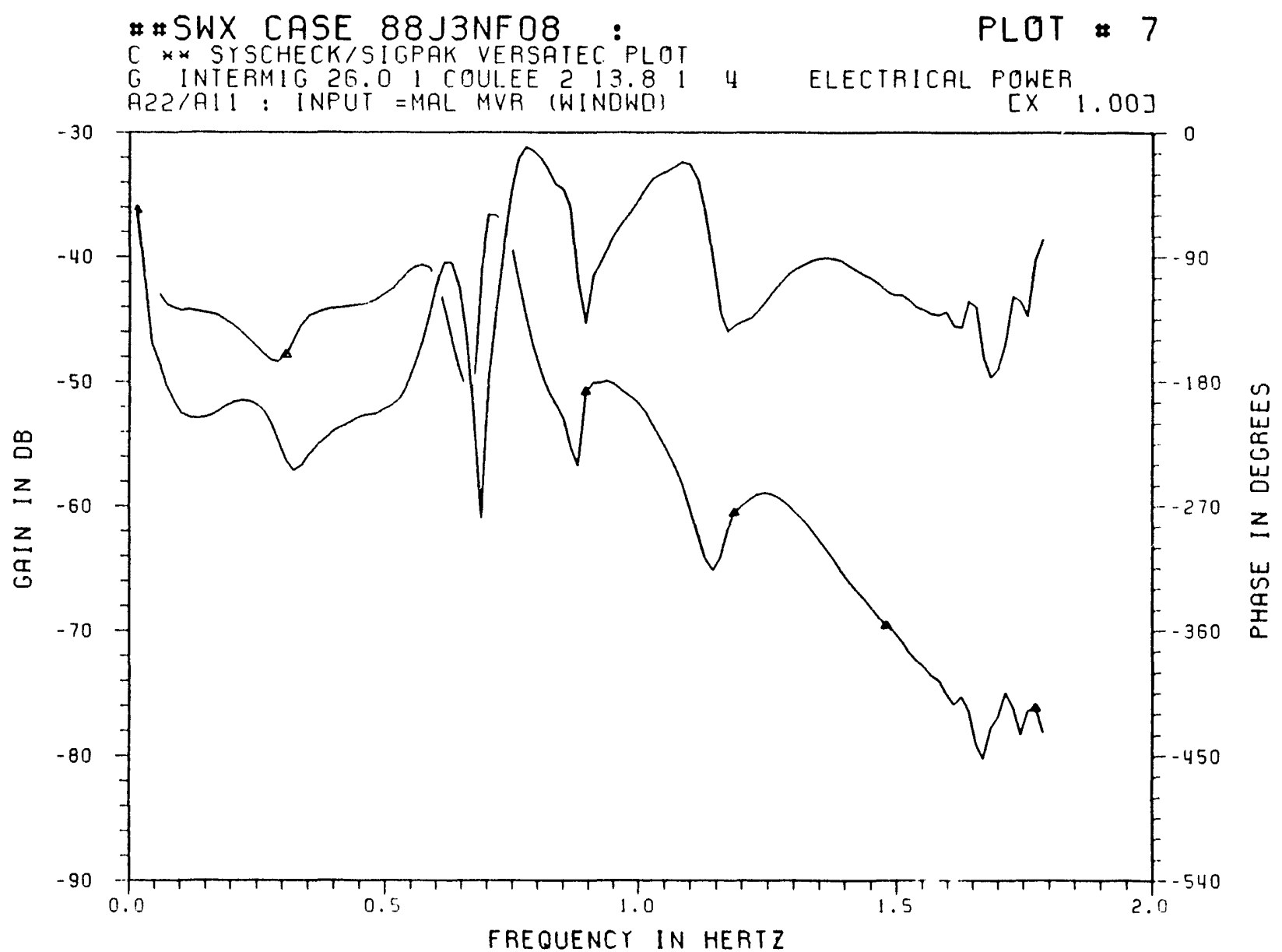

FIGURE 8. FREQUEICY RESPOHSE OF INIEAMOUNTAIN ELECTRICAL POWEA IO SHUNT REACTIVE CONIROL AT MALIN, CASE $88 J 3$ NFO 8

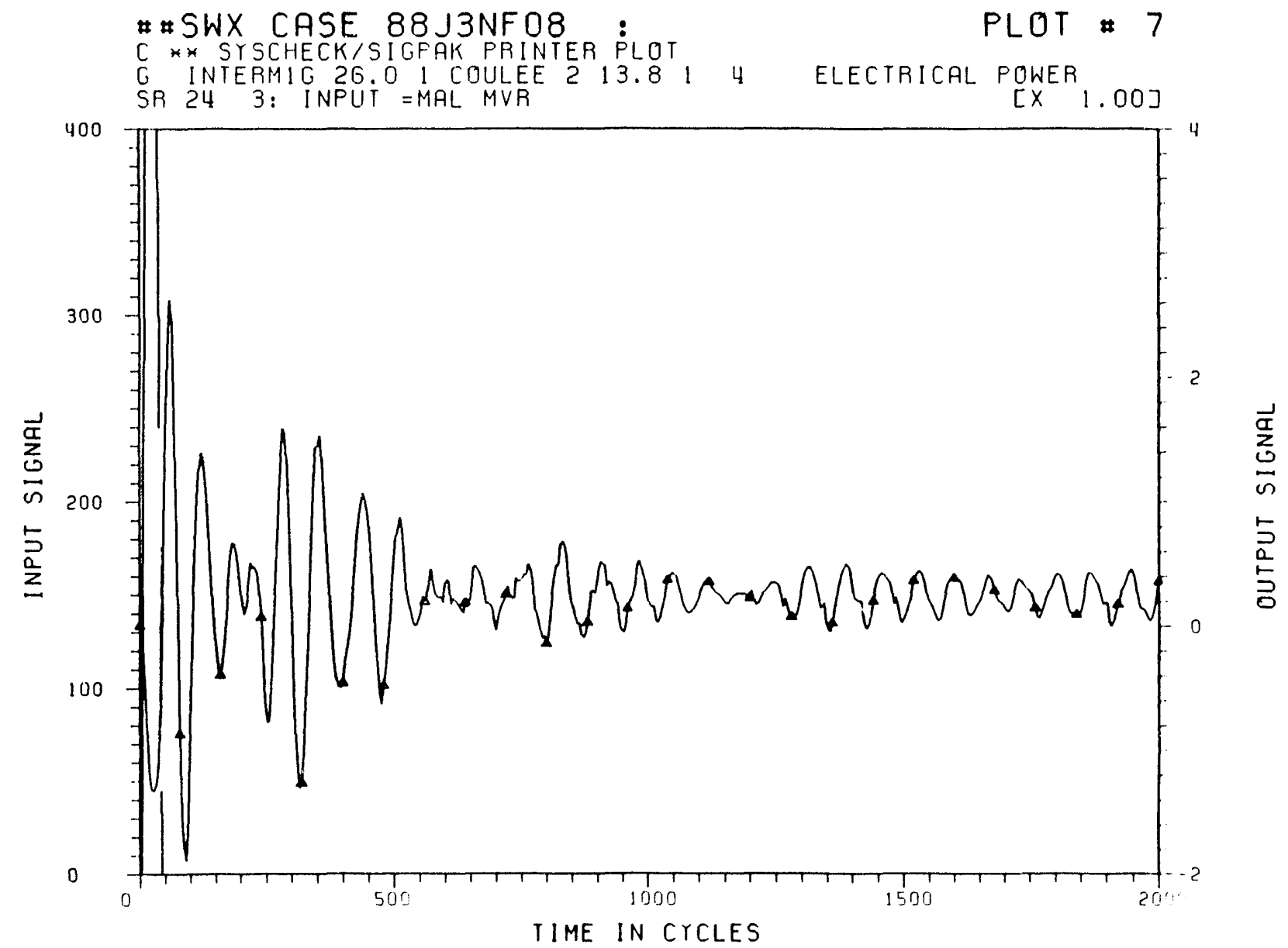

FICUAE 8.0. INTERMOUNTAIN RINGOOWN FOA BRIEF MVAR LORD PULSE RT MALIN 
*PRONY S-TABLE FOR PRS NUMBER 1
*SIGNAL-TO-NO!SE RRTIO = $41.2730 \quad$ FOP NMODES $=57$ DISPLAY TPIM LEVEL $=0.20000 E+00$

$\begin{array}{ccc}\text { MODE } & \text { DAMPING } & \text { FRO (HZ) } \\ 1 & 0.0004547 & 0.0000000 \\ 3 & 0.3060890 & 0.0000000 \\ 4 & 0.1541357 & 0.1894256 \\ 7 & 0.0228886 & 0.6259056 \\ 8 & 0.0242587 & 0.7686995 \\ 9 & 0.0135782 & 0.8698549 \\ 10 & 0.0683574 & 1.0393390 \\ 11 & 0.0211222 & 1.1189360 \\ 12 & 0.0951192 & 1.2562006 \\ 13 & 0.1518059 & 1.3987931\end{array}$

REL WT
0.2651484
1.0000000
0.8136875
0.3307859
0.9225584
0.2368852
0.8394789
0.3102971
0.2615300
0.7131960

PHASE

0.000000

180.000000

$-45.107132$

$-72.335313$

$-11.878057$

155.314818

$-82.722458$

148.161545

0.215356

168.337949
AMPL ITUDE

0.4232691

1. 5963479

1. 2989284

0.5280494

1. 4727242

0.3781512

1.3401004

0.4953421

0.4174929

1. 1385088

*PROIYY S-TABLE FOR PRS NUMBER $?$

* SIGNAL-TO-NOISE RATIO= 39.7840 FOR NMODES $=57$ DISPLAY TRIM LEVEL $=0.20000 E+00$

$\begin{array}{ccc}\text { MODE } & \text { DAMPINC } & \text { FRO (HZ) } \\ 3 & 0.1616185 & 0.1724272 \\ 6 & 0.0219559 & 0.6254471 \\ 7 & 0.0246519 & 0.7681117 \\ 8 & 0.0146653 & 0.8703887 \\ 9 & 0.0648711 & 1.0389818 \\ 10 & 0.0208640 & 1.1163789 \\ 12 & 0.0871524 & 1.3473008 \\ 21 & 0.1137001 & 2.6514754\end{array}$

REL WT
0.3679002
0.3412128
1.0000000
0.2768451
0.6930962
0.3376111
0.3423678
0.2245454
PHASE

21.964036

78.938446

174.148297

1.872721

163.071025

64.640025

$-150.844375$

15.900442

AMPL I TUDE

0.4955053

0.4595615

1. 3468473

0.3728681

0.9334948

0.4547106

0.4611171

0.3024284

* PRONY S-TABLE FOR PRS NUMBER 3

* SIGNAL-TO-NOISE RATIO = 35.1830 FOR NMODES $=57$

DISPLAY TRIM LEVEL $=0.20000 E+00$

$\begin{array}{ccc}\text { MODE } & \text { DAMPINC } & \text { FRO (HZ) } \\ 36 & 4.5909934 & 4.6890331 \\ 57 & 7.5461307 & 7.4999996\end{array}$

REL WT
1.0000000
0.9451398
PHASE

$-7.343048$

180.000000
AMPL I TUDE 18.4208121 17.4102431

*PRONY S-TABLE FOR PRS NUMBER 4

*SICNAL - TO-NOISE RATIO= $=33.9630$ FOR NMODES $=56$ DISPLRY TRIM LEVEL $=0.20000 E+00$

$\begin{array}{ccc}\text { MODE } & \text { DRMPING } & \text { FRQ (HZ) } \\ 2 & 0.5674434 & 0.0000000 \\ 6 & 0.0228520 & 0.6261223 \\ 7 & 0.0234593 & 0.7679752 \\ 8 & 0.0165688 & 0.8701703 \\ 9 & 0.0643263 & 1.0206950 \\ 10 & 0.0230992 & 1.1177581 \\ 11 & 0.1414904 & 1.2984470 \\ 28 & 0.6062894 & 3.5282053 \\ 52 & 0.4178921 & 6.9254830\end{array}$

\begin{tabular}{lr} 
REL WT & \multicolumn{1}{c}{ PHASE } \\
0.2202136 & 0.000000 \\
0.3853091 & 17.776547 \\
1.0000000 & -177.246773 \\
0.3545205 & 59.168199 \\
0.4411944 & -30.447535 \\
0.4093708 & -126.184647 \\
0.4347561 & 145.588309 \\
0.2849384 & -111.174224 \\
0.2471036 & -41.991753
\end{tabular}

AMPL I TUDE 0.2287726

0.4002848

1.0388667

$0.368 \geq 996$

0.4583422

0.4252817

0.4516536

0.2960130

0.2567077

*PRONY S-TABLE FOR PRS NUMBEP 5

* SIGNAL -TO-NOISE RATIO = 38.0900 FOR NMODES $=57$ DISPLAY TRIM LEVEL $=0.20000 E+00$

$\begin{array}{ccc}\text { MODE } & \text { DAMPINC } & \text { FRO (HZ) } \\ E & 0.0209870 & 0.6264725 \\ 7 & 0.0251221 & 0.7679650 \\ 8 & 0.0131034 & 0.8701600 \\ 9 & 0.0354755 & 1.0595370\end{array}$

$\begin{array}{rr}\text { REL WT } & \text { PHASE } \\ 0.3322948 & 100.792417 \\ 1.0000000 & 7.900470 \\ 0.2832670 & -90.514821 \\ 0.3284814 & 102.020825\end{array}$

RMPL I TUDE 0.3360954 1.0114372 0.2885068 0.3322383

FIGIURE Q.1. PRONY SOLUTION TABLE FOR SLIOINO-HINOOH FITS TO DNTERMOUNTAIN PIINODOWN

TBAR = 15 SECONOS (225 SAMPLES) 


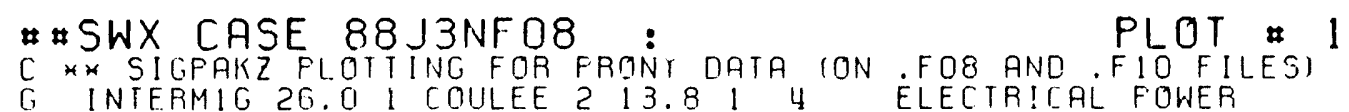
G. INTERMIG 26.01 COULEE 2 I3.814
NO. SOLLITIONS $=32$

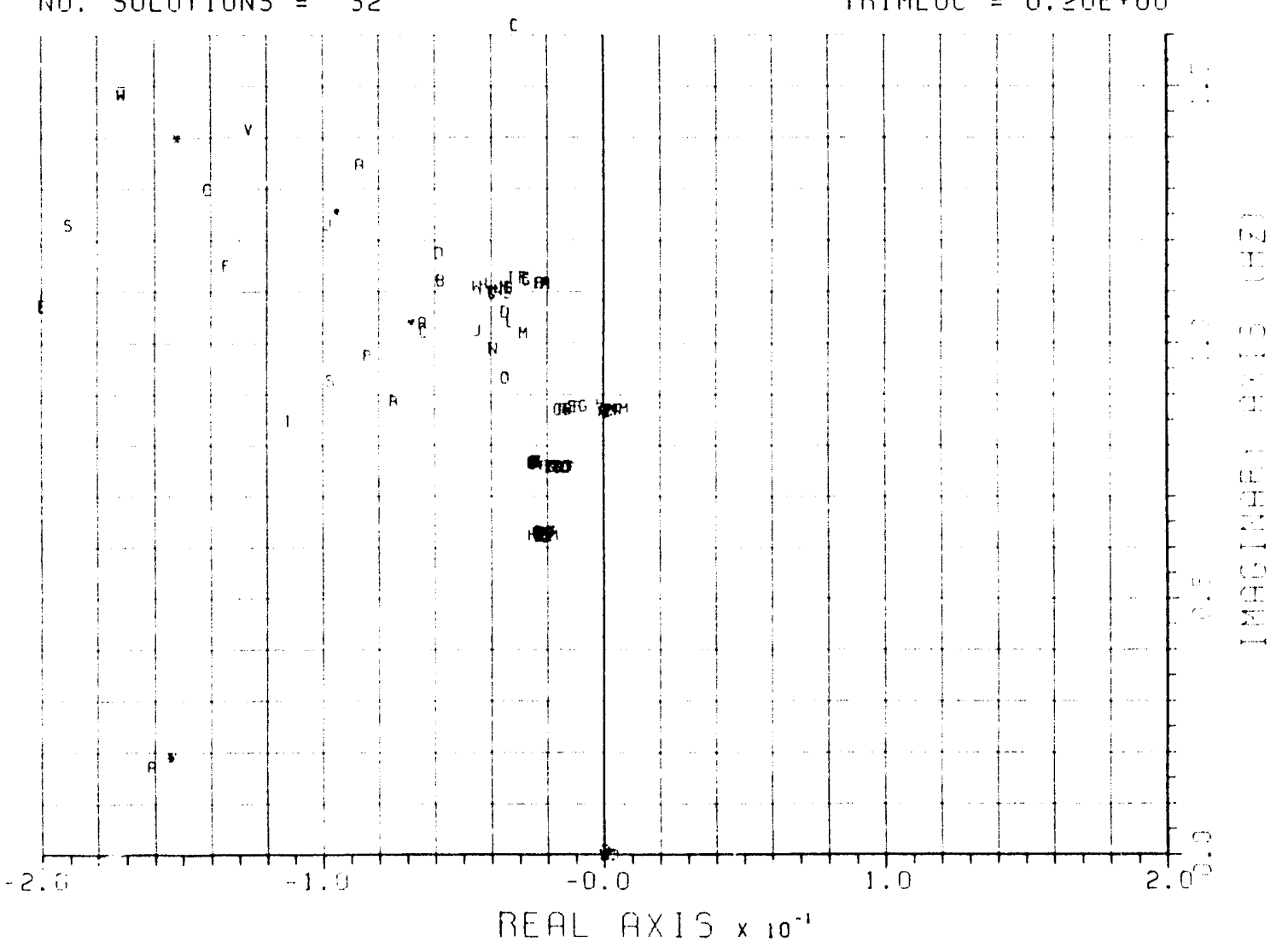

FIGURE 8.2. PRONY SOLUIION LOCUS FOR SLIOIHG-WINDOW FITS TO INIERMOUNTAIN RINGOOWN TBAR = 15 SECONCS 1225 SAMPLESI 


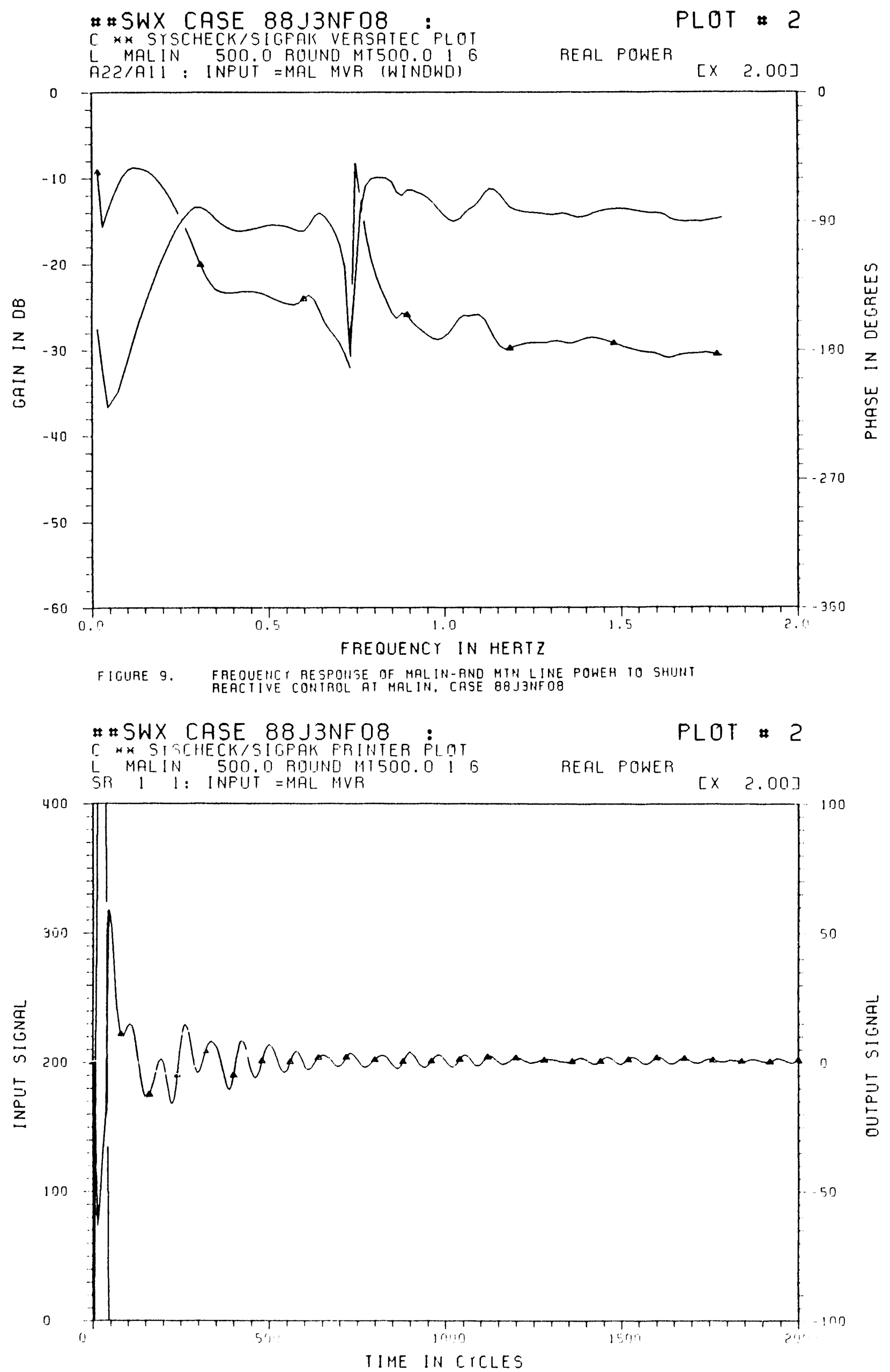

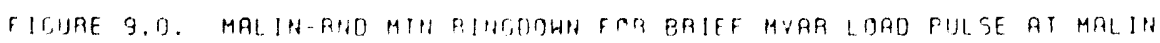


*PRONY S-TABLE FOR PRS NUMBER 1

- SI INAL-TI-NOISE RATIO = 80.8200 FOP NMODES $=57$

DISPLAY TFIM LEVEL $=0.20000 \equiv+00$

$\begin{array}{ccccc}\text { MODE } & \text { DAMPING } & \text { FRO (HZ) } & \text { REL WT } & \text { PHASE } \\ 2 & 0.0000225 & 0.0000000 & 0.8824101 & 180.000000 \\ 4 & 0.0728815 & 0.2888887 & 0.6251564 & -72.417115 \\ 5 & 0.2008923 & 0.3621256 & 1.000000 & 30.566841 \\ 8 & 0.0237263 & 0.7633214 & 0.2453349 & 66.868575\end{array}$

AMPL I TUDE

29.0897142

20.6090340

32.9662054

8.0877593

\#PRONY S-TABLE FOR PRS NUMBER 2

* SIONAL-TO-NOISE RATIO = 64.0440 FOR NMODES $=56$ DISPLAY TRIM LEVEL $=0.20000 E+00$

$\begin{array}{ccccr}\text { MODE } & \text { DAMPING } & \text { FRO (HZ) } & \text { REL WT } & \text { PHASE } \\ 1 & 0.2998617 & 0.0000000 & 0.6942648 & 180.000000 \\ 4 & 0.0644633 & 0.2994547 & 1.000000 & -18.044282 \\ 5 & 0.0891269 & 0.5165796 & 0.2294768 & 23.290965 \\ 7 & 0.0225862 & 0.7609123 & 0.8109101 & -104.318721 \\ 9 & 0.0686053 & 1.0022057 & 0.4426215 & 46.090300\end{array}$

AMPL I TUDE

5.9093813

8.5117115

1. 9532404

6.9022330

3.7674665

* PRONY S-TABLE FOR PRS NUMBER 3

* SICNAL-TO-NOISE RATIO = 57.8350 FOR NMODES $=57$ DISPLAY TRIM LEVEL $=0.20000 E+00$

$\begin{array}{ccccrr}\text { MODE } & \text { DAMPINC } & \text { FRO (HZ) } & \text { FEL WT } & \text { PHASE } & \text { AMPLITUDE } \\ 3 & 0.0859255 & 0.2168223 & 0.3341491 & 100.954514 & 2.0757543 \\ 4 & 0.0631280 & 0.2988781 & 0.9852736 & 56.788432 & 6.1205793 \\ 5 & 0.1071129 & 0.5340866 & 0.398411 & 133.979158 & 2.4753265 \\ 7 & 0.0226366 & 0.7587513 & 1.000000 & 83.799456 & 6.2120607 \\ 9 & 0.0797884 & 1.027176 & 0.7429854 & -105.909806 & 4.6154701 \\ 11 & 0.0846850 & 1.1659624 & 0.4154877 & 15.745507 & 2.5810348 \\ 13 & 0.1081001 & 1.3835734 & 0.2330754 & 57.844196 & 1.4478785\end{array}$

*PRONY S-TABLE FOR PRS NUMBER 4

* SIONAL-TO-NOISE RATIO = 56.9560 FOR NMODES $=56$

DISPLRY TRIM LEVEL $=0.20000 E+00$

$\begin{array}{ccccrr}\text { MODE } & \text { DAMPING } & \text { FRO (HZ) } & \text { REL WT } & \text { PHRSE } & \text { AMPLITUDE } \\ 4 & 0.0643141 & 0.3016693 & 0.7054667 & 120.320395 & 4.8699238 \\ 7 & 0.0207480 & 0.7584268 & 0.7472865 & -93.591542 & 5.1586112 \\ 9 & 0.0659586 & 1.0548875 & 0.4538175 & 79.251891 & 3.1327586 \\ 10 & 0.0278928 & 1.1240294 & 0.2096558 & 98.218372 & 1.4472798 \\ 11 & 0.3744082 & 1.1551334 & 1.000000 & -123.749944 & 6.9031235 \\ 12 & 0.1174704 & 1.2907154 & 0.3282809 & 92.248690 & 2.2661635\end{array}$

*PRONY S-TABLE FOR PRS NUMBER 5

*SIUNAL-TC-NOISE RRTIO = 58.0320 FOR NMODES = 56 DISPLAY TRIM LEVEL $=0.20000 E+00$

$\begin{array}{ccc}M O D E & D P M F I N E & F F O \quad(1-Z) \\ 3 & 0.0651264 & 0.3017567 \\ 5 & 0.1234960 & 0.4639326 \\ 6 & 0.0210196 & 0.6337859 \\ 7 & 0.020448 & 0.7576536 \\ 9 & 0.0596480 & 1.0530185 \\ 10 & 0.0252728 & 1.1252890 \\ 11 & 0.1171720 & 1.2802904\end{array}$

FEL WT PHPSE

RMPLITUDE

3.8035728

0.9691789

1. $18: 5407$

4.6547984

1. 912786 ?

1. 3572566

1. 2234845

FIOURE Q.1. PRONY SOLUTION TRBLE FOR SLIOINO-WINDOW FITS TO MALIH-RNO MTN PINCOOWN

TBPR = 15 SECONOE LEZ SAMP LES: 


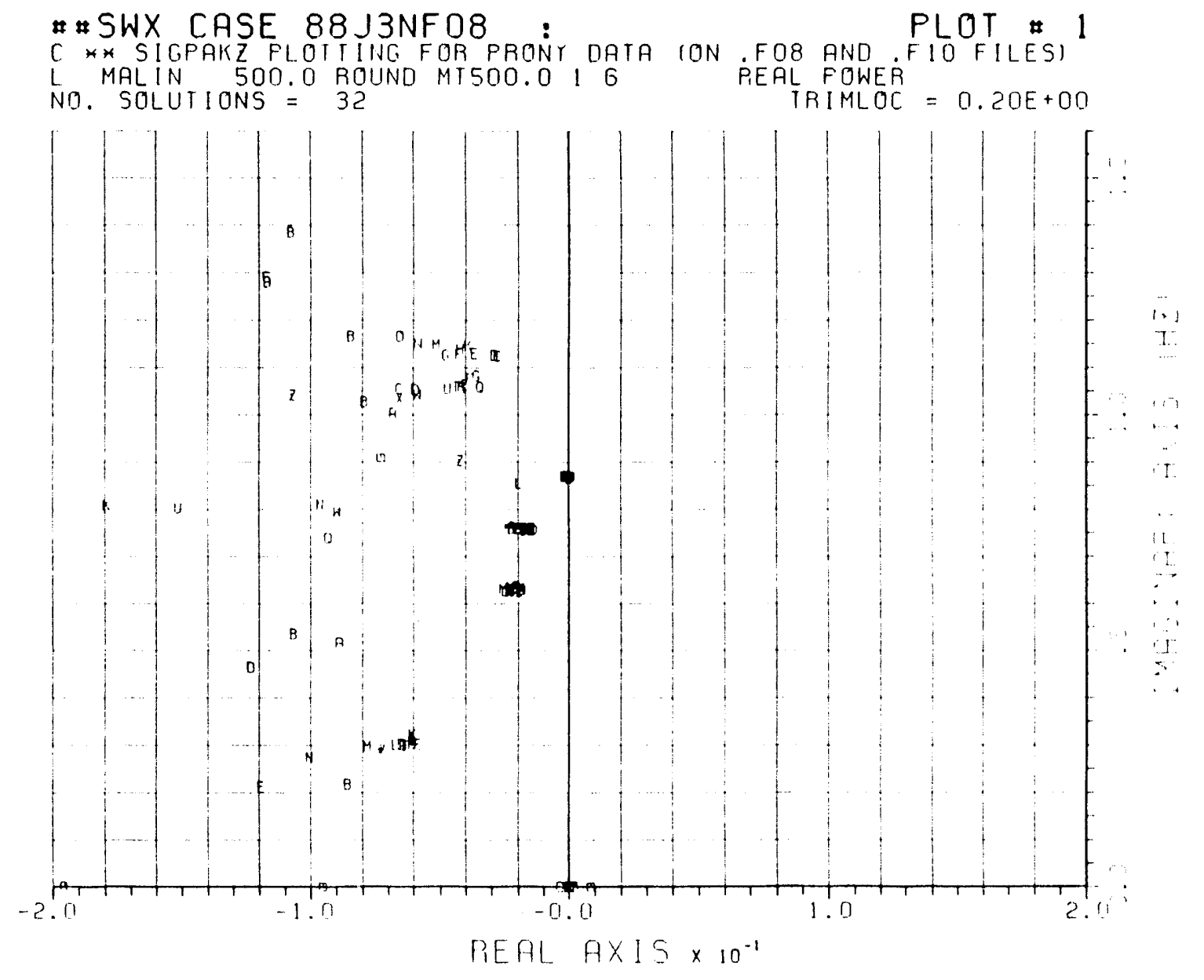

FIOURE 9.2. PRONY SOLUIIOH LOCHS FOR SLIOING-HINOOW FITS IO MALIN-FND MIN RINGDOWH TBAR $=$ IS SECOHOS 1225 SAMPLESI 
* SWX CASE 93 JTAS434:

C MKSYSCHECK/SIGPAK PRINTER PLOT

SR 48 2: INPUT $=$ MALIN $V$

VOL TAGE

PLOT * 1

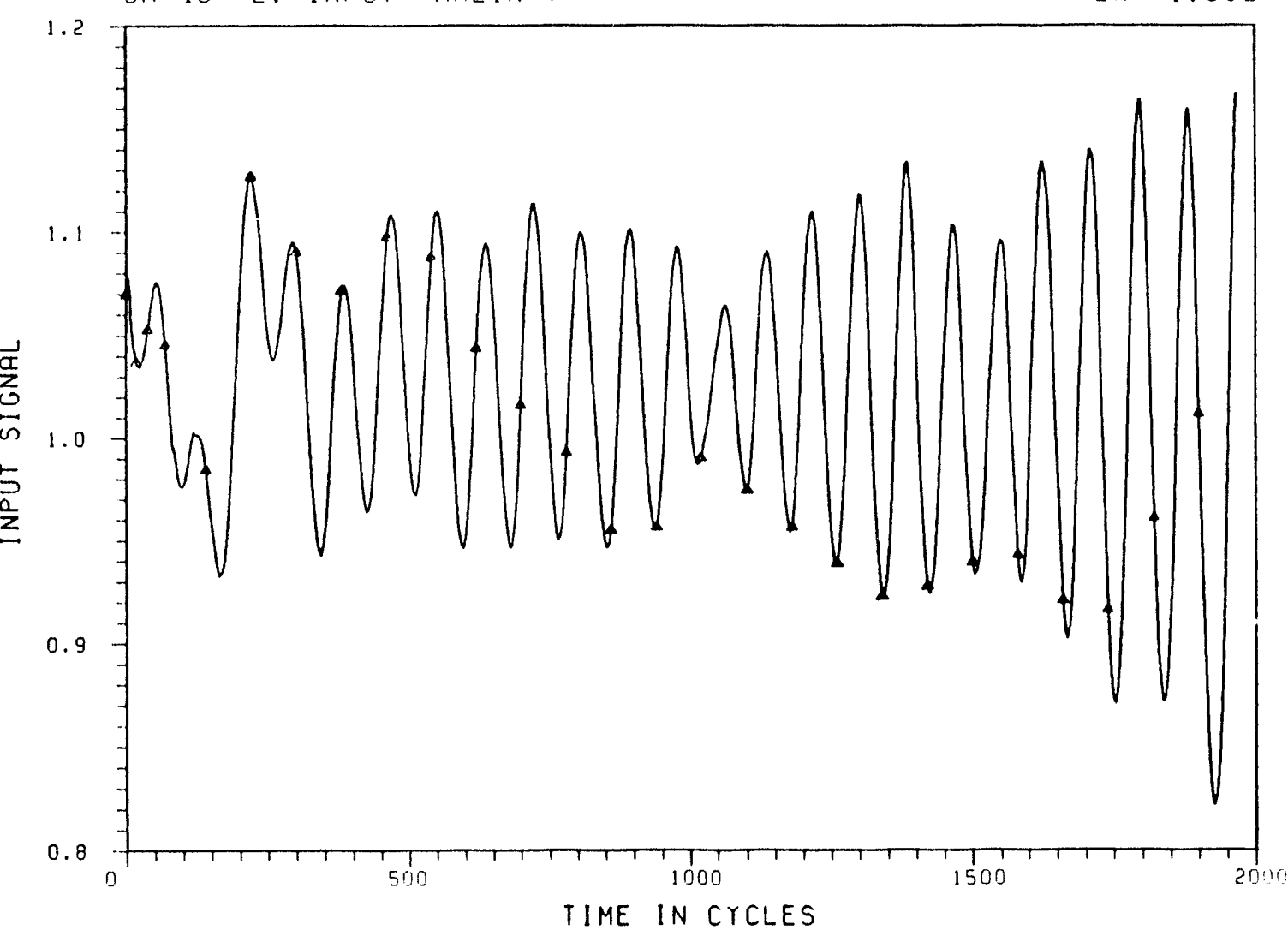

FIGURE 10. MALIN $500 \mathrm{KV}$ VOLTAGE SWINGS FOLLOWING $3100 \mathrm{MW}$ HVOC BIPOLE LOSS. CASE 93 JIAS4 34

* SWX CASE 93 JTAS434:

$C \times *$ SISCHECK/SIGFAK VERSATEC FLOT B MALIN 500.02

AIIFFT: INPUT = IAAL IN V (WINDWD)

PLOT $: 2$

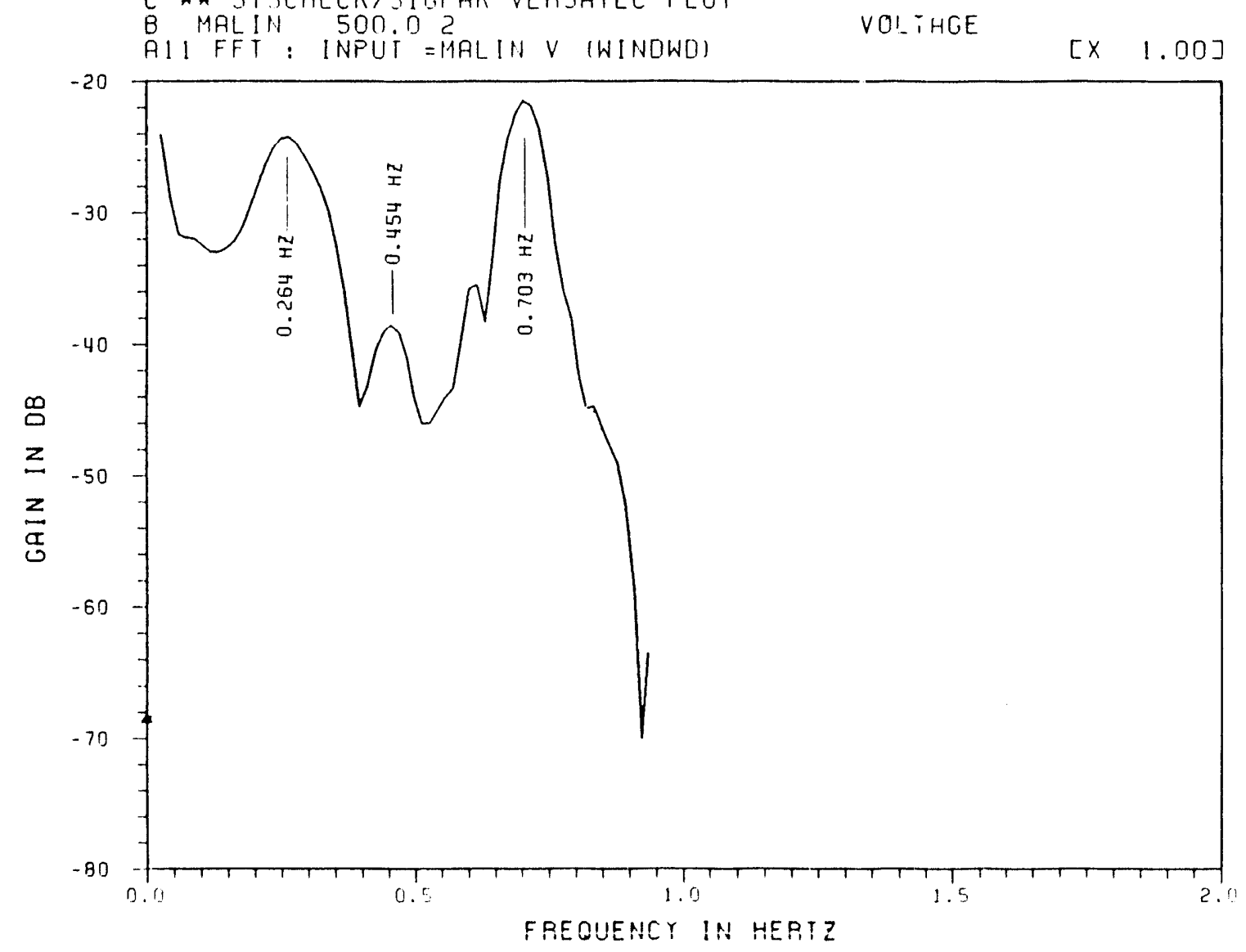

FIGURE 10.0. AUIOSFECTRUM OF MALIN VOLTACE SWINTS. CASE $9331 A 5434$ ISICNAL HANHEO IWICE 
*PRONY S-TABLE FOR PRS NUMBER 1

* SIGNAL-TO-NOISE RATIO=71.0370 FOR NMODES = 57

DISPLAY TRIM LEVEL $=0.20000 E+00$

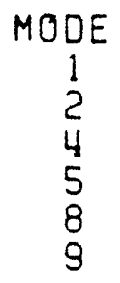

DAMPINC
0.2507711
-0.0033904
0.0533181
0.0517744
-0.0028251
0.0818172

FRO $(H Z)$
0.0000000
0.000000
0.2524768
0.2947856
0.7069375
0.7679518

REL WT

PHASE

0.2245312

0.7853385

1.0000000

0.4310798

0.5746017

180.000000

180.000000

$-52.518535$

75.799699

30.730795

$0.2086905-159.276406$

AMPLITUDE

0.0253453

0.0886496

0.1128808

0.0486606

0.0648615

0.0235571

*

* SIONAL-TO-NOISE RATIO = E3.8420 FOR NMODES $=55$

DISPLAY TRIM LEVEL $=0.20000 E+00$

$\begin{array}{cccccc}\text { MODE } & \text { DAMPING } & \text { FRO IHZ) } & \text { REL WT } & \text { PHASE } & \text { AMPLITUDE } \\ 1 & 0.2333248 & 0.0000000 & 0.2428668 & 180.000000 & 0.0151514 \\ 2 & -0.0112851 & 0.0178693 & 0.238736 & 145.318381 & 0.0148934 \\ 3 & 0.0438085 & 0.2545110 & 0.9964704 & -15.964311 & 0.062163 \\ 4 & 0.0779187 & 0.3018175 & 0.8023276 & 84.725816 & 0.050536 \\ 7 & -0.0037762 & 0.7075482 & 1.0000000 & -160.685480 & 0.0623854\end{array}$

*PRONY S-TABLE FOR PRS NUMBER 3

* SIGNAL-TO-NOISE RATIO = 71.8300 FOR NMODES = 56

OISPLAY TRIM LEVEL $=0.20000 \Xi+00$

$\begin{array}{cccccc}\text { MODE } & \text { DAMPING } & \text { FRO (HZ) } & \text { REL WT } & \text { PHASE } & \text { AMPLITUDE } \\ 2 & 0.0116725 & 0.0000000 & 0.5404121 & 0.000000 & 0.0322512 \\ 3 & 0.0382744 & 0.2608543 & 0.666954 & 17.76843 & 0.0398031 \\ 4 & 0.0979031 & 0.2727004 & 0.999310 & 134.237450 & 0.0596413 \\ 7 & -0.0050119 & 0.7090000 & 1.0000000 & 6.047108 & 0.0596788\end{array}$

\#PRONY S-TABLE FOR PRS NUMBER 4

:SIONAL-TO-NOISE RATIO = 65.8330 FOR NMODES $=56$

DISPLAY TRIM LEVEL $=0.20000 E+00$

$\begin{array}{cccccc}\text { MODE } & \text { DAMPINO } & \text { FRO (HZ) } & \text { REL WT } & \text { PHASE } & \text { AMPLITUDE } \\ 2 & -0.0091296 & 0.0156373 & 0.3346139 & 159.521664 & 0.0240047 \\ 3 & 0.0408693 & 0.2481736 & 0.4526176 & 119.002078 & 0.0324701 \\ 7 & -0.0002819 & 0.7089000 & 1.000000 & 173.306371 & 0.0717385\end{array}$

*PRONY S-TABLE FOR PPS NUMBEF 5

-SIUNAL-TO-NOSSERFTIO = E2.1770 FOR NMODES = 57

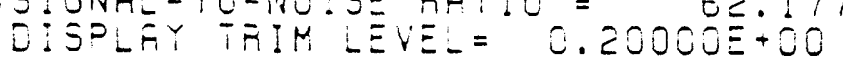

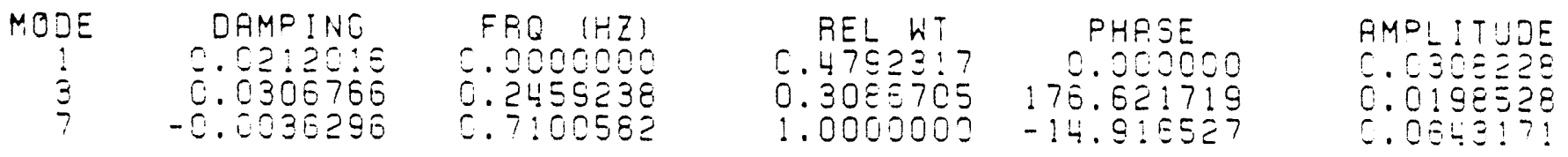

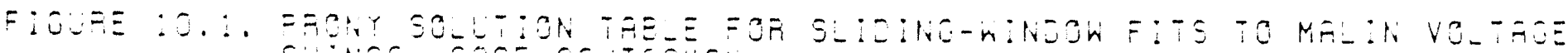

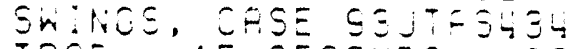
TBAF = I5 SECONES IES SAMPLES! 
* SWX CASE 93 JTAS434

C. XSICPAKZ FLOTIING FOR PRONT DATA ION FO8 AND . FIO FILESI NO. SOLLINIONS $=$ ? VOL TAS.E

IRIMLOC $=0.20 E+00$

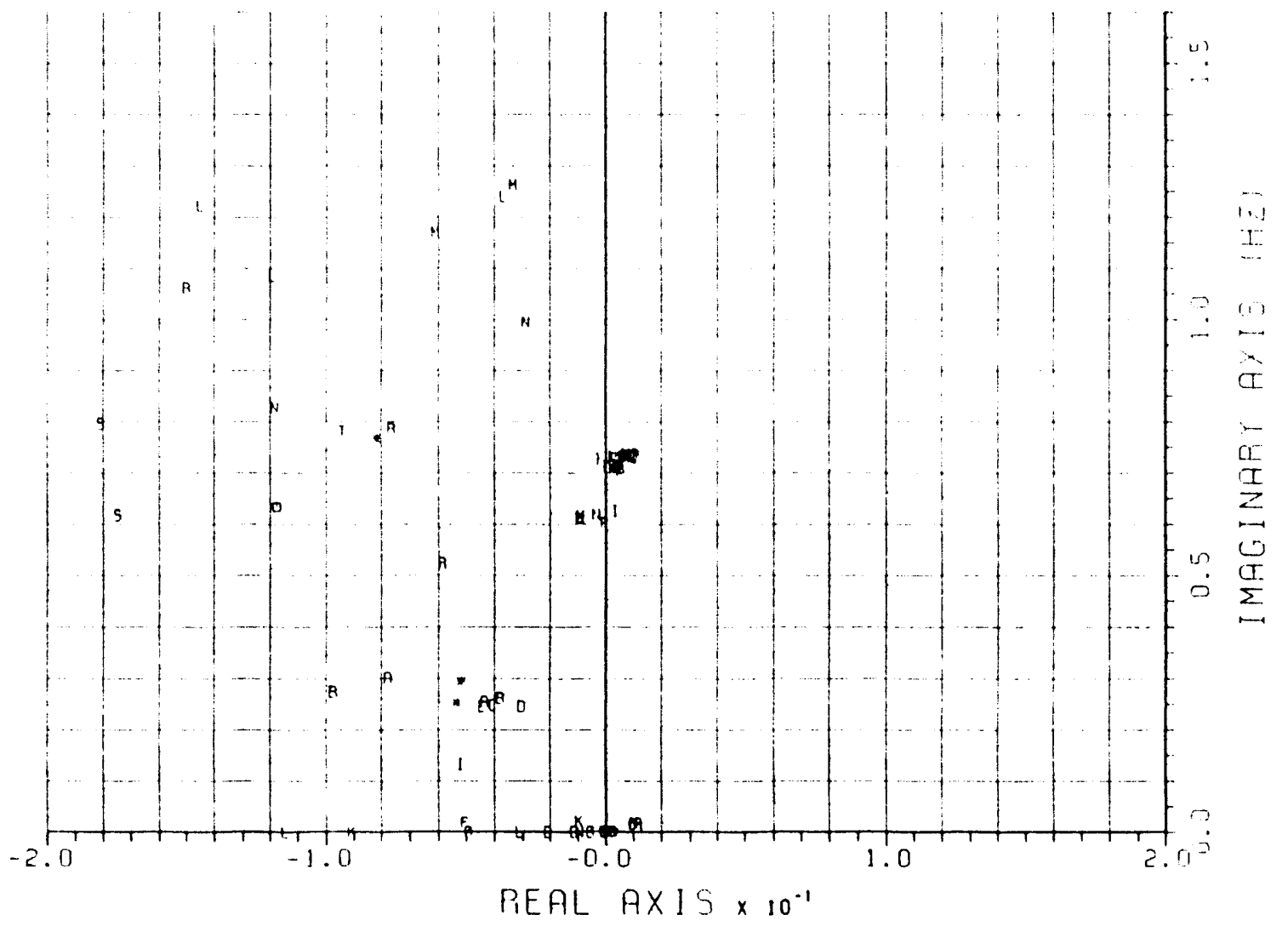

FIGURE 10.2. PAONY SOLUIION LOCUS FOR SLIDING-HINOOH FIIS TO MALIN VOLTAGE

SHINGS. CASE 93 J IAS434 15 SELONOS 1225 SAMPLESI 


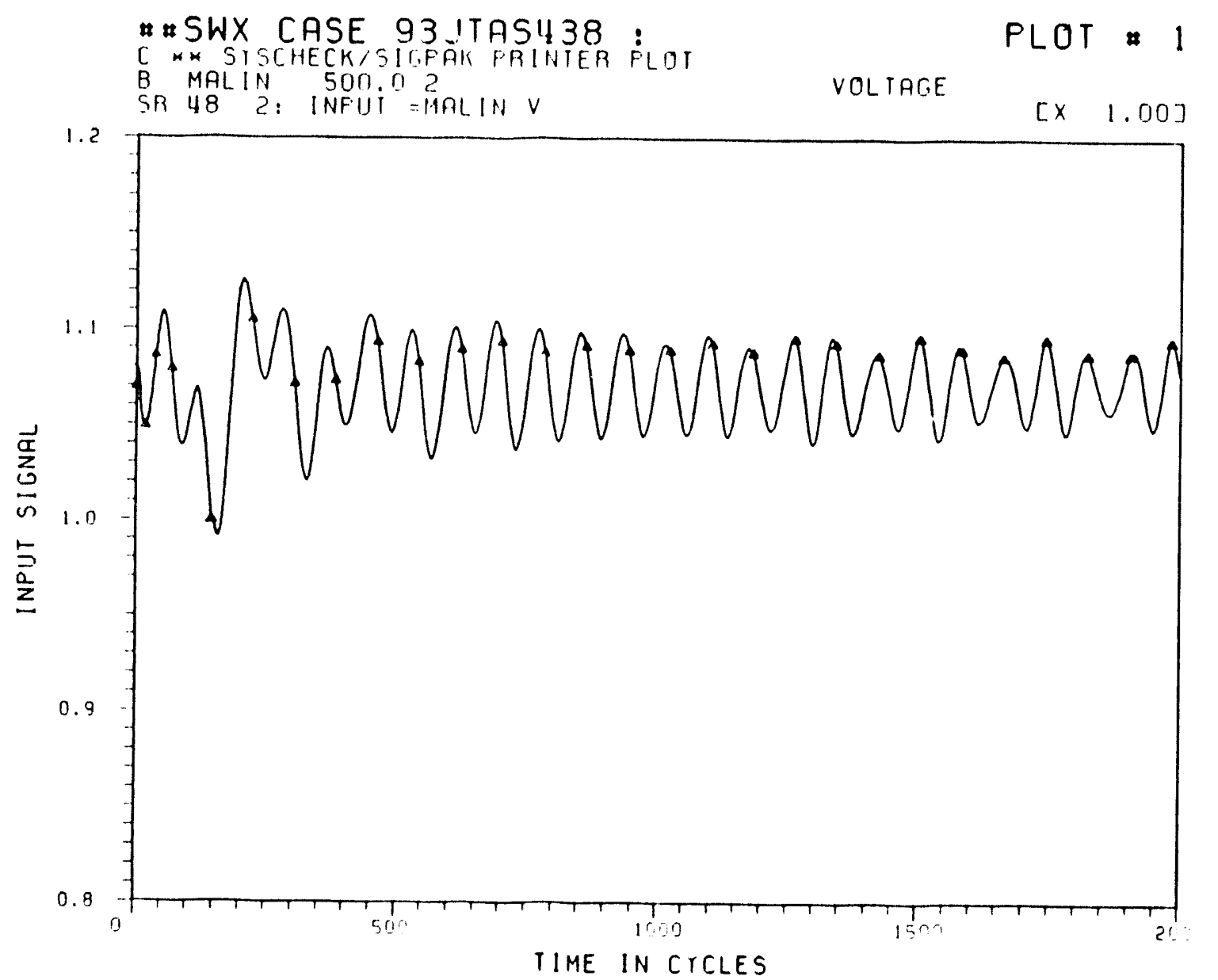

TIME IN CYCLES

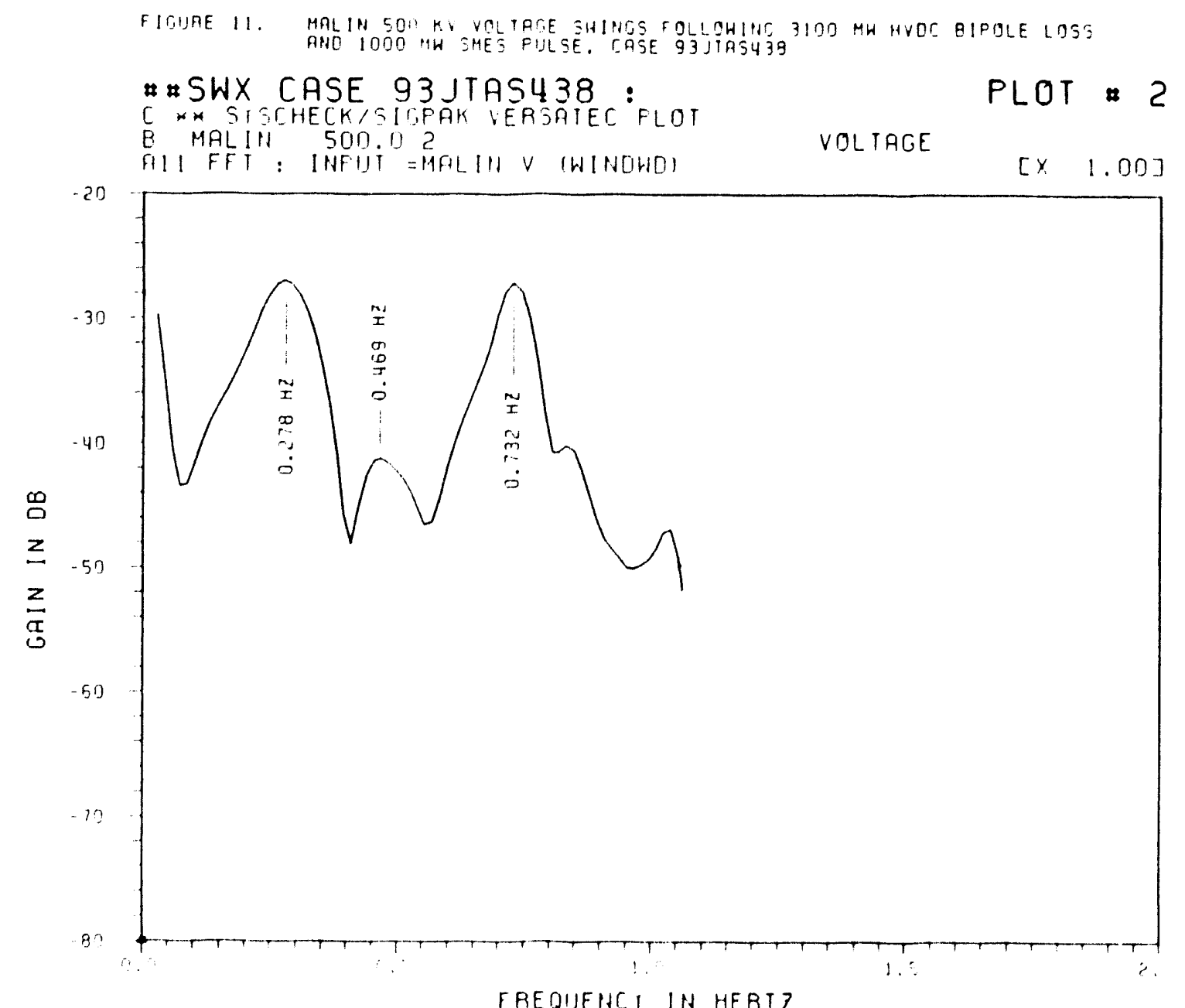

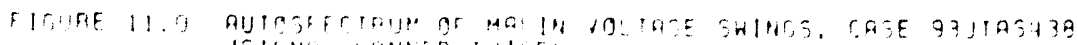


* "DRONY S-TABLE FOR PRS NUMBER 1 $\because$ SIGNAL-TO-NOISE RATIO $=63.6400$ FOR NMODES $=56$ DISPLAY TRIM LEVEL $=0.20000 E+00$

$\begin{array}{ccccrr}\text { MODE } & \text { DAMPING } & \text { FRO (HZ) } & \text { REL WT } & \text { PHASE } & \text { AMPLITUDE } \\ 1 & -0.0007505 & 0.0000000 & 0.6998179 & 180.000000 & 0.032324 \\ 3 & 0.0486296 & 0.2742443 & 0.7132557 & -14.813149 & C .039431 \\ 5 & 0.165835 & 0.4729539 & 0.377480 & -169.544116 & 0.0174347 \\ 6 & 0.0072559 & 0.7391544 & 0.9067387 & 92.743713 & 0.0418794 \\ 7 & 0.0215525 & 0.7871297 & 0.3196454 & -111.680377 & 0.0147634 \\ 10 & 0.1416762 & 1.1002561 & 1.0000000 & -111.256658 & 0.0461869 \\ 11 & 0.2027071 & 1.1946111 & 0.9995692 & 28.978326 & 0.0461670\end{array}$

*PRONY S-TABLE FOR PRS NUMBER 2

* IGNAL-TO-NOISE RATIO = 40.4560 FOR NMODES $=55$ DISPLAY TRIM LEVEL $=0.20000 E+00$

$\begin{array}{cl}\text { MODE } & \text { DAMPING } \\ 2 & 0.0010892 \\ 3 & 0.0503860 \\ 5 & 0.3267843 \\ 6 & 0.0060984 \\ 7 & 0.0430224 \\ 10 & 0.1043088 \\ 15 & 0.3878178\end{array}$

FRO $(H Z)$
0.0000000
0.2724491
0.4976419
0.7406040
0.7991343
1.1630711
1.9598462

REL WT
0.4330416
0.7105371
0.9852078
1.0000000
0.4355697
0.2039446
0.2225328

PHASE

0.000000

55.444561

$-97.503347$

$-97.372869$

39.490016

86.648172

130.219279

AMPL I TUDE

0.0174303

0.0285998

0.0396555

0.0402509

0.0175321

0.0082090

0.0089571

* PRONY S-TABLE FOR PRS NUMBER 3

* SIGNAL-TO-NOISE RATIO $=34.8860$ FOR NMODES $=55$

DISPLAY TRIM LEVEL $=0.20000 E+C 0$

$\begin{array}{cccccr}\text { MODE } & \text { DAMPING } & \text { FRO (HZ) } & \text { REL WT } & \text { PHASE } & \text { AMPLITUDE } \\ 4 & 0.0514083 & 0.2737419 & 0.5540265 & 118.951168 & 0.0240772 \\ 7 & 0.0070342 & 0.7418911 & 1.000000 & 77.429644 & 0.0434585 \\ 8 & 0.0471773 & 0.7740529 & 0.4772593 & -119.475627 & 0.0207410\end{array}$

* PRONY S-TABLE FOR PRS NUMBER 4

*SIGNAL-TO-NOISE RRTIO= $=72.6300$ FOR NMODES $=56$ DISPLAY TRIM LEVEL $=0.20000 E+00$

$\begin{array}{ccc}\text { MODE } & \text { DAMPING } & \text { FRO (HZ) } \\ 1 & 0.0116693 & 0.0000000 \\ 2 & 0.0069002 & 0.0000000 \\ 3 & 0.0520962 & 0.2750464 \\ 7 & 0.0033004 & 0.7397810\end{array}$

$\begin{array}{lr}\text { REL WT } & \text { PHASE } \\ 0.5204470 & 180.000000 \\ 0.8536619 & 0.000000 \\ 0.6002498 & -176.898812 \\ 1.0000000 & -102.013156\end{array}$

AMPL I TUDE

0.0173990

0.0285387

0.0200669

0.0334309

*PRONY S-TABLE FOR PRS NUMBER 5

*SIONAL-TO-NOISE RATIO = G8.7030 FOR NMOOES = 56

DISPLAY TRIM LEVEL $=0.20000 E+00$
$\operatorname{MOD} E$
DAMPINE
0.0524898
FRIO $(\mathrm{HZ})$
0.2752722
REL WT
PHPSE
0.7411541
0.4870417
$-110.935757$
AMPLITUDE
0.0163811
0.0336339

FIOUPE 1.1.1 PRONY SOLLTION TABLE FOR SLIDINO-WINOOW FITS TO MALIN VOLTRGE SWINCS. CASE 93JTRS438

TBAR $=15$ SECONDS (225 SAMPLES $)$ 


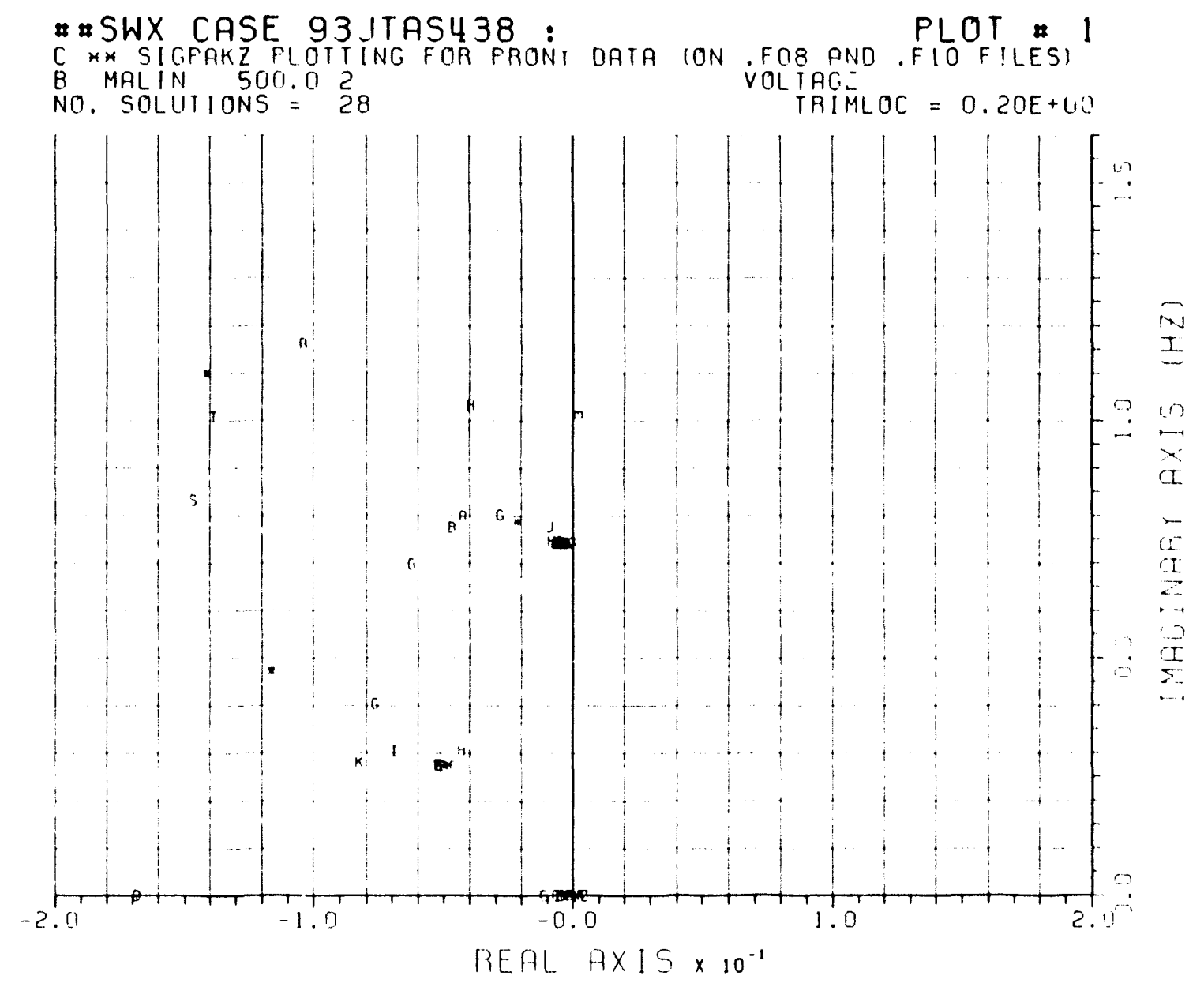

FIGUAE 11.2. PAONY SOLUTION LOCUS FOA SLIOING-WINDOW FITS TO MALIN VOLTAGE SWINCS. CASE 93 JTAS438

IBAR = 15 SECONOS 1225 SAMPLESI 

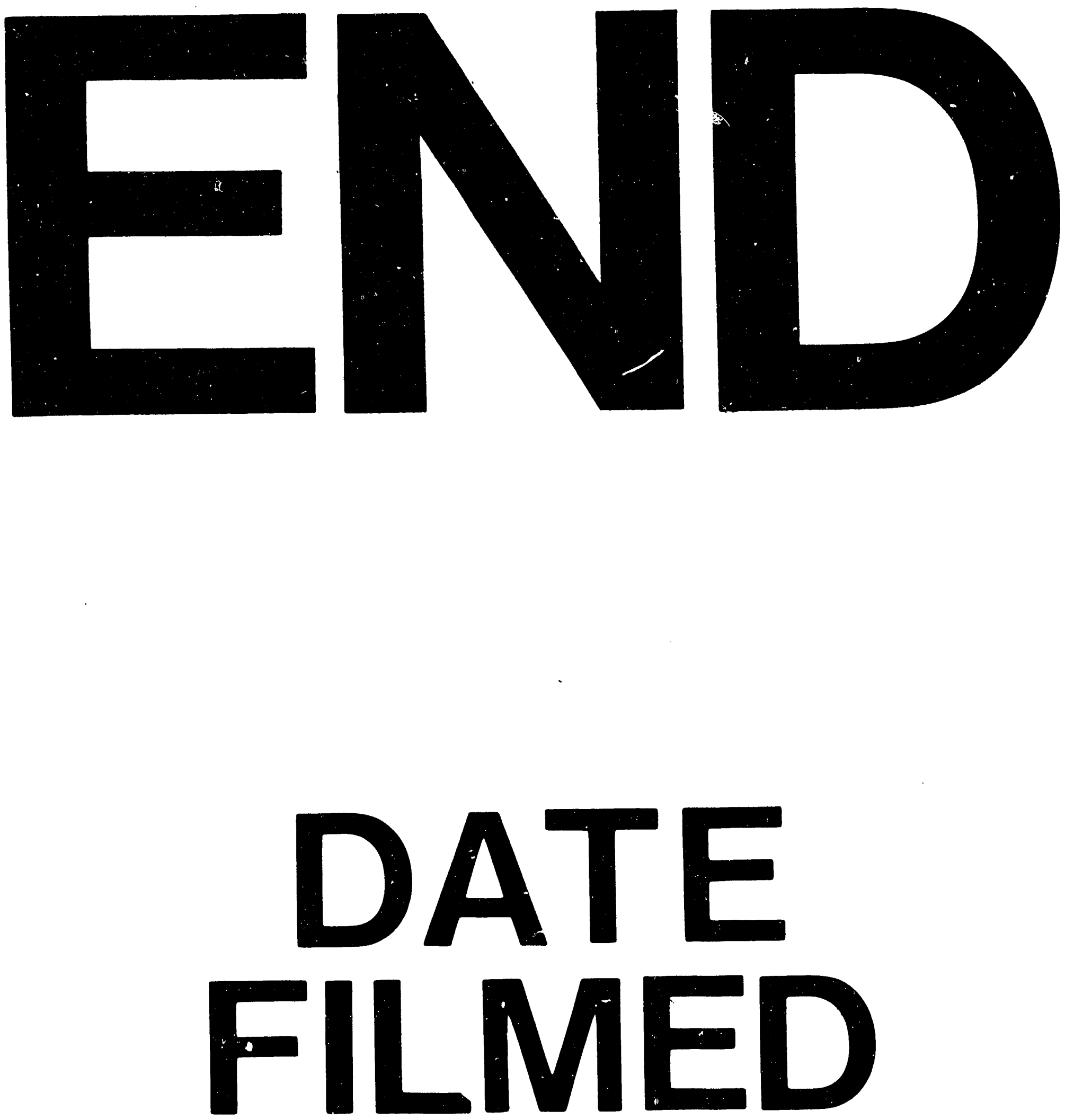

1

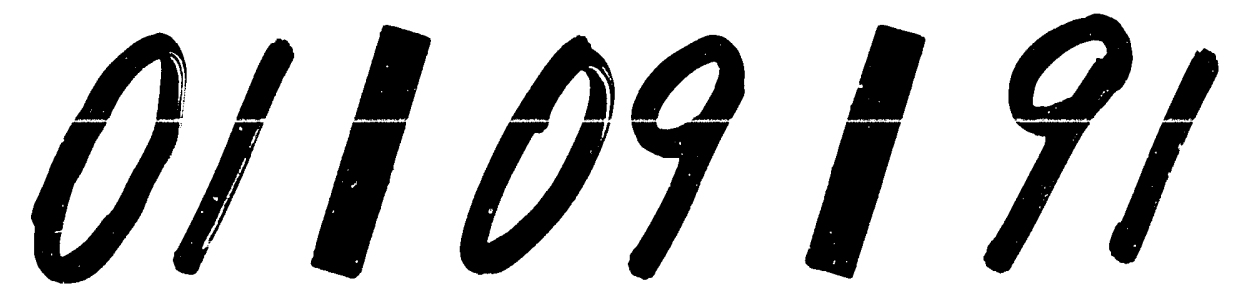

$-\cdots$ 
